\title{
VARIABILITY IN LONG-WAVE RUNUP AS A FUNCTION OF NEARSHORE BATHYMETRIC FEATURES
}

\author{
A Thesis \\ by \\ LAUREN MCNEILL DUNKIN
}

\begin{abstract}
Submitted to the Office of Graduate Studies of
Texas A\&M University

in partial fulfillment of the requirements for the degree of

MASTER OF SCIENCE
\end{abstract}

May 2010

Major Subject: Civil Engineering 


\title{
VARIABLITY IN LONG-WAVE RUNUP AS A FUNCTION OF NEARSHORE BATHYMETRIC FEATURES
}

\author{
A Thesis \\ by \\ LAUREN MCNEILL DUNKIN
}

\author{
Submitted to the Office of Graduate Studies of \\ Texas A\&M University \\ in partial fulfillment of the requirements for the degree of \\ MASTER OF SCIENCE
}

Approved by:

Chair of Committee, Jennifer L. Irish

Committee Members, James Kaihatu

Douglas Sherman

Head of Department, John Niedzwecki

May 2010

Major Subject: Civil Engineering 


\begin{abstract}
Variability in Long-wave Runup as a Function of Nearshore Bathymetric Features.

(May 2010)

Lauren McNeill Dunkin, B.S., University of South Alabama

Chair of Advisory Committee: Dr. Jennifer L. Irish
\end{abstract}

Beaches and barrier islands are vulnerable to extreme storm events, such as hurricanes, that can cause severe erosion and overwash to the system. Having dunes and a wide beach in front of coastal infrastructure can provide protection during a storm, but the influence that nearshore bathymetric features have in protecting the beach and barrier island system is not completely understood. The spatial variation in nearshore features, such as sand bars and beach cusps, can alter nearshore hydrodynamics, including wave setup and runup. The influence of bathymetric features on long-wave runup can be used in evaluating the vulnerability of coastal regions to erosion and dune overtopping, evaluating the changing morphology, and implementing plans to protect infrastructure.

In this thesis, long-wave runup variation due to changing bathymetric features as determined with the numerical model XBeach is quantified (eXtreme Beach behavior model). Wave heights are analyzed to determine the energy through the surfzone. XBeach assumes that coastal erosion at the land-sea interface is dominated by bound long-wave processes. Several hydrodynamic conditions are used to force the numerical model. The XBeach simulation results suggest that bathymetric irregularity induces 
significant changes in the extreme long-wave runup at the beach and the energy indicator through the surfzone. 


\section{ACKNOWLEDGEMENTS}

I first must thank Dr. Jennifer Irish who has been a fount of information and guidance and her support throughout this research project has been invaluable. I would also like to thank my committee members, Dr. James Kaihatu and Dr. Doug Sherman, for their time in reviewing this research. I would also like to thank the sponsor, Joint Airborne Lidar Bathymetric Center of Expertise, for allowing me to work on this interesting project. I am also very grateful to Jordan Schaefer who spent countless hours running codes. I must also thank my fellow graduate students at Texas A\&M for their ideas, encouragement, and friendship. I want to thank my parents, James and Michele, for their support and willingness to be a sounding board about the project even if they did not understand the technical details. I would like to express my gratitude to the rest of my immediate and extended family for their support and encouragement. Finally, I would like to thank my husband, Cooper, who has been my strength and a constant source of encouragement. Thank you for believing in me. 
NOMENCLATURE

$<\eta>$

A

$\mathrm{A}_{2}$

$A_{R}$

$\mathrm{A}_{\mathrm{S}}$

$\mathrm{A}_{\mathrm{w}}$

c

$\mathrm{c}_{\mathrm{g}, \mathrm{x}}$

$\mathrm{c}_{\mathrm{g}, \mathrm{y}}$

$\mathrm{c}_{\theta}$

D

$\mathrm{D}_{\text {High }}$

$\mathrm{D}_{\text {Low }}$

Droller

$\mathrm{D}_{\text {wave }}$

$\mathrm{E}_{\mathrm{f}}$

$\mathrm{E}_{\text {lowfrequencyenergy }}$

$E_{\text {roller }}$

$E_{\text {totalenergy }}$

$\mathrm{E}_{\text {wave }}$

$f_{\text {rep }}$ maximum setup

scale parameter for Dean profile

dimensionless scale parameter

area of roller

surface roller component

wave action

speed of wave propagation

$\mathrm{x}$-direction wave group velocity

y-direction wave group velocity

velocity in directional space

energy gain

dune high

dune low

roller dissipation

dissipation of the wave

mean energy flux

low frequency energy

roller energy

total energy

wave energy

representative intrinsic frequency 


$\begin{array}{ll}\mathrm{F}_{\mathrm{x}} & \text { wave induced stress in x-direction } \\ \mathrm{F}_{\mathrm{y}} & \text { wave induced stress in y-direction } \\ \mathrm{g} & \text { acceleration due to gravity } \\ \mathrm{GIS} & \text { Geographic Information System } \\ \mathrm{h} & \text { water depth } \\ \mathrm{H} & \text { wave height } \\ \mathrm{h}_{1 / 10 \mathrm{Lo}} & \text { water depth at distance of } 1 / 10 \text { of deep water wave length } \\ \mathrm{h}_{1 / 3} \text { Lo } & \text { water depth at distance of } 1 / 3 \text { of deep water wave length } \\ \mathrm{H}_{\mathrm{b}} & \text { breaking wave height } \\ \mathrm{h}_{\mathrm{bt}} & \text { water depth at bar } \\ \mathrm{H}_{\mathrm{mo}} & \text { moment wave height } \\ \mathrm{H}_{\mathrm{o}} & \text { deep water wave height } \\ \mathrm{H}_{\mathrm{rms}} & \text { root mean square wave height } \\ \mathrm{H}_{\mathrm{s}} & \text { significant wave height } \\ \mathrm{h}_{\mathrm{tr}} & \text { empirion of wave breaking } \\ \mathrm{k} & \text { water depth at trough } \\ \mathrm{L}_{\mathrm{o}} & \text { wave number } \\ \mathrm{L}_{\mathrm{R}} & \text { deep water wave length } \\ \mathrm{m}_{1} & \text { empirical shape parameter } \\ \mathrm{Q}_{2} & \end{array}$




\begin{tabular}{|c|c|}
\hline $\mathrm{R}$ & runup \\
\hline $\mathrm{R}_{2}$ & two percent runup \\
\hline $\mathrm{R}_{\text {High }}$ & high runup \\
\hline $\mathrm{R}_{\mathrm{ig}}$ & infragravity runup \\
\hline $\mathrm{R}_{\text {Low }}$ & low runup \\
\hline $\mathrm{S}$ & swash \\
\hline Sxx & cross-shore component of radiation stress \\
\hline $\mathrm{T}$ & time \\
\hline $\mathrm{u}$ & velocity in horizontal \\
\hline $\mathrm{u}$ & velocity in $\mathrm{x}$-direction \\
\hline $\mathrm{V}$ & velocity in $y$-direction \\
\hline $\mathrm{x}$ & cross-shore direction \\
\hline XBeach & extreme beach behavior model \\
\hline $\mathrm{x}_{\mathrm{tr}}$ & distance from trough to shoreline \\
\hline $\mathrm{y}$ & distance from shoreline \\
\hline $\mathrm{Z}_{\mathrm{b}}$ & bathymetry \\
\hline$\alpha$ & constant of proportionality \\
\hline$\beta$ & slope component \\
\hline$\beta_{f}$ & average slope \\
\hline$\gamma$ & ratio of wave height to water depth \\
\hline$\eta$ & free surface \\
\hline$\eta_{\text {mean }}$ & mean free surface \\
\hline
\end{tabular}


$\lambda$

$\xi$

$\xi_{\text {storm }}$

$\rho$

$\sigma$

$\tau_{\mathrm{bx}}$

$\tau_{\text {by }}$

$\chi$ distance of surface roller component

Iribarren number

storm Iribarren number

density

intrinsic wave frequency

bed shear stress in $\mathrm{x}$-direction

bed shear stress in $y$-direction

calibration parameter 
TABLE OF CONTENTS

Page

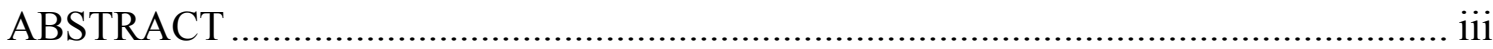

ACKNOWLEDGEMENTS ...........................................................................

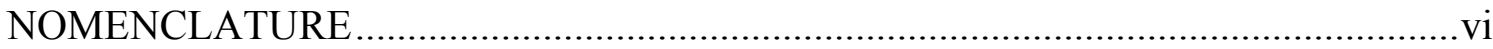

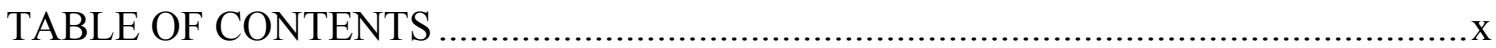

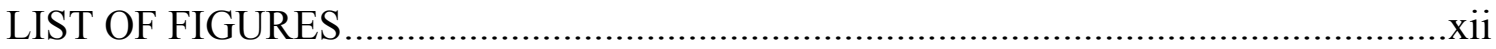

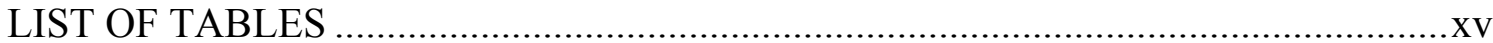

1. INTRODUCTION: VARIABLITY IN LONG-WAVE RUNUP AS A

FUNCTION OF NEARSHORE BATHYMETRIC FEATURES ................................

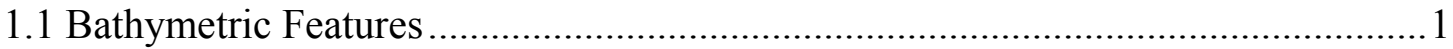

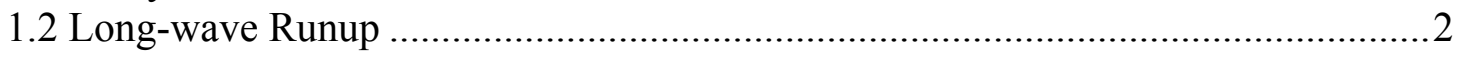

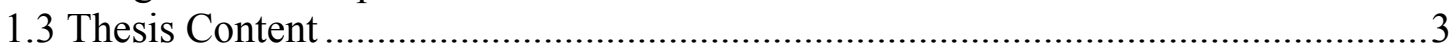

2. BACKGROUND AND LITERATURE REVIEW ..............................................

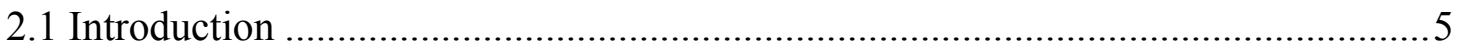

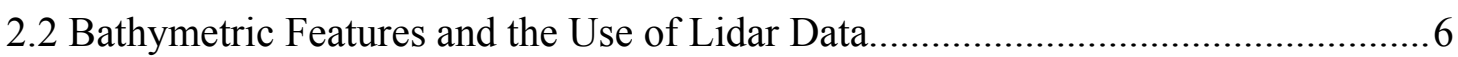

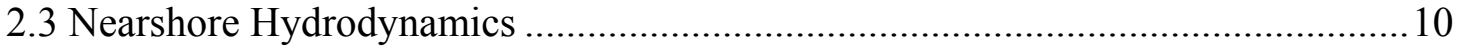

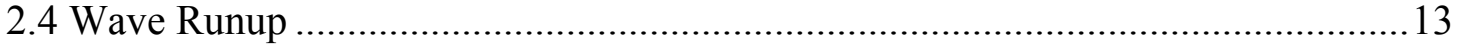

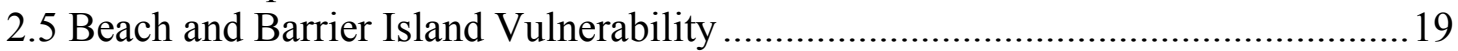

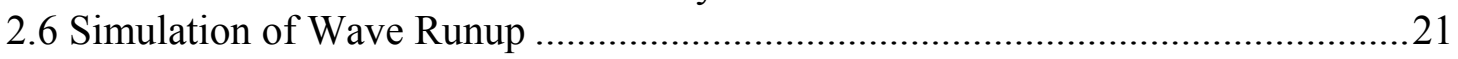

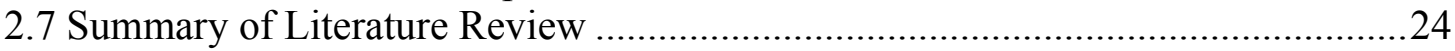

3. SITE LOCATION AND GRID GENERATION .................................................27

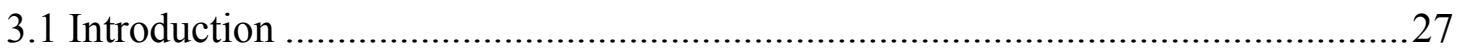

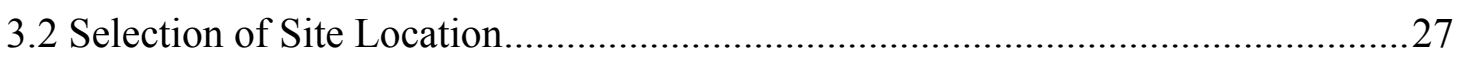

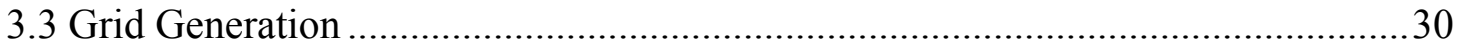

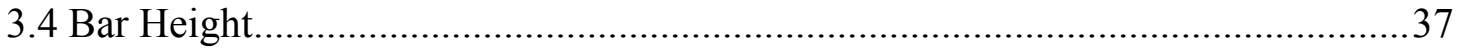

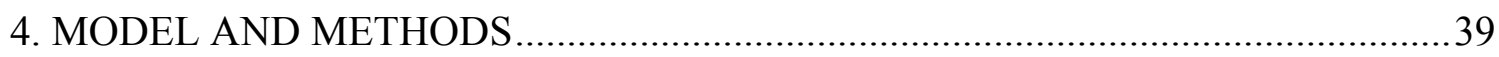

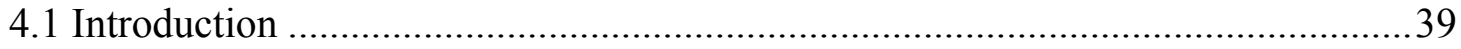

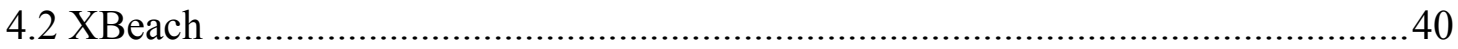




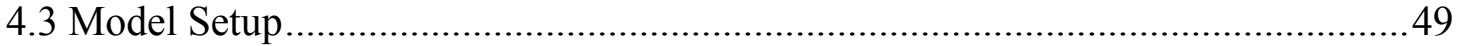

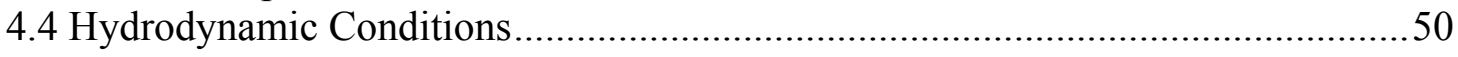

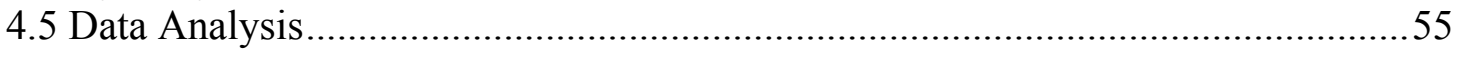

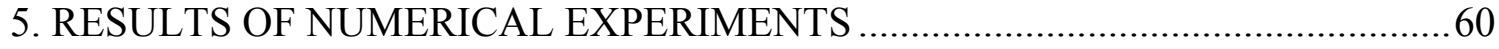

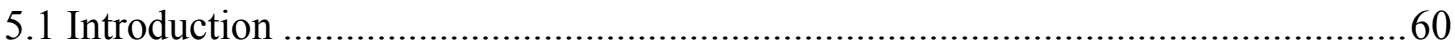

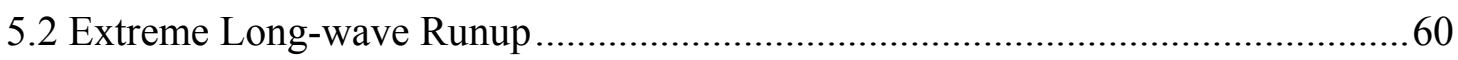

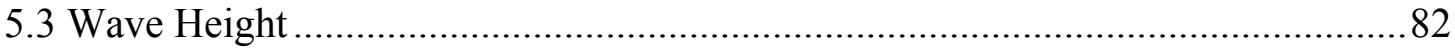

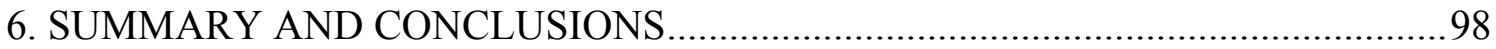

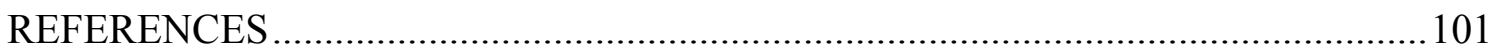

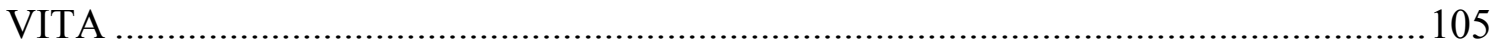




\section{LIST OF FIGURES}

Page

Figure 1. Beach profile divided into three segments (modified from Wang and Davis, 1998) 8

Figure 2. Surfzone regions (from Svendsen et al., 1978)....

Figure 3. Horizontal momentum for waves entering shallow water (modified from Longuet-Higgins and Stewart, 1964)

Figure 4. Setup and runup definition sketch (modified from Holman, 1986)..... 15

Figure 5. Definition sketch of variables for quantifying impact of storms on barrier islands (From Sallenger, 2000)

Figure 6. Surface roller for a shallow water wave (modified from Svendsen, 1984)....23

Figure 7. Florida panhandle from Escambia County to Bay County (Google Earth, 2010).

Figure 8. Lidar data from central coastal region of Bay County Florida 31

Figure 9. Profiles generated using eCoastal for Bay County Florida..........................32

Figure 10. Initial profile (blue) and profile after smoothing (red) ..............................33

Figure 11. 3D offshore bar bathymetry (left) and 2D contour of offshore bar bathymetry (right)

Figure 12. Dean equilibrium beach profile (From HEC-25, 2008) 35

Figure 13. 3D no bar bathymetry (left) and 2D contour of no bar bathymetry (right)....36

Figure 14. 3D bar-rip bathymetry (left) and 2D contour of bar-rip bathymetry (right)...36

Figure 15. Variation in bar height .38

Figure 16. Coordinate system utilized for XBeach (From Roelvink et al., 2007) 
Figure 17. Staggered grid showing cell center and interface (From Roelvink et al., 2007)

Figure 18. CDF for determining wave component direction for spectrum (From Roelvink et al., 2007) .47

Figure 19. Hurricane Ivan (2004) track (From noaa.gov/hurricanes/viewer, 2010) ......51

Figure 20. Surge data during Hurricane Ivan (2004) after tide removed 52

Figure 21. Wave height data during Hurricane Ivan (2004) .......................................52

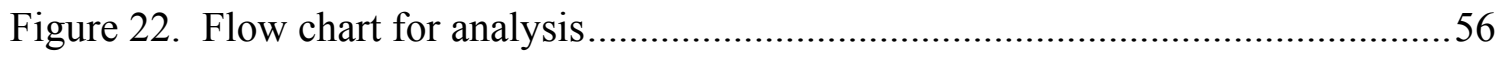

Figure 23. Location of last wet/dry point on the grid....................................................58

Figure 24. Long-wave runup time series.................................................................59

Figure 25. Extreme long-wave runup for no bar bathymetry ..........................................62

Figure 26. Extreme long-wave runup for continuous bar bathymetry .............................64

Figure 27. Extreme long-wave runup for bar-rip bathymetry ........................................66

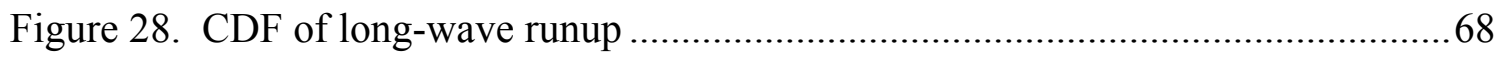

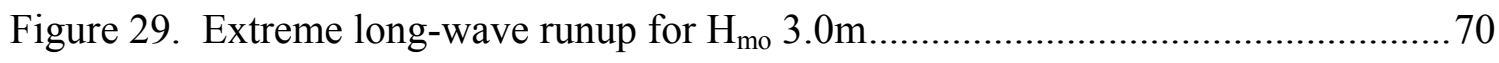

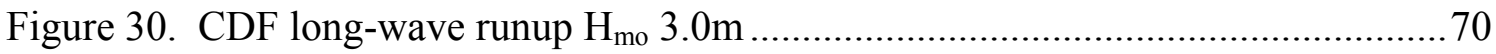

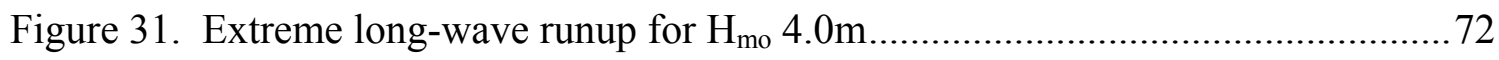

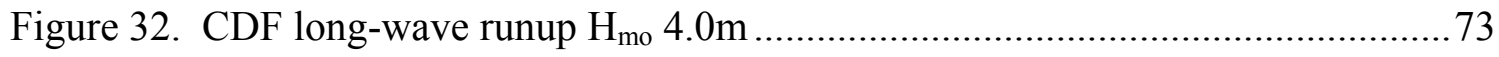

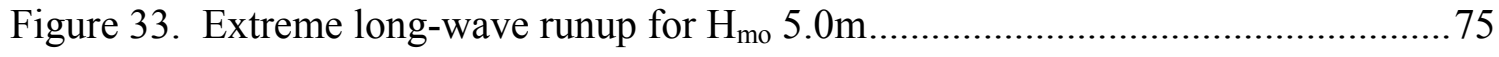

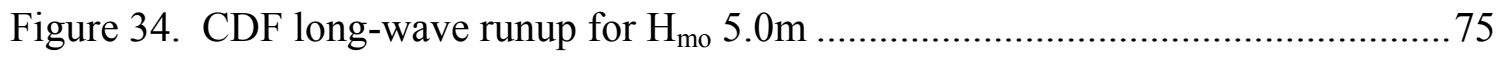

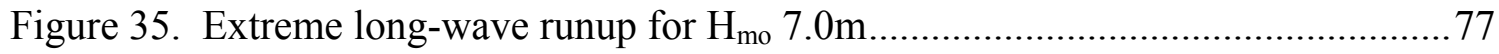

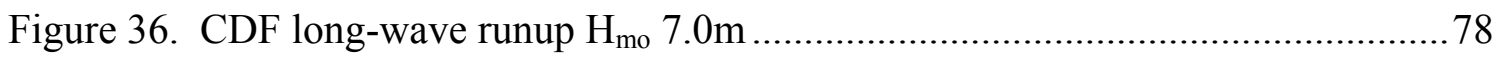


Figure 37. Mean extreme long-wave runup for various wave conditions .80

Figure 38. Mean extreme long-wave runup standard deviation for various wave conditions

Figure 39. Energy indicator through the surfzone for no bar bathymetry. 84

Figure 40. Energy indicator through the surfzone for continuous bar bathymetry

Figure 41. Energy indicator through the surfzone for bar-rip bathymetry 85

Figure 42. Wave height and velocities for $\mathrm{H}_{\mathrm{mo}} 3.0 \mathrm{~m}$ for no bar bathymetry (top), continuous bar bathymetry (middle), and bar-rip bathymetry (bottom) .......86

Figure 43. Energy indicator through the surfzone for $\mathrm{H}_{\mathrm{mo}} 3.0 \mathrm{~m}$

Figure 44. Wave height and water level for $\mathrm{H}_{\mathrm{mo}} 3.0 \mathrm{~m}$ for no bar bathymetry (top), continuous bar bathymetry (middle), and bar-rip bathymetry (bottom) .......88

Figure 45. Energy indicator through the surfzone for $\mathrm{H}_{\mathrm{mo}} 4.0 \mathrm{~m}$ .89

Figure 46. Wave height and water level for $\mathrm{H}_{\mathrm{mo}} 4.0 \mathrm{~m}$ for no bar bathymetry (top), continuous bar bathymetry (middle), and bar-rip bathymetry (bottom)

Figure 47. Energy indicator through the surfzone for $\mathrm{H}_{\mathrm{mo}} 5.0 \mathrm{~m}$. .91

Figure 48. Wave height and water level for $\mathrm{H}_{\mathrm{mo}} 5.0 \mathrm{~m}$ for no bar bathymetry (top), continuous bar bathymetry (middle), and bar-rip bathymetry (bottom)

Figure 49. Energy indicator through the surfzone for $\mathrm{H}_{\mathrm{mo}} 7.0 \mathrm{~m}$

Figure 50. Wave height and water level for $\mathrm{H}_{\mathrm{mo}} 7.0 \mathrm{~m}$ for no bar bathymetry (top), continuous bar bathymetry (middle), and bar-rip bathymetry (bottom)

Figure 51. Mean longshore energy through the surfzone. .96 


\section{LIST OF TABLES}

Page

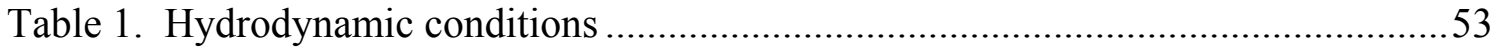

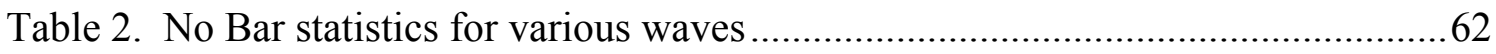

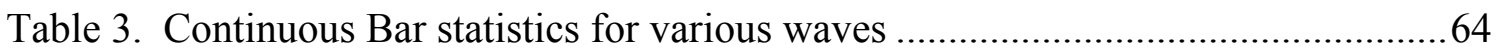

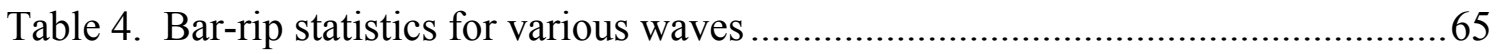

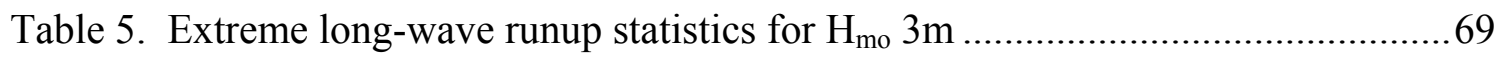

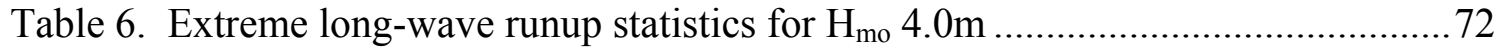

Table 7. Extreme long-wave runup statistics for Hmo 5.0m .................................. 74

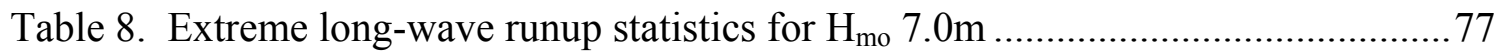

Table 9. Mean extreme long-wave runup comparison of no bar bathymetry

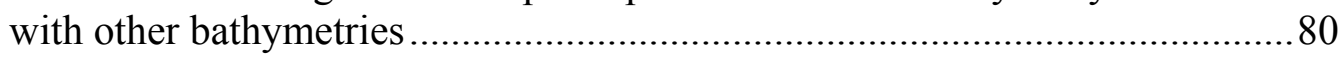




\section{INTRODUCTION: VARIABLITY IN LONG-WAVE RUNUP AS A FUNCTION}

\section{OF NEARSHORE BATHYMETRIC FEATURES}

\subsection{Bathymetric Features}

Beaches and barrier islands are vulnerable to extreme storm events, such as hurricanes, that can cause severe erosion and overwash to the system. Having dunes and a wide beach in front of coastal infrastructure can provide protection during a storm, but the influence that nearshore bathymetric features have in protecting the beach and barrier island system is not completely understood. The spatial variation in nearshore features, such as sand bars and beach cusps, can alter nearshore hydrodynamics, including wave setup and runup. The influence of bathymetric features on long-wave runup can be used for evaluating the vulnerability of coastal regions to erosion and dune overtopping (Stockdon et al., 2006), evaluating the changing morphology, and implementing plans to protect infrastructure.

The objective of this research is to determine the influence of nearshore features on long-wave runup at the land/sea interface and quantify energy dissipation within the surf zone as an indication of erosion potential. The XBeach (eXtreme Beach behavior model) numerical model (Roelvink et al., 2007; McCall, 2010) will be used for the research of understanding the influence of bathymetric features on long-wave runup and an energy dissipation relation through the surf zone. The XBeach model will be forced with

This thesis follows the style of the Journal of Geophysical Research. 
several hydrodynamic conditions with varying water levels and wave heights to determine long-wave runup and energy dissipation relation. These objectives will be completed for a set of idealized grids representative of bathymetry and topography to determine the influence of nearshore bathymetric features.

\subsection{Long-wave Runup}

The study area, on the Florida panhandle (USA), is characterized by a complex offshore bar and beach cusp system, which exhibits periodic bar-rips, continuous bar, and multiple bars in some locations. Bathymetric and topographic lidar for the Florida panhandle will be analyzed to characterize these bathymetric features, and a series of idealized bathymetric scenarios will be developed to evaluate long-wave runup and an energy dissipation relation with XBeach. These bathymetric scenarios include (1) no offshore bar, (2) continuous offshore bar, and (3) bar-rip. The subaerial topography in all scenarios will be specified as a plane beach, thus allowing long-wave runup response to bathymetric variability to be quantified. Several steady-state hydrodynamic conditions, representative of hurricane conditions, will be specified to force the numerical simulations. XBeach is a numerical model capable of determining nearshore wave and currents, predicting overwash, and breaching of barrier islands (Roelvink et al. 2007; McCall, 2010). XBeach will be used to run the hydrodynamic conditions specified above for the analysis of long-wave runup at the land/sea interface.

XBeach assumes that coastal erosion at the land-sea interface is dominated by spectrally-generated, bound long waves. As such, the long-wave runup will be analyzed 
at the land/sea interface. Several hydrodynamic conditions with different wave values will be used to force the model with the idealized grids.

The propagation of the waves will be predominantly shore-normal with the grid setup in Cartesian coordinates. For each simulation, long-wave runup time series will be developed by extracting the instantaneous land-sea interface profile-wise from the spatial XBeach water surface elevation output. These time series will be analyzed using zero upcrossing, and runup statistics will be developed. The two percent runup (Stockdon et al., 2006) will be determined by ranking the waves and obtaining the value for the $98^{\text {th }}$ percentile. The two percent runup is considered to be highly correlated with erosion (Stockdon et al., 2006). The extreme long-wave runup is considered to be the two-percent runup. The mean long-wave runup will also be obtained.

The wave heights for profiles alongshore will be analyzed and the location of breaking will be determined for each profile. The integral of the squared wave height for broken waves is found through the surf zone. The $\int H^{2} d x$ can be considered as an indication of energy dissipation. Energy dissipation can be an indication of erosion due to sediment transport.

\subsection{Thesis Content}

This thesis is divided into five sections. Section 1 presents a general overview of nearshore bathymetric features and the long-wave runup. Section 2 presents an overview of existing research related to bathymetric features and lidar data; long-wave runup; vulnerability of beach and barrier island; and simulations of long-wave runup. The third 
section discusses the site selection and the bathymetric and topographic grids. The fourth section includes an explanation of the numerical model which is used for the analysis of the effects of bathymetric features on long-wave runup. This section also discusses the processes of analyzing the data. Section 5 discusses and compares the results of XBeach for the long-wave runup and energy dissipation in the surf zone as a measure of the amount of erosion. Section 6 includes conclusions and recommendations for further research.

Knowing the influence that complex bathymetric features have on instantaneous water levels at the coast is essential for predicting the vulnerability of a coastal region to erosion during extreme storm events. This research will quantify the expected variability in instantaneous water level and wave condition as a function of bathymetric variability with the goal of providing insight on protecting existing coastal infrastructure and for improving planning of future coastal development projects. 


\section{BACKGROUND AND LITERATURE REVIEW}

\subsection{Introduction}

Beaches and barrier islands are vulnerable to extreme storm events, such as hurricanes, that can cause severe erosion and overwash to the system. Knowing the impact that extreme storms have on coastal regions is vital to the safety of society and infrastructure, since approximately $48 \%$ of the total United States population lives within coastal regions that are vulnerable to storms (U.S. Census Bureau, 2010). In order to better protect and plan for further development along the coast, nearshore features must be studied and mapped to determine the influence on hydrodynamic conditions, especially during extreme storm events (Guenther et al., 1994). The spatial variation in nearshore features, such as sand bars and beach cusps, are highly dynamic and can be altered due to changing hydrodynamic conditions on both the long and short term (Plant and Holman, 1997; Wang and Davis, 1998). The nearshore features can influence the nearshore hydrodynamics, such as wave setup and runup, which can be analyzed using numerical models that are able to solve the complex conditions in the surf zone (Schaffer et al., 1993; Kennedy et al., 2000; Van Gent and Giarrusso, 2005; Roelvink et al., 2007). The influence of bathymetric features on runup can be used for evaluating the vulnerability of coastal regions to erosion and dune overtopping, evaluating the changing morphology, and implementing plans to protect infrastructure (Sallenger, 2000; Stockdon et al., 2006).

This section provides an overview of barrier island vulnerability as it relates to common bathymetric features and the use of lidar data to determine bathymetric 
features, long-wave runup, and numerical models used to determine free surface elevation. Section 2.2 provides an overview of bathymetric features and the use of lidar for coastal applications. Section 2.3 of this literature review will give a background on the development of the present knowledge of wave runup and the development of empirical equations. The vulnerability of beach and barrier island systems will be discussed in Section 2.4. Section 2.5 will describe numerical models to determine runup. A summary of the literature reviewed will be discussed in Section 2.6.

\subsection{Bathymetric Features and the Use of Lidar Data}

The spatial variation in nearshore features, such as sandbars and beach cusps, can alter nearshore hydrodynamics and can be highly variable. The dynamic environment along the coast requires the thorough analysis of offshore features (Plant and Holman, 1997; Wang and Davis, 1998) which can be obtained through Light Detection and Ranging (lidar) (Brock et al., 2002; Guenther et al., 1994). Lidar data is collected along much of the coastal United States and can be used to map bathymetric features, such as sandbars.

In order to understand the complexities of offshore features, the equilibrium beach profile must be studied. The equilibrium profile is the balance of both destructive and constructive forces (Dean and Dalrymple, 2002). The equilibrium beach profile concept was first developed by Dean (1977) and described as

$$
h(y)=A y^{2 / 3}
$$

where $h$ is the water depth, $y$ is the distance from the shoreline, and $A$ is a scale 
parameter which is dependent on sediment characteristics. This mathematical form of the equilibrium beach profile does not capture sandbars or any longshore variation. The equilibrium profile is useful for coastal engineering projects and understanding nearshore hydrodynamics; however, at the shoreline, a limitation of this form is that the equilibrium profile predicts an infinite slope. The slope of the equilibrium profile is dependent on sediment characteristics, the wave climate, initial slope, and height of the berm (Dean, 1991). Understanding an area's equilibrium state and its expected evolution due to varying hydrodynamic conditions is important for predicting the response of profiles which is useful for coastal projects, such as beach nourishment. The equilibrium beach profile concept can be used to understand the response of the profile due to nearshore processes, which explains the tendency for bars to form with steep waves and milder slopes (Dean, 1991).

Sandbars are highly dynamic due to wave height variations (Plant and Holman, 1997). Plant and Holman (1997) used two data sets for the analysis of sandbar variability. The response of the sandbar may be correlated with the morphological feedback associated with sediment transport which controls the movement and growth of the sandbar. Sediment transport relates bathymetric changes in the sediment continuity equation as

$$
\frac{\partial Q}{\partial x}=-\frac{\partial Z_{b}}{\partial t}
$$

where $Q$ is the sediment transport, $x$ is the cross-shore direction, $Z_{b}$ is the bathymetry, and $t$ is time. Along with sediment transport, a phase shift was also found to be 
influential in the sandbar response (Plant and Holman, 1997) which controls the movement of the sandbar to growth ratio. The results show that the sandbars moved onshore when the significant wave height was less than $1 \mathrm{~m}$ and offshore for wave heights greater than $1 \mathrm{~m}$ (Plant and Holman, 1997). The magnitude of the sandbar response increased as the significant wave height or the ratio of the root mean square wave height to water depth increased (Plant and Holman, 1997).

The bar and trough are important features of the nearshore bathymetry that are subject to variation due to short-term and long-term changes in wave conditions (Wang and Davis, 1998). The beach profile has been divided into three regions where two parameters for grain size can be used to better describe the equilibrium profile associated with the area (Figure 1).

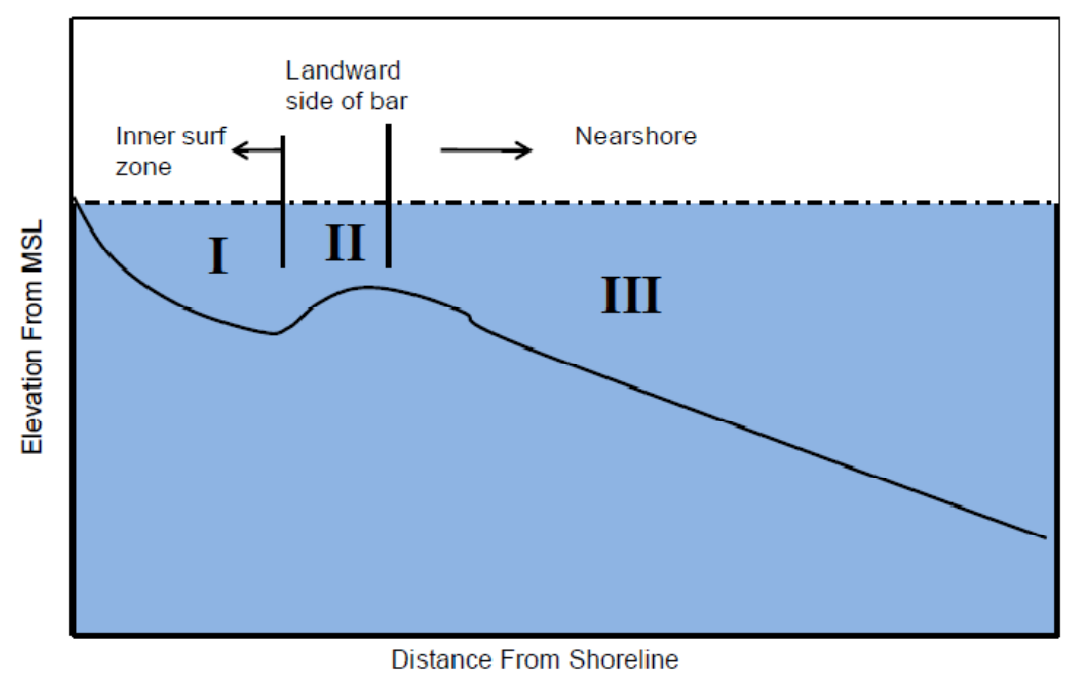

Figure 1. Beach profile divided into three segments (modified from Wang and Davis, 1998) 
The inner surf zone can be described by

$$
h(x)=A_{1} x^{m_{1}}
$$

where $A_{l}$ is a dimensional scale parameter for inner surf, $x$ is from $0<x \leq x_{t r}$ where $x_{t r}$ is distance from trough to shoreline, and $m_{l}$ is empirical shape parameter controlling beach slope which is similar to the Dean (1977) equilibrium profile (Equation 2.1). The equation for the region landward of the bar can be described as

$$
h(x)=h_{t r}+\frac{h_{b t}-h_{t r}}{x_{b t}-x_{t r}}\left(x-x_{t r}\right)
$$

where $h_{t r}$ is water depth at trough bottom, $h_{b t}$ is water depth at bar top, $x$ is from $x_{t r}<x \leq x_{b t}$ where $x_{b t}$ is distance from bar top to shoreline (Wang and Davis, 1998). The equation for the nearshore profile is described as

$$
h(x)=A_{2}\left(x-x_{2}\right)^{m_{2}}
$$

where $A_{2}$ is a dimensional scale parameter for the nearshore zone, and $m_{2}$ is an empirical shape parameter controlling beach slope (Wang and Davis, 1998). The three segment approach requires input for the inner surf zone, landward side of the bar, and the nearshore. The three segment approach is similar to the Dean equilibrium beach profile when it is divided into segments. Variation in sediment grain size and slope are fundamental for a barred beach profile (Wang and Davis, 1998). The beach and barrier island system are complex and dynamic, but the benefit to the mainland during an extreme storm event is paramount. Mapping of the offshore can aid in the understanding of the bathymetric features which is extremely important both before and after storms 
since significant changes can occur to the topography and bathymetry.

Bathymetry and topography can be mapped using a lidar system, which is a remote mapping technology that uses a scanning laser to determine elevation (Guenther et al., 1994). The use of lidar data to determine erosion and overwash after storms has been vital to understanding the hydrodynamic forces that occur during the storm. Lidar data is a fundamental part of understanding bathymetric features and the variability that occurs both in the long-term and short-term. Knowing the spatial variability of bathymetric features is important for understanding the influence that they have on hydrodynamic conditions at the coast.

\subsection{Nearshore Hydrodynamics}

The nearshore region (Figure 2) is defined as the region between the shoreline and an offshore location where waves are no longer influenced by depth because of the large water depth (Svendsen, 2006). As waves propagate toward the coast, energy is transferred in the waves. As the depth decreases, wave heights increase to a point of breaking.

The breaking of a wave causes energy to dissipate and results in the wave height decreasing (Svendsen, 2006). For breaking to continue though the surfzone, the water depth must also decrease to maintain the wave height to water depth ratio that allows for wave breaking defined as

$$
(H / h)=0.78
$$

which was determined by McCowan (1894). 

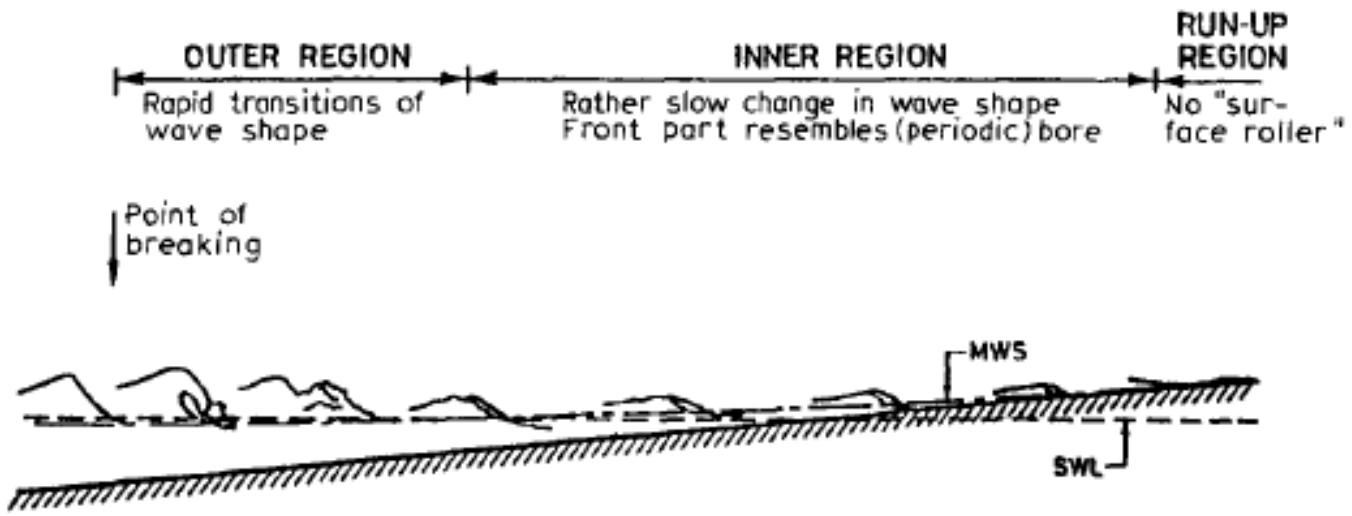

Figure 2. Surfzone regions (from Svendsen et al., 1978)

Energy flux in the surfzone can be described as

$$
\begin{gathered}
E_{f x}=\rho g c H^{2} B \\
c=\sqrt{g h} \\
B=\frac{1}{\rho g c H^{2}} \int_{-h o}^{\zeta}\left[p_{D}+\frac{1}{2 \rho}\left(u_{w}^{2}+w_{w}^{2}\right)\right] u d z
\end{gathered}
$$

where $u_{w}$ and $w_{w}$ are the depth uniform velocity, $p$ is pressure (Svendsen, 2006).

Battjes and Janssen (1978) assumed that unbroken wave heights follow the Rayleigh distribution. As the waves propagate shoreward, the breaking wave height is dependent on the water depth. Therefore, the probability of breaking can be described as

$$
Q_{b}=P\left(H>H_{m}\right)=e^{-\frac{H_{m}^{2}}{2 H^{2}}}
$$

where $H_{m}$ is the breaking wave height dependent on depth (Svendsen, 2006).

The average dissipation becomes 


$$
\bar{D}=-\frac{\alpha}{4} \rho g \frac{H_{m}^{2}}{T_{m}} Q_{b}
$$

where $T_{m}$ is the mean spectral period, $Q_{b}$ is the breaking probability, and $\alpha$ is a empirical coefficient (Svendsen, 2006). Breaking probability decreases as waves pass over a shallow bar, which results in a significant decline in the dissipation rate (Svendsen, 2006).

Changes in wave height also cause changes in radiation stress, which is the excess momentum flux due to waves (Longuet-Higgins and Stewart, 1964). For a wave propagating in the $\mathrm{x}$-direction, the radiation stress has two components due to momentum and pressure described as

$$
\begin{gathered}
S_{x x}=S_{m}+S_{p} \\
S_{m}=\overline{\int_{-h_{o}}^{\zeta} \rho u_{w}^{2} d z} \\
S_{p}=\overline{\int_{-h_{o}}^{\zeta} p_{D} d z-\frac{1}{2} \rho g \overline{\eta^{2}}}
\end{gathered}
$$

where $u_{w}$ is a depth uniform velocity, $p$ is pressure, $\eta$ is free surface elevation (Svendsen, 2006). As the waves propagate toward the coast over decreasing water depth and just before breaking, there is an increase in radiation stress, which causes a set down in the mean water level (Svendsen, 2006). Radiation stress decreases as wave energy dissipates through the surfzone (Svendsen, 2006). The decreasing radiation stress causes a setup of the mean water level. The next section discusses wave runup in more detail. 


\subsection{Wave Runup}

Wave runup is defined as the water level maximum on a beach from individual waves with respect to still water level which is comprised of setup and swash (Stockdon et al. 2006). The experiments of prior investigators (Hunt, 1959; Longuet-Higgins and Stewart, 1964; Bowen et al., 1968; and Battjes, 1974) have led to the present knowledge of runup. Wave runup can be described as the time varying position of the last wet/dry point on the shoreline; however, to begin, the journey to the definition of runup must first start with understanding the hydrodynamic forcing as waves propagate into shallow water. Longuet-Higgins and Stewart (1964) introduce radiation stress as excess momentum flow due to waves. The momentum balance for a sloping bottom considering only direction of wave propagation (here in the x-direction) after simplifications can be described as

$$
\frac{d S_{x x}}{d x}=-\rho g(\eta+h) \frac{d \eta}{d x}
$$

where $S_{x x}$ is the cross-shore component of radiation stress, $\rho$ is density, $g$ is acceleration due to gravity, and $\eta$ is the free surface (Longuet-Higgins and Stewart, 1964). As waves propagate into shallow water, the waves begin to feel the bottom causing them to shorten, steepen, and then break resulting in changes in radiation stress and ultimately the mean surface level (Longuet-Higgins and Stewart, 1964). The balance of forces can be seen in Figure 3. 


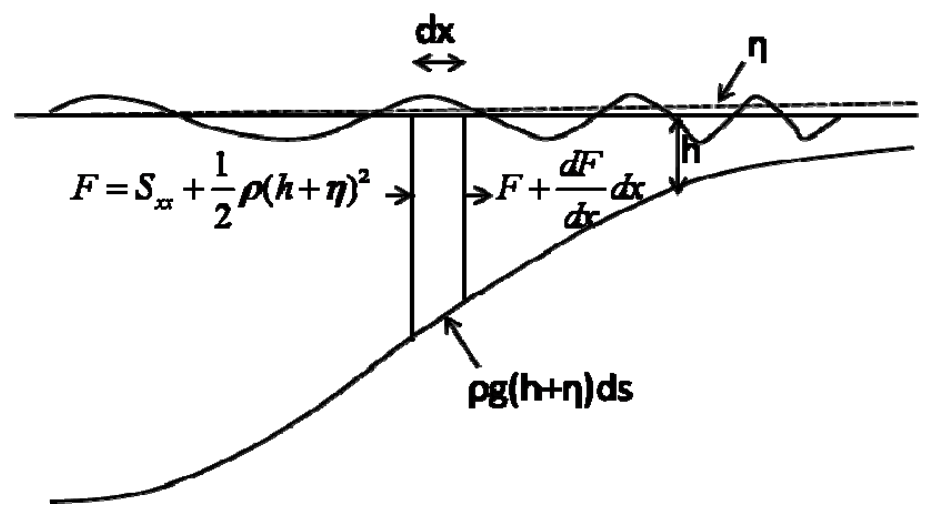

Figure 3. Horizontal momentum for waves entering shallow water (modified from Longuet-Higgins and Stewart, 1964)

The cross-shore momentum balance can be further modified as

$$
\frac{d \eta}{d x}=-\frac{3}{2} \alpha^{2} \frac{d h}{d x}
$$

where $\alpha$ is a constant of proportionality (Longuet-Higgins and Stewart, 1964). By analysis of experimental result, Longuet-Higgins and Stewart (1964) concluded that within the surf zone alpha is equal to approximately 0.32 .

Building on the work of Longuet-Higgins and Stewart (1964), Bowen et al. (1968) assumed that the broken wave height remains proportional to mean water depth which can be described as

$$
\gamma=(H / h)
$$

where $\gamma$ is the ratio of wave height , $\mathrm{H}$, to water depth within the surf zone.

Experimental results showed that within the region after breaking the wave height tended to be linearly related to mean water depth and that the maximum setup at the 
beach was of the same order of the wave amplitude (Bowen et al., 1968). As the free surface elevation and water depth go to zero, the setup increases. The resulting simplified equation for wave setup can be described as

$$
\eta=0.38 \gamma H_{b}
$$

where $H_{b}$ is the broken wave height (Bowen et al., 1968). Setup and runup definition sketch can be seen in Figure 4.

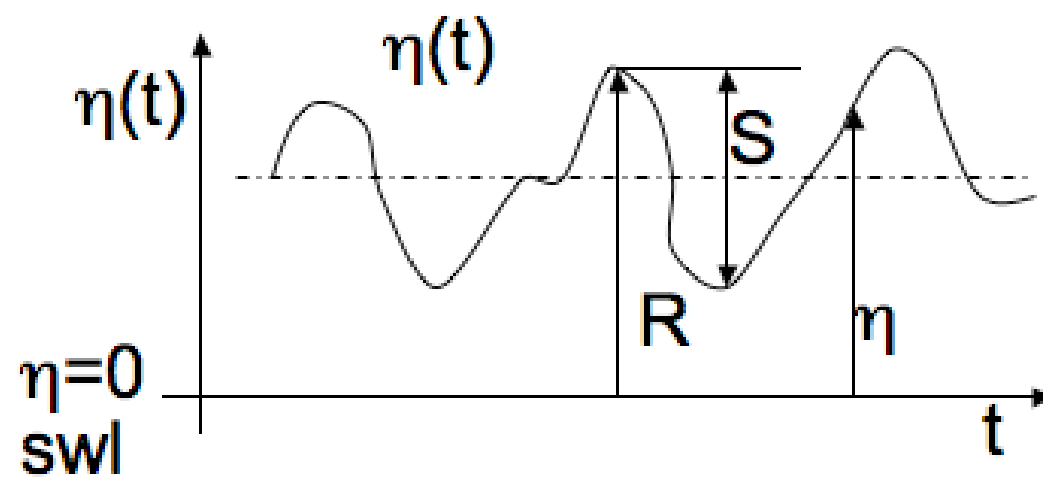

Figure 4. Setup and runup definition sketch (modified from Holman, 1986)

Further insight into the nearshore environment can be described by the parameter set of wave height, deep water wave length, wave period, and beach steepness. The surf similarity parameter, or Iribarren number, relates the wave steepness and beach slope described as

$$
\xi=\frac{\tan \beta}{\left(H / L_{o}\right)^{1 / 2}}
$$


and for natural sloping beaches the equation becomes

$$
\xi=\frac{\beta}{\left(H / L_{o}\right)^{1 / 2}}
$$

where $L_{o}$ is deep water wave length and $\beta$ is a slope component which is useful for flow characteristics (Battjes, 1974). The Iribarren number was also shown to be a fundamental parameter in determining wave runup described by the following equation proposed by Hunt (1959)

$$
R / H=1.0 \xi
$$

which is a simplified version of

$$
R / H=2.3 \frac{\tan \beta}{\left(\frac{H}{T^{2}}\right)^{1 / 2}}
$$

which was determined by Hunt (1959) for computing wave runup.

Swash was discussed in Bowen et al. (1976) and Battjes (1974) as the vertical distance of water that "swashed" on the beach in places that had been previously "dry". Miche (1951) explained that the two parts of monochromatic waves consist of a progressive and standing component. The standing component reaches the highest level at the shoreline where the amplitude is dependent on beach slope and deep water period.

As waves propagate toward the coast, the breaking waves dissipate energy, but some of the energy is converted to runup which has the potential to cause beach and dune erosion (Holman, 1986; Ruggiero et al., 2004; Stockdon et al., 2006). The development of wave runup theories were obtained by analyzing field experiments. 
Field experiments were conducted on a natural beach to determine the extreme runup statistics (Holman, 1986). Results showed that there is considerable variability in the wave runup due to setup than if just swash were considered (Holman, 1986). For storms, the Iribarren number was found to be lower resulting in lower frequency waves becoming predominate (Holman, 1986). The storm Iribarren number was found to be

$$
\xi_{\text {storm }}=6.3 \beta
$$

which can be used to describe the two percent runup level as

$$
R_{2}=(5.2 \beta+0.2) H_{s}
$$

where $H_{s}$ is the significant wave height and the equation is based on the analysis of the experimental results (Holman, 1986).

Field experiments were conducted to obtain video of runup data in order to develop better theories for predicting the two percent wave runup on natural beaches, building on the work by Holman (1986). The two percent runup is considered to be highly correlated with erosion of beaches and dunes (Stockdon et al., 2006). After analyzing the data, the two percent runup equation is described as

$$
R_{2}=1.1\left[\langle\eta\rangle+\frac{S}{2}\right]
$$

where $\langle\eta\rangle$ is maximum setup and $S$ is swash including incident and infragravity bands. The relationship includes the slightly non-Gaussian nature of swash on natural beaches (Stockdon et al., 2006). The equation was further modified by parameterizing the setup and swash to include beach slope, deep water wave height, and deep water wave length and regression parameters. The final form of the extreme runup equation is 
described as

$$
R_{2}=1.1\left(0.35 \beta_{f}\left(H_{o} L_{o}\right)^{1 / 2}+\frac{\left[H_{o} L_{o}\left(0.563 \beta_{f}^{2}+0.004\right)\right]^{1 / 2}}{2}\right)
$$

where $\beta_{f}$ is the average slope, $H_{o}$ is the deep water wave height, $L_{o}$ is the deep water wave length. The Iribarren number relates beach slope to the square root of deep water wave steepness, which for highly dissipative conditions, the Iribarren number is less the 0.3 (Stockdon et al., 2006). For these dissipative conditions, the extreme runup equation is described as

$$
R_{2}=0.043\left(H_{o} L_{o}\right)^{1 / 2}
$$

for Iribarren numbers less than 0.3. These runup equations were formulated for single profiles to remove the longshore variability. However, the differences associated from a single profile and variability in longshore profiles may be $38 \%$ for highly threedimensional topography (Stockdon et al., 2006).

Runup data was obtained in Agate Beach, Oregon to investigate highly dissipative beaches using video for several cross-shore transects (Ruggiero et al., 2004). Foreshore beach slope greatly influenced runup along with the significant runup period which decreased linearly with increasing beach slope (Ruggiero et al., 2004). The infragravity component of runup was found to be linearly correlated with the beach slope. The data from these runup experiments were used to find a linear fit through the infragravity band to determine the infragravity runup equation as 


$$
R_{i g}=0.33 H_{s}+0.33
$$

where $H_{s}$ is the deep water significant wave height (Ruggiero et al., 2004). Low frequency energy was also a dominating factor for the highly dissipative beach. The spectra for the region with a steeper slope had more energy at the higher frequencies than the milder sloping region. The sloping of the beach and the high energy wave conditions offshore caused significant morphodynamic and hydrodynamic results in the cross-shore where sandbars are located hundreds of meters from the shoreline (Ruggiero et al., 2004). The variability of profiles in the longshore is not considered which could influence the correlation of beach slope on runup. The beach slope was found to be highly correlated to the amount of runup experienced on the beach, especially in the infragravity band (Ruggiero et al., 2004). Runup is the driving force of erosion and overwash during extreme storm events. As such, runup must be understood to identify the damages that could occur during a storm.

\subsection{Beach and Barrier Island Vulnerability}

Beaches and barrier islands are vulnerable to extreme storm events, such as hurricanes. Barrier islands act as a natural defense for the mainland during extreme storm events. Many barrier islands have people inhabiting them and as such there is considerable infrastructure on these dynamic environments. Within the United States, approximately $48 \%$ of the total population live in areas that are vulnerable to hurricanes (U.S. Census Bureau, 2010). Also, valuable infrastructure are at risk to damage due to extreme storm events. Along the coast, roads and bridges are built in the unique 
environment where the potential for loads from waves and surge can be expected. Bridges and roads are typically built to minimize cost while maximizing efficiency and not for the extreme loads from surge (Douglass et al., 2006). As such, understanding the hydrodynamic processes associated with extreme storm events and how they are affected by bathymetric features is imperative for the safety of society and infrastructure.

Erosion and overwash are negative impacts caused by storms on beaches and barrier islands. Having dunes and a wide beach can be the first line of defense of protecting the infrastructure or the mainland from damage.

Sallenger (2000) categorized four distinct impact regions during an extreme storm event. The different impact regions considered coastal geometry and hydrodynamic processes including runup. Figure 5 shows the definition of the variables $\mathrm{R}_{\text {High }}, \mathrm{R}_{\text {Low }}, \mathrm{D}_{\text {High }}$, and $\mathrm{D}_{\text {Low }}$ which are the high and low runup and the high and low dune elevation, respectively.

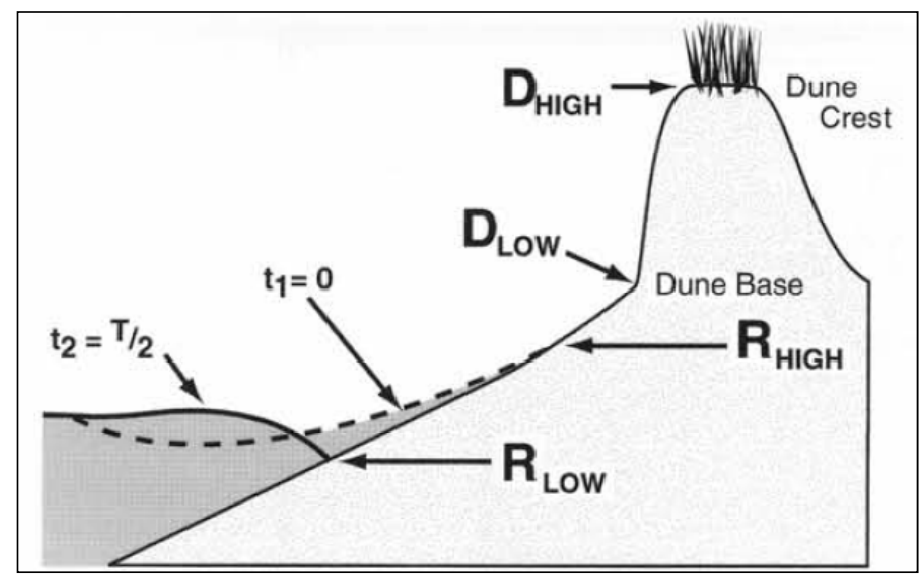

Figure 5. Definition sketch of variables for quantifying impact of storms on barrier islands (From Sallenger, 2000) 
$\mathrm{R}_{\text {High }}$ includes the two percent runup as described by Holman (1986), discussed above, and the influence of tide and storm surge given by

$$
R_{\text {High }}=R_{2 \%}+\eta_{\text {mean }}
$$

The first impact region is the swash regime where the ratio of $\mathrm{R}_{\mathrm{High}}$ and the $\mathrm{D}_{\mathrm{High}}$ equals the ratio of $\mathrm{D}_{\text {Low }}$ and $\mathrm{D}_{\text {High. }}$. Erosion is limited to the area seaward of the dunes. Once the critical limit given in equation 2.29 is reached, the region is considered to be in the collision regime (Sallenger, 2000). As runup increases, the dunes begin to be overtopped, which happens when $\mathrm{R}_{\text {High }}$ is greater than $\mathrm{D}_{\text {High }}$, resulting in the overwash region. The inundation regime occurs when the barrier island is completely inundated which happens when $\mathrm{R}_{\mathrm{Low}}$ is greater than $\mathrm{D}_{\text {High }}$ (Sallenger, 2000). The four impact regions that occur during an extreme storm event can be used to assess damage to the area.

\subsection{Simulation of Wave Runup}

The theories used within the numerical models must resolve the complex physics that arise as waves move from deep water to shallow water. Shoaling, refraction, diffraction, wave breaking, and runup are a few of the hydrodynamic conditions that must be solved. Numerical models that determine surf zone hydrodynamics have been paramount in the development of models that predict runup (Schaffer et al., 1993; Kennedy et al., 2000; Van Gent and Giarrusso, 2005; Roelvink et al., 2008; McCall et al., 2010). 


\subsubsection{Boussinesq Models}

The modified Boussinesq type equations are more robust at predicting the hydrodynamic conditions in shallow water than attempting to perform the Navier-Stokes equations over a large distance (Schaffer et al., 1993; Kennedy et al., 2000; Van Gent and Giarrusso, 2005). Modeling wave breaking and runup using the Boussinesq equations requires some modifications to allow for the wave breaking and dissipation in the surf zone.

Schaffer et al. (1993) used a roller based assumption to improve the Boussinesq equations to predict wave breaking along with runup in the surf zone. Including the surface roller improves the momentum equation. The surface roller greatly increases the magnitude of radiation stress and energy flux for shallow water where the energy flux can be described as

$$
\frac{\partial E_{f, w}}{\partial x}=\rho g \frac{H^{3}}{4 h T} D
$$

where $E_{f}$ is the mean energy flux, $T$ is the wave period, and $D$ is the energy gain (Svendsen, 1984). The surface roller in shallow water is shown in Figure 6 where the velocity in the horizontal direction is denoted by $u, c$ is the speed of propagation of the wave, $\lambda$ is the distance of the surface roller component, and $A_{s}$ is the surface roller component. 


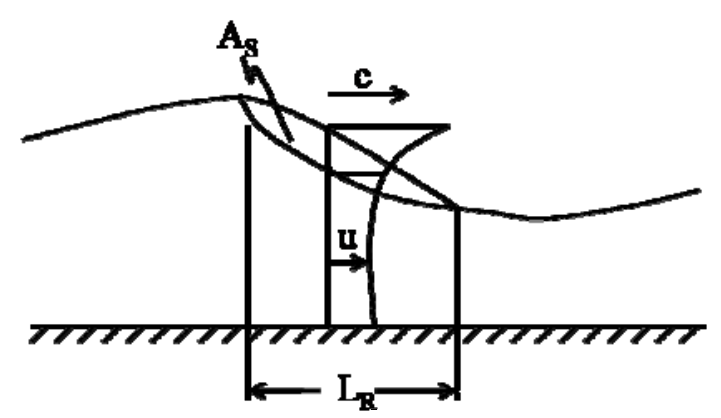

Figure 6. Surface roller for a shallow water wave (modified from Svendsen, 1984)

The addition of the surface roller allows the model to portray wave breaking over an offshore bar feature, wave setup, and the changing breaker location for irregular waves (Schaffer et al., 1993).

Another Boussinesq model, Triton, was used to compute wave conditions at the toe of a dike. The bar and trough offshore features were varied to determine the resulting influence on the wave conditions at the toe of the structure (Van Gent and Giarrusso, 2005). The results showed that the level of the bar and trough had very little impact on the wave conditions at the toe of the structure; however, the level of the low tide terrace greatly affected the wave conditions (Van Gent and Giarrusso, 2005). The model also predicts low-frequency energy which is important for determining runup. Low frequency energy can be estimated by

$$
\frac{E_{\text {lowfrequencyengery }}}{E_{\text {totalenergy }}}=0.0025\left(\frac{H_{m o}}{h_{1 / 10^{L}}}\right)\left(\frac{H_{m o}}{h_{1 / 3} L_{o}}\right)^{0.5}
$$

where $h_{1 / 10 L o}$ and $h_{1 / 3}$ Lo are the water depths at a distance of $1 / 10$ and $1 / 3$ of the deep 
water wavelength from the toe of the structure (Van Gent and Giarrusso, 2005).

\subsubsection{XBeach}

After Hurricane Ivan (2004) devastated the Florida panhandle, research was conducted to understand the hydrodynamic forces that caused the damage. Santa Rosa Island, Florida was an area that was greatly affected by the hurricane because the region is a low lying barrier island. McCall et al. (2010) used a numerical model to analyze the impacts of Hurricane Ivan on Santa Rosa Island. Extreme Beach Behavior Model (XBeach) is a time-dependent 2DH model that solves equations for cross-shore and longshore hydrodynamic conditions on the order of wave groups (Roelvink et al., 2007; McCall et al., 2010). XBeach solves for wave propagation, shallow water equations, sediment transport, and continuity equations that can be used for morphological changes.

The four regimes of storm impacts that were developed by Sallenger (2000) were modeled successfully using XBeach including swash, collision, overwash, and inundation (Roelvink et al., 2007; McCall et al., 2010). The grid varied in the longshore and was $1 \mathrm{~km}$ in length. Lidar data were used to create the grid for the model and to ensure that the XBeach results were consistent with the lidar data after the storm. Wave and surge conditions from Hurricane Ivan were used for the hydrodynamic forcing of the model. Overwash caused by runup as well as inundation were predicted by the model and the results appeared consistent with the observed conditions of the island after the storm which were obtained from lidar data (McCall et al., 2010).

\subsection{Summary of Literature Review}

The background studied in this literature review emphasized the vulnerability of 
beaches and barrier islands to runup from extreme storm events and the importance that is placed on understanding bathymetric features and how they influence hydrodynamic conditions in the surf zone. Offshore sandbars are bathymetric features that are highly dynamic. The hydrodynamic conditions that occur in the surf zone are complex and models have been developed that can reasonably predict the forcing in the nearshore environment. The journey from radiation stress to wave runup is important because it conveys the process required to obtain the present knowledge of runup which is complex due to the hydrodynamic conditions in the surf zone. Field experiments were fundamental in developing the present wave runup relationships and are still dependent on specific characteristics at the coast, such as slope of the bathymetry.

Much of the previous research using numerical models has focused on the morphodyanmics that occur due to extreme storm events (Roelvink et al., 2007; McCall et al., 2010). Wave runup is a driving force to morphodynamic changes on the beach or barrier island during a storm. At present, the influence that nearshore bathymetric features have on wave runup is not fully understood. Using a Boussinesq model to determine the effects of offshore features, such as sandbars, has been studied with results that show that the level of the bar does not significantly influence runup (Van Gent and Giarrusso, 2005). In the research of Van Gent and Giarrusso (2005), the level of the offshore features changed vertically, but the horizontal distance from the structure was not adjusted.

The literature studied addresses the myriad research topics that are important to understanding the hydrodynamic processes that occur during extreme storm events that 
cause wave runup on beaches and barrier islands. However, this thesis focuses on the variability of long-wave runup as it is influenced by nearshore bathymetric features during storm events. 


\section{SITE LOCATION AND GRID GENERATION}

\subsection{Introduction}

This thesis provides results that show the influence of nearshore bathymetric features on long-wave runup. In order to show the effects bathymetry has on long-wave runup at the land/sea interface, an area must be selected that exhibits bathymetric features, such as a nearshore bar or a nearshore bar with a rip. Bathymetric features will be identified and categorized using lidar data. Lidar data was provided by the Joint Airborne Lidar Bathymetry Technical Center of Expertise (JALBTCX) for the Florida panhandle region for several years, which was used to select the location with the desired bathymetric features. Once the area with lidar data was chosen, the grids were created. The generation of grids with the chosen bathymetric features were created so that the subaerial topography in all scenarios was specified as a plane beach, thus allowing longwave runup response to bathymetric variability to be quantified. The grids were used with several hydrodynamic scenarios in order to determine the influence of bathymetric features on long-wave runup. Section 3.2 describes the selection of the site and Section 3.3 explains about the grid generation.

\subsection{Selection of Site Location}

The warm waters of the Gulf of Mexico and relatively shallow depths make the coastal communities along the Gulf of Mexico extremely vulnerable to impacts from hurricanes. While hurricanes can make landfall anywhere, the past few years have resulted in a large number of hurricanes impacting Florida. The 2004 and 2005 
hurricane season was very active for this area with several named storms including Frances 2004, Ivan 2004, Dennis 2005, and Katrina 2005. These storms caused considerable damage to private and public property. After Ivan 2004, Dennis 2005, and Katrina 2005, lidar data were collected for the Florida panhandle to show the changes in bathymetry and topography after the hurricanes. The set of lidar data was from the coastal area of Escambia County Florida to Bay County Florida (Figure 7).

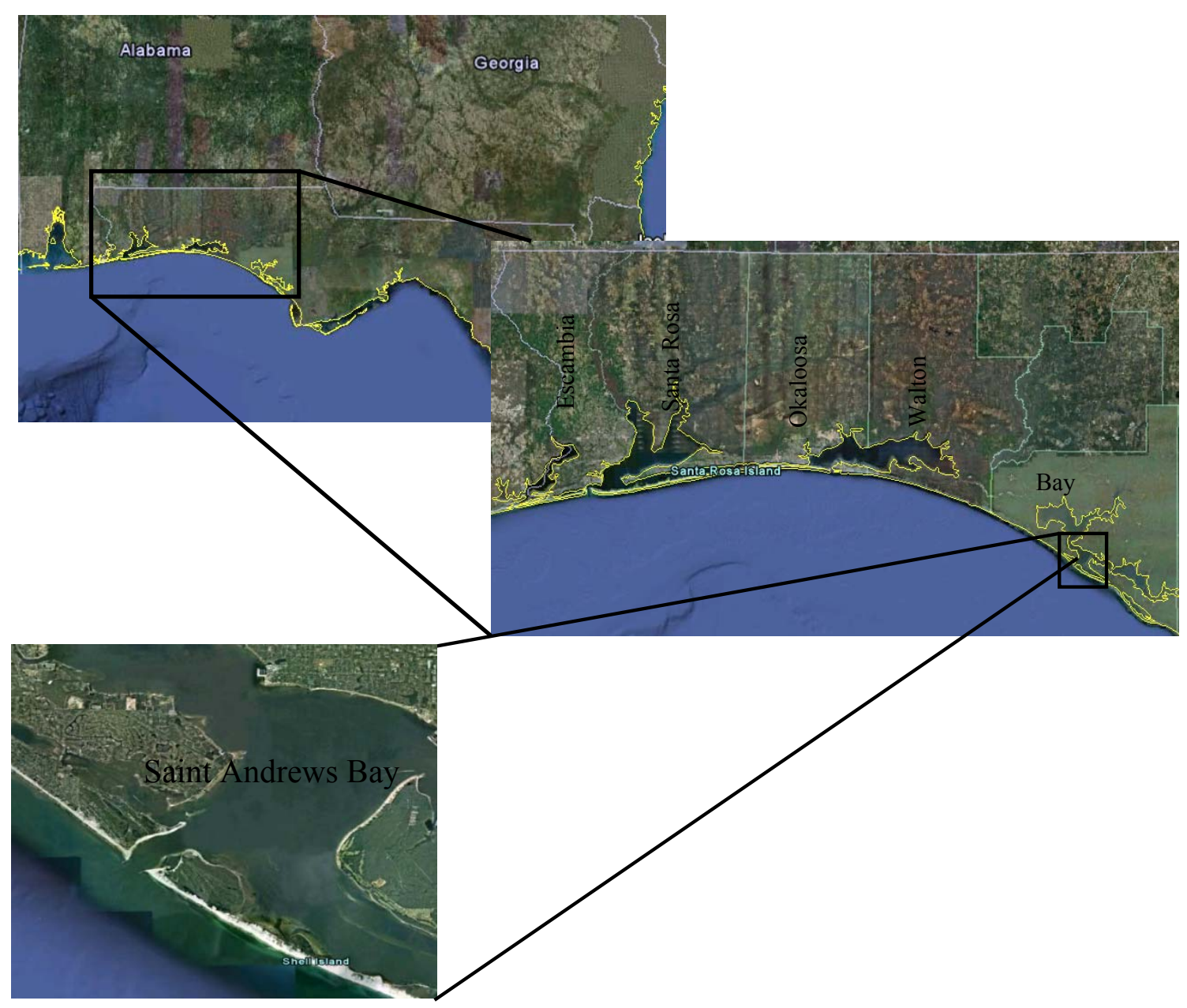

Figure 7. Florida panhandle from Escambia County to Bay County (Google Earth, 2010) 
The lidar data projection is Geographic Coordinate System North America 1983. Mapping, before and after the storms, provides valuable information as to the impacts of the hurricane. As such, lidar data was provided for several different times which show the changes in bathymetry and topography. Some lidar data sets were insufficient for showing reasonably good results of bathymetry due to the clarity of the water. Lidar data was viewed using a Geographic Information System (GIS) through ArcGIS developed by Environmental Systems Research Institute (ESRI, 2009). There are several criteria for determining the site to be selected. The area to be chosen for the study must have:

1) sufficiently good lidar data that shows bathymetry and topography,

2) bathymetry that exhibits the desired features, such as an offshore bar

3) topography must be at an elevation that overtopping will not occur for the hydrodynamic conditions that will be discussed in a later section After viewing all of the lidar data sets, the area with the most complete bathymetric and topographic lidar was in Bay County, Florida. This area, on the Florida panhandle, is characterized by a complex offshore bar and beach cusp system, which exhibits periodic bar-rips, continuous bar, and multiple bars in some locations. Also, the topography for most of the area is higher than in other areas along the Florida panhandle which will minimize the likelihood of overtopping.

The coastal region of Bay County is a beach system that is backed by bays and lagoons (Figure 8). The coastal community of Bay County, Florida is vulnerable to extreme storm events where the population and infrastructure are at risk to damage. 
Because of the warm climate and white sand beaches, the area is a popular destination for tourism. Tourism to Florida is a very important part of the economy where the revenue generated is around $\$ 57$ billion (State of Florida, 2010), with the majority of

tourism being associated with the coastal areas. Bay County has a population of 148,000 where the majority of the people live near the coast (U.S. Census Bureau, 2000). The majority of the County's coastal region is well developed, but some areas such as near the inlet are not as developed. There is a state park located westward of the inlet into Saint Andrews Bay. Finding areas that are not developed was important for the generation of the grid since having buildings or other coastal structures in the grid is not wanted.

\subsection{Grid Generation}

Lidar data from the Bay County area was analyzed in ArcGIS. In order to make the grid, profiles needed to be created from the lidar data. This was accomplished by using the eCoastal tools. The eCoastal tools were developed by the U.S. Army Corps of Engineers to be used within GIS and are freely available for download. The eCoastal tools are a compilation of tools that aid in the analysis of lidar data and that are useful for coastal engineering work such as determining the amount of shoreline change, generating profiles, determining erosion and accretion, and determining characteristics of offshore features. 


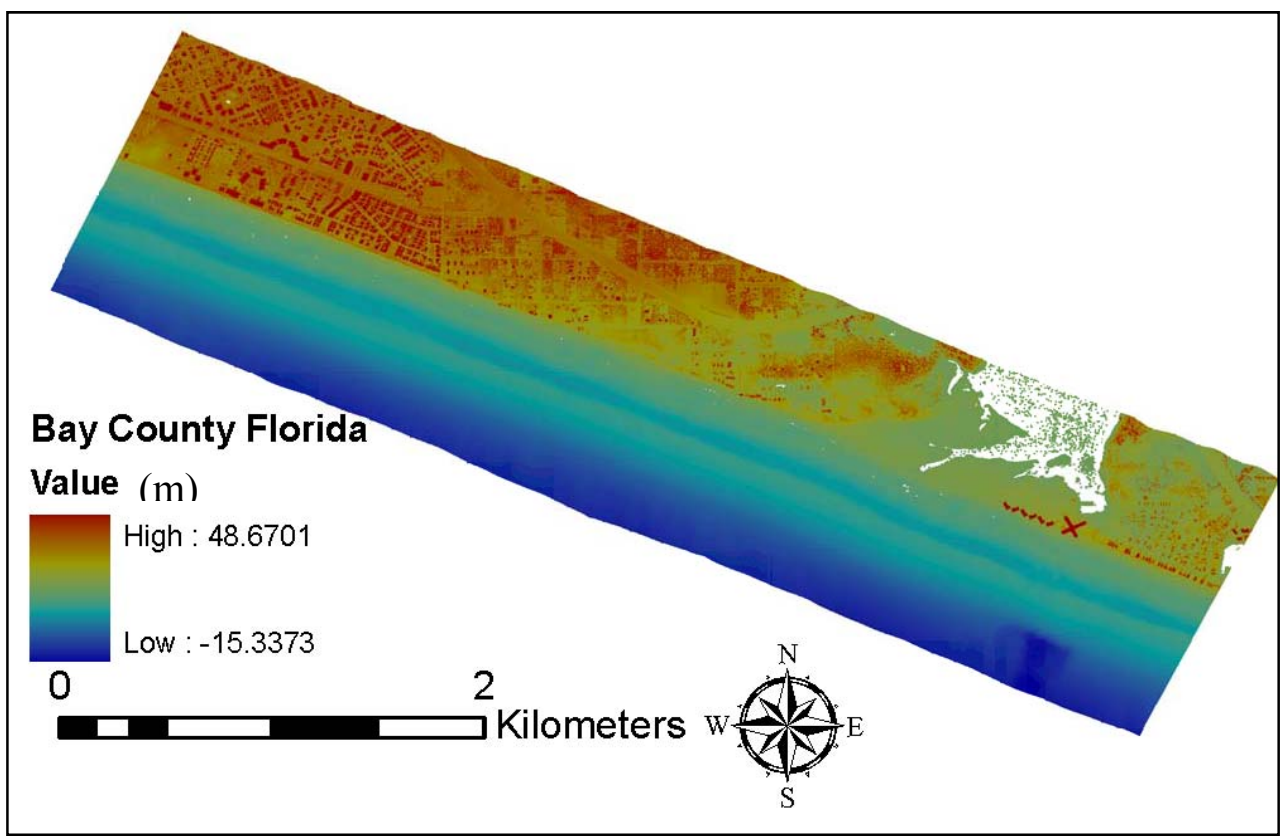

Figure 8. Lidar data from central coastal region of Bay County Florida

The eCoastal auto profiling tool which allows the user to specify the spacing between each profile and the length was used to determine profiles. Transects are drawn parallel to the shoreline for the length of lidar data set for the southern most portion of Bay County Florida. Figure 9 shows the profiles generated using eCoastal auto profiler tool. The spacing between the profiles was set to be every 30.5 meters (100 feet) and the length was approximately 1,000 meters. 


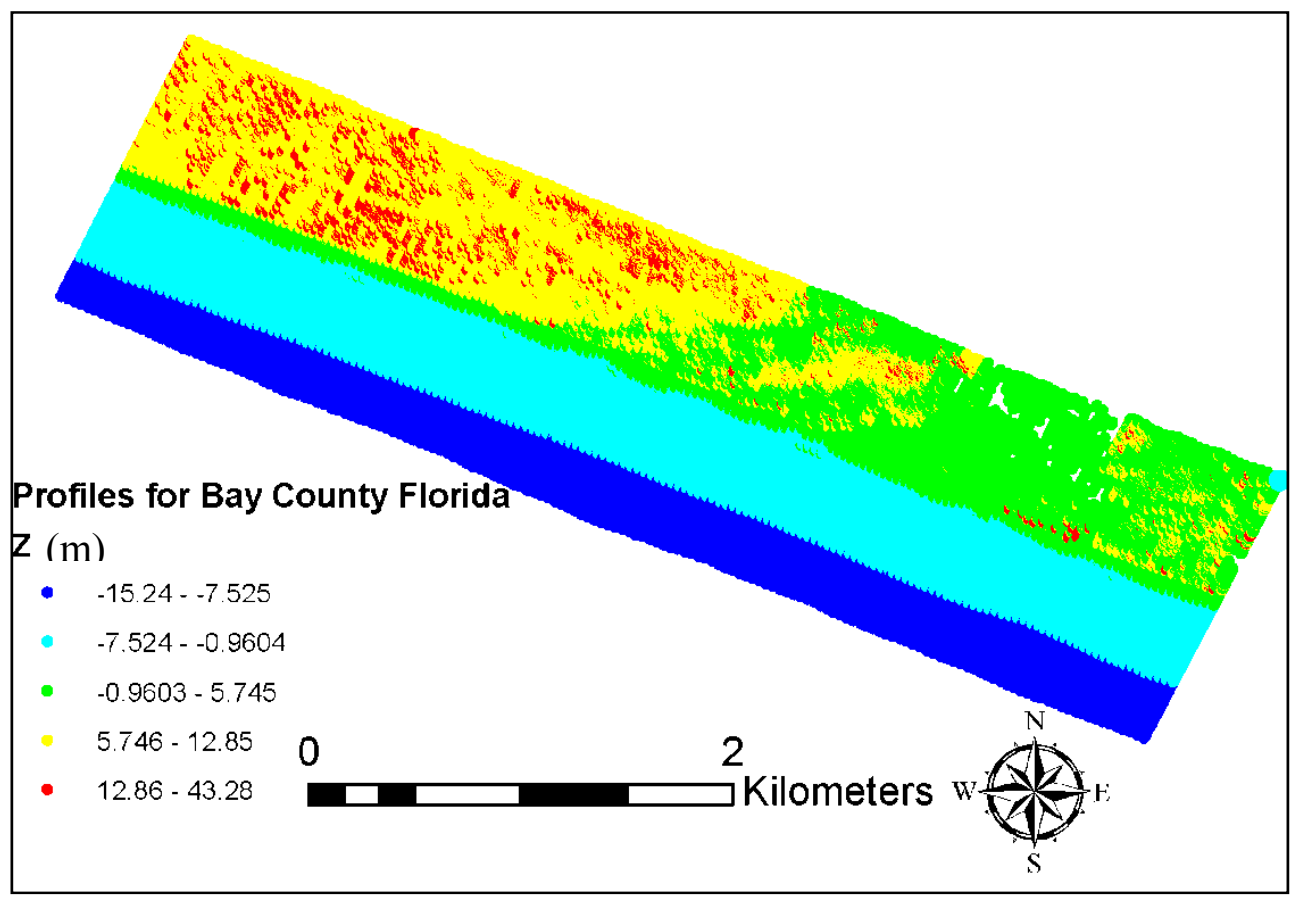

Figure 9. Profiles generated using eCoastal for Bay County Florida

After analyzing the profiles created, a profile was chosen that was void of any buildings and that had a topography that was sufficiently high to prevent overtopping. The profile to be used for the generation of the initial grid has an offshore bar feature and is located in Bay County Florida in St. Andrews State Park near the inlet to Saint Andrew Bay.

The profile has some irregular features at the shoreline, but were not pronounced enough to be considered as offshore bars. Therefore, the profile was smoothed to remove the irregularities near the shore to develop an idealized profile free of very small bathymetric irregularities. The profile was smoothed using the USGS (U.S. Geological 
Survey) smoothing code (Plant and Holman, 1997). Cubic spline interpolation was used for the smoothing using weights and specifying the conditions at the boundaries. Also, the profile had some data gaps offshore where the lidar data was not obtained at a fine resolution. In addition to smoothing to remove the irregularities at the shoreline, the gaps in the profile offshore were filled in. The weight of the spline curvature penalty determines the amount of smoothing that will occur. The boundary condition is set so that the first derivative disappears at the boundary. Figure 10 shows the original profile and the smoothed profile.

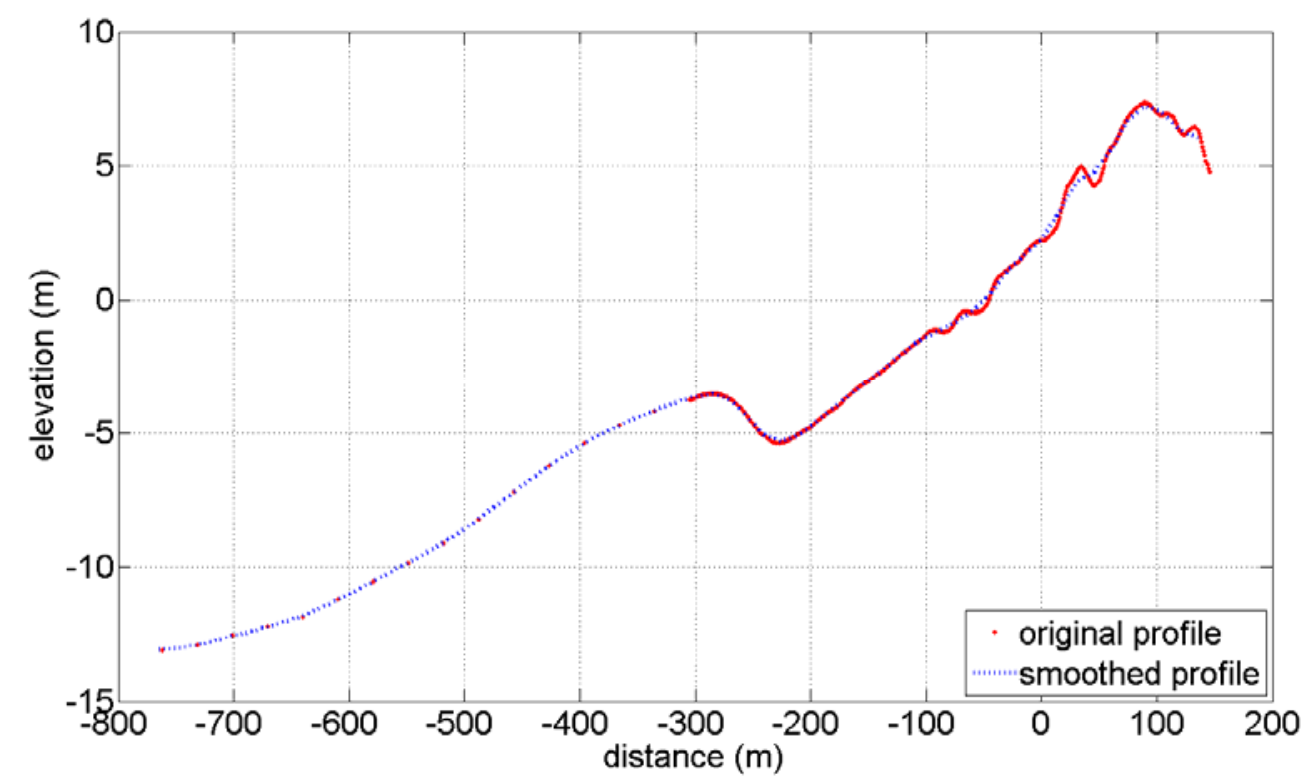

Figure 10. Initial profile (blue) and profile after smoothing (red)

After the profile was smoothed to remove the irregularities at the shoreline, the single profile was used to create the first of three bathymetries. The bathymetries created from this single profile consist of: 
1) continuous offshore bar (continuous bar)

2) smooth profile with no offshore bar (no bar)

3) offshore bar with a rip in the center (bar-rip)

The continuous bar bathymetry was created from the smoothed profile where the grid spacing in the cross shore direction varies from $5 \mathrm{~m}$ offshore of the bar crest to $1 \mathrm{~m}$ shoreward of the offshore bar crest and on the beach. This setup in the cross-shore direction will be important for the numerical model simulations by increasing efficiency by using fine resolution where data analysis will occur. Figure 11 shows the continuous bar bathymetry. The bathymetry in the longshore direction is spaced every 2 meters. The total longshore distance is 750 meters.
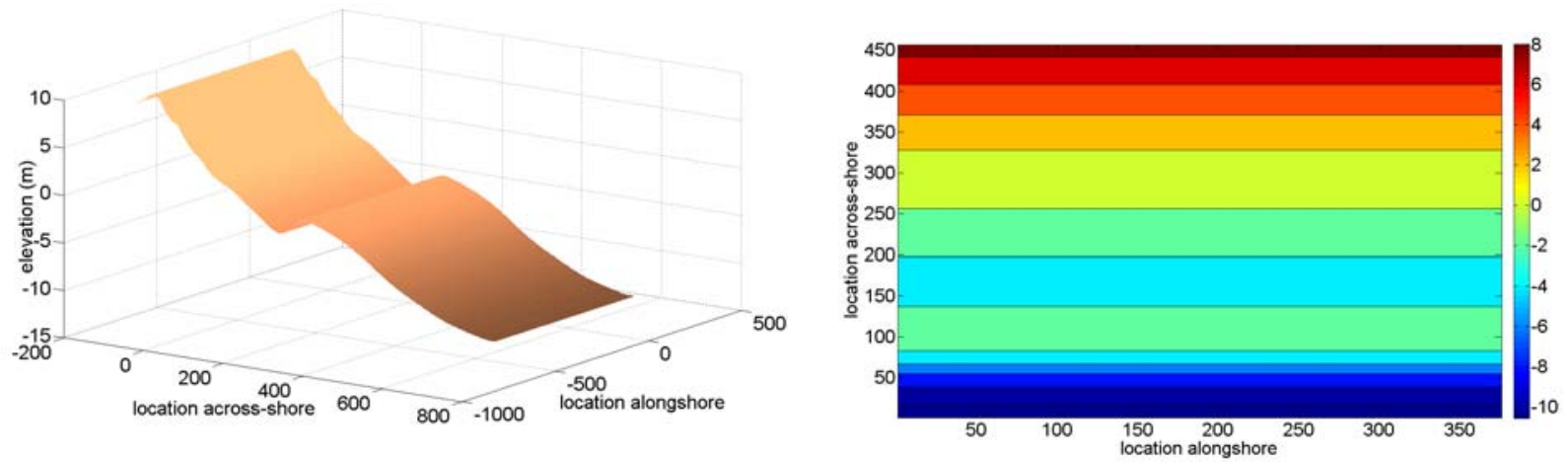

Figure 11. 3D offshore bar bathymetry (left) and 2D contour of offshore bar bathymetry (right)

The no bar bathymetry was created by removing the offshore bar and replacing it with an equilibrium profile beginning at an elevation of $-2.5 \mathrm{~m}$ offshore. The Dean 
equilibrium profile Equation 2.1 is used to create the nearshore portion of the bathymetry (Figure 12).

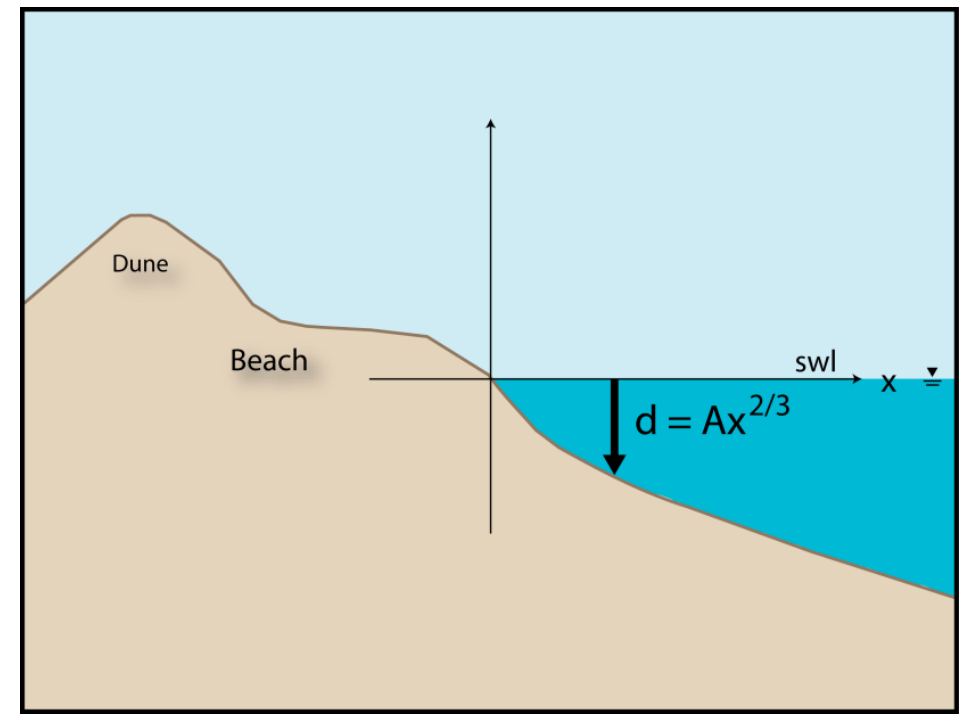

Figure 12. Dean equilibrium beach profile (From HEC-25, 2008)

Sediment characteristics were found for the Pensacola Florida area and used to determine the equilibrium beach profile (see Equation 2.1). The equilibrium profile was merged with the shoreward portion of the bar grid. At a depth of -2.5 meters offshore, the equilibrium profile and the profile from the offshore bar were merged. Merging the profiles at this depth is done to ensure that the profiles are consistent at the shoreline. This ensures that any variability in the long-wave runup data is due to bathymetric features and not onshore variability. Figure 13 shows the no bar bathymetry. 

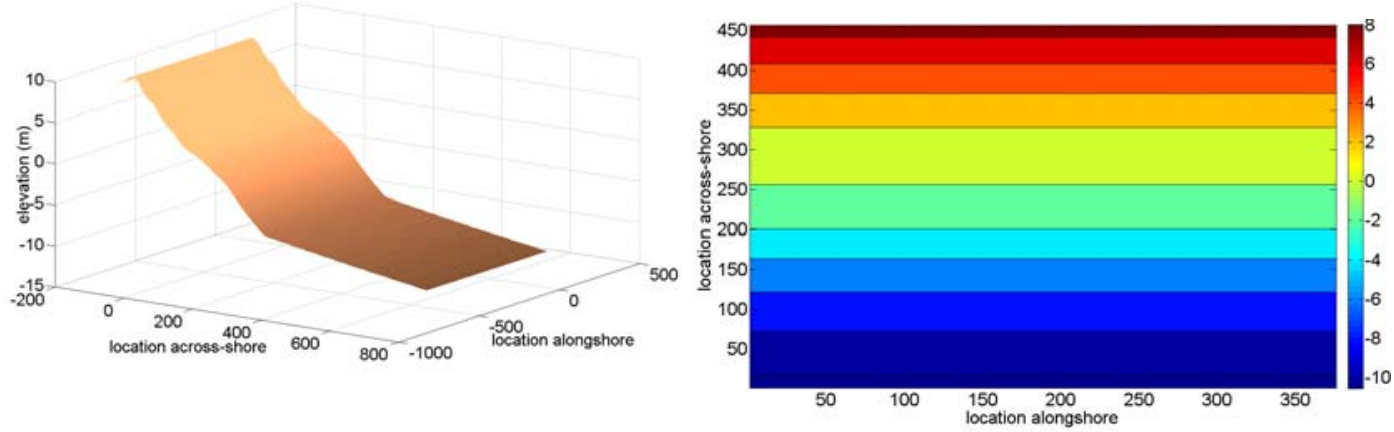

Figure 13. 3D no bar bathymetry (left) and 2D contour of no bar bathymetry (right)

The bar-rip bathymetry is a combination of the no bar and the bar bathymetry where the rip in the center of the bar-rip is caused by the no bar bathymetry. On both sides of the bar-rip portion of the bathymetry, the continuous offshore bar bathymetry is used to complete the bar-rip bathymetry. Figure 14 shows the bar-rip bathymetry.
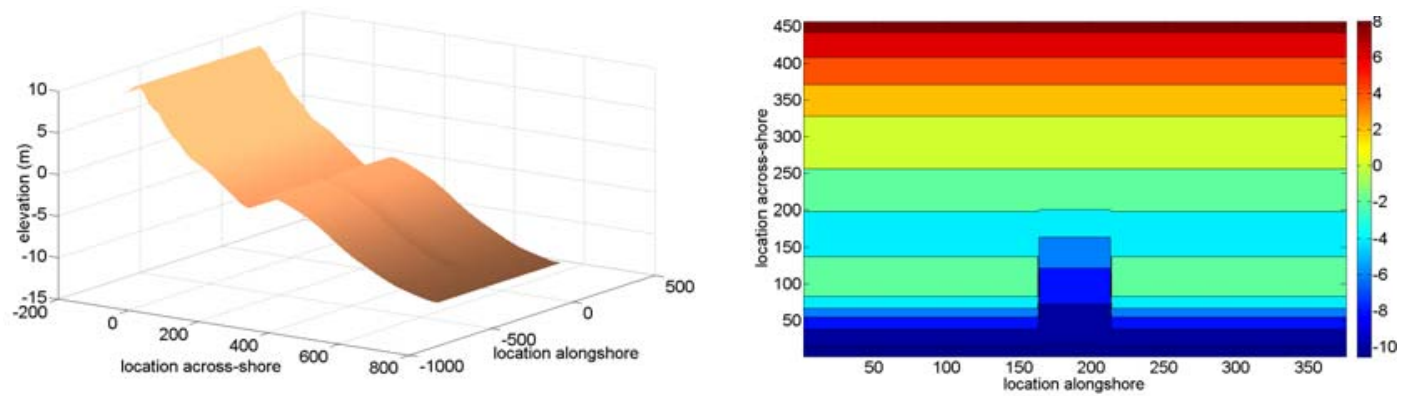

Figure 14. 3D bar-rip bathymetry (left) and 2D contour of bar-rip bathymetry (right)

The rip in the center of the bar is 100 meters wide. The width of the rip in the center of the bar was based on observations of bar-rip features from the Florida panhandle lidar 
data. In nature, having a rip in the center of a continuous bar causes interesting features, such as rip currents.

\subsection{Bar Height}

Having an offshore bar may be an important factor in influencing runup during extreme storm events, but the depth over the bar will determine if waves break before the bar, on the crest of the bar, or after the bar. The initial lidar data show that the elevation of the bar crest for Bay County, Florida is approximately 3.5 meters below the still water level. The level of the bar was adjusted so that the depth of the bar was 1.0 meter below the still water level. The level of the bar was adjusted because for the original profile the nearshore feature was at level where there would be less of an influence from the waves. Also, after analyzing lidar data from other locations on the Florida panhandle, the crest of the nearshore bar feature varies from $3.5 \mathrm{~m}$ to $0.5 \mathrm{~m}$ below the still water level. Adjusting the level of the bar was accomplished after the profile was smoothed where the profile was raised $2.5 \mathrm{~m}$. Figure 15 shows the original profile and the adjusted profile with the water depth over bar at 1.0 meter. The $1.0 \mathrm{~m}$ depth over bar was chosen in order to facilitate the analysis of long-wave runup.

The water depth at the offshore boundary was adjusted to be about 10.5 meters below the still water level for the profile with the water depth over the bar is 1.0 meter. This depth occurs 630 meters from the shoreline. This distance will allow for waves of a magnitude associated with storm events to propagate toward the shore. 


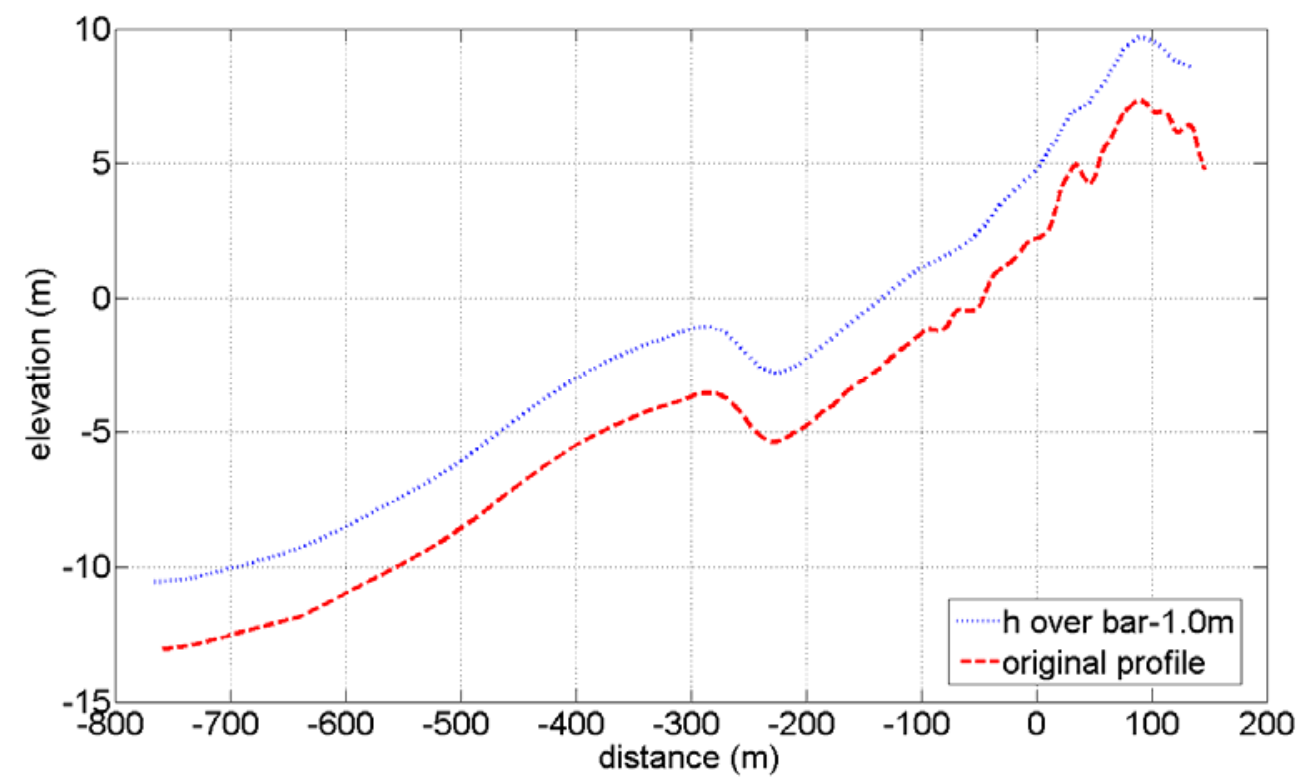

Figure 15. Variation in bar height

The location where the waves break will be dependent on the height of the wave and the level of the bar. Scenarios for waves to break seaward of the bar, on the crest of the bar, and shoreward of the bar have been chosen and will be discussed in further detail in Section 4.3. 


\section{MODEL AND METHODS}

\subsection{Introduction}

This section explains the background and setup of the numerical model used for the analysis of long-wave runup on the coast due to varying bathymetric features. XBeach is a depth averaged $(2 \mathrm{DH})$ numerical model that solves for wave propagation, shallow water equations, sediment transport, and continuity equations that can be used for morphological changes (Roelvink et al., 2007; McCall, 2010). XBeach assumes that coastal erosion at the land-sea interface is caused by bound long-waves.

As mentioned in Section 3, the three bathymetries (offshore bar, no bar, and barrip) will be used to determine the effects of long-wave runup on varying bathymetric features. Several hydrodynamic conditions will be used to force the numerical model. The numerical model XBeach is used to force the various hydrodynamic conditions for the different bathymetries to analyze long-wave runup and wave height. The water level output from XBeach is used to analyze the long-wave runup. Also, the wave heights are analyzed for cross-shore profiles along the grid.

XBeach outputs the results for the simulation and the results are analyzed using MATLAB which is an environment used for numerical computation. Statistical analysis will be completed on the results from XBeach. Specifically, the 2-percent long-wave runup will be analyzed since the two percent runup, which typically includes shortwaves, is considered to be highly correlated with erosion (Stockdon et al., 2006). Section 4.2 will give a background and application on the numerical model, XBeach. The model setup will be provided in Section 4.3. The hydrodynamic conditions will be 
discussed in Section 4.4. The process to analyze the results using MATLAB will be explained in Section 4.5.

\subsection{XBeach}

XBeach is an evolving, open-source code using Fortran 90/95 which is capable of determining nearshore wave and currents, predicting overwash, and breaching of barrier islands (Roelvink et al., 2007; McCall, 2010). XBeach is capable of modeling all of the regions that were discussed by Sallenger (2000). For this thesis, XBeach version 12 was used and the specific parameters of this version will be discussed in more detail in Section 4.5. XBeach is a depth averaged (2DH) numerical model which can handle wetting and drying (Roelvink et al., 2007; McCall, 2010). XBeach solves for wave propagation, shallow water equations, sediment transport, and continuity equations that can be used for morphological changes.

$\mathrm{XBeach}$ uses a coordinate system where the $\mathrm{x}$-direction is oriented perpendicular to the coast and the y-direction is oriented parallel to the coast (Roelvink et al., 2007). The origin of the grid can be specified and is defined relative to world coordinates (xw, yw). The grid must be rectangular, but the $\mathrm{x}$ and $\mathrm{y}$ grid spacing can vary. Figure 16 shows the coordinate system for XBeach.

The grid used for XBeach is a staggered grid where the free surface water levels and bathymetric changes are defined in the center of the cell. The velocity components and the sediment transport components are defined in the interface of the cell (Roelvink et al., 2007). 


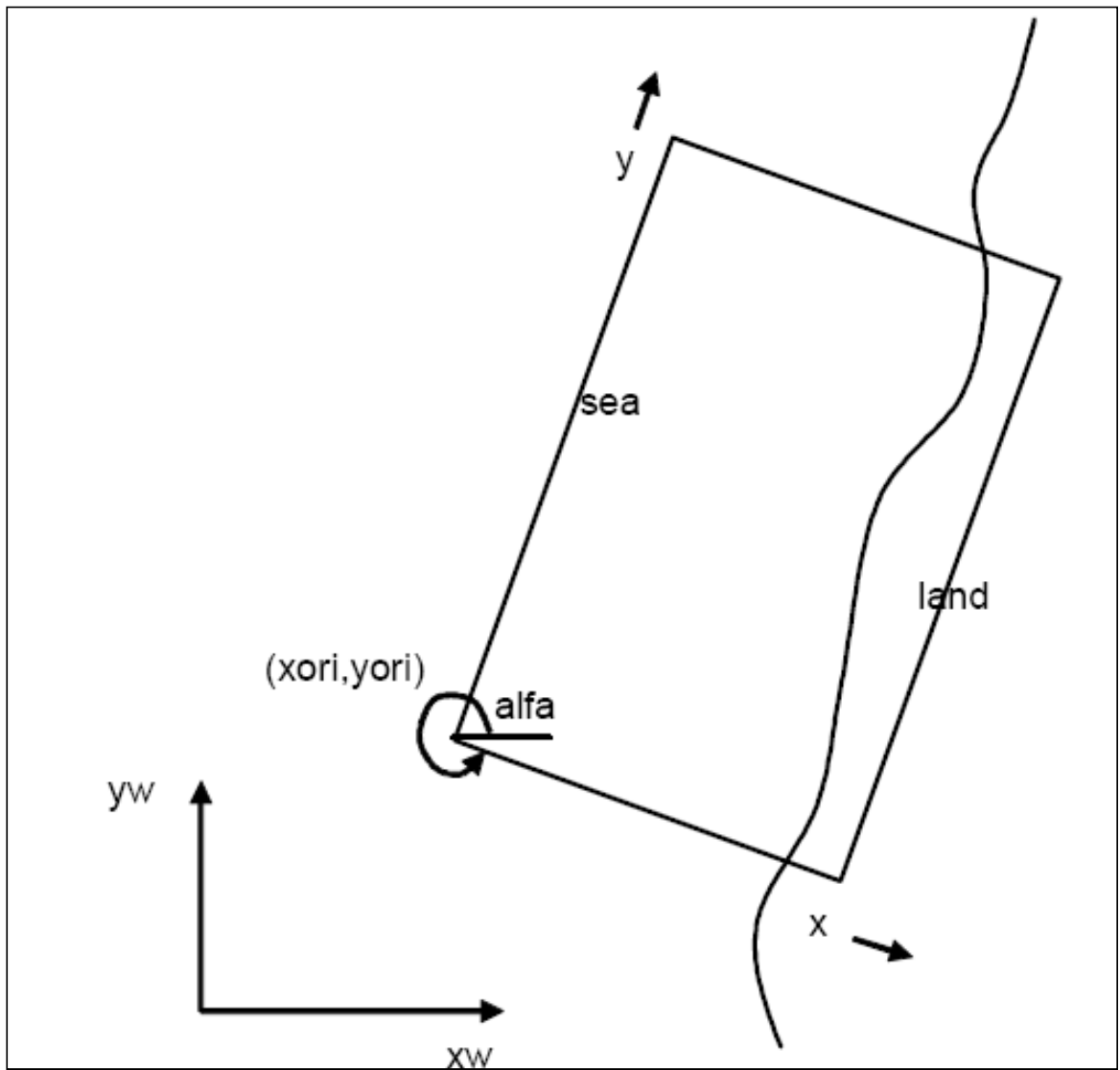

Figure 16. Coordinate system utilized for XBeach (From Roelvink et al., 2007) 
The wave energy balance, energy, surface roller energy, and radiation stresses are also defined at the cell center (Roelvink et al., 2007). However, the radiation stress gradients are defined at the cell interface. Figure 17 shows the staggered grid and the location of the cell center and interface. The velocities (uu,vv) are at the cell interface. For output, the velocities $\mathrm{u}$ and $\mathrm{v}$ are interpolated from the cell interface so that they are located in the center of the cell. Water level, zs, is located in the cell center.

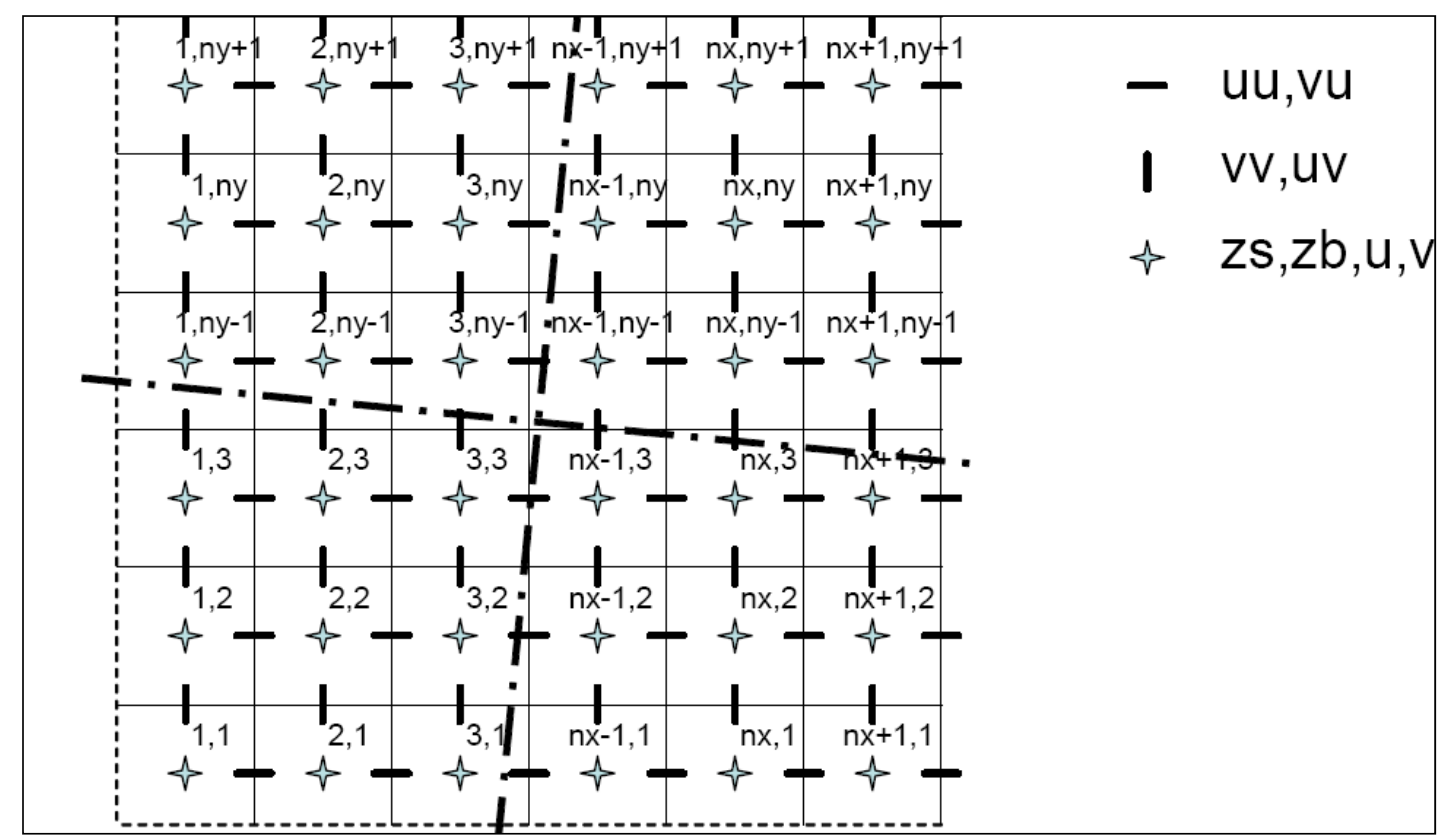

Figure 17. Staggered grid showing cell center and interface (From Roelvink et al., 2007)

There are several governing equations that are used within XBeach. The equations include short wave equations, roller energy balance, shallow water equations, sediment transport, and bottom updating. For this thesis, the relevant equations include short wave equations, roller energy balance, and shallow water equations, since morphological changes are not considered in the analysis. 
The short wave action balance is solved in XBeach for wave groups which can be described as

$$
\frac{\partial A_{w}}{\partial t}+\frac{\partial c_{g, x} A_{w}}{\partial x}+\frac{\partial c_{g, y} A_{w}}{\partial y}+\frac{\partial c_{\theta} A_{w}}{\partial \theta}=-\frac{D_{\text {waves }}}{\sigma}
$$

where $A_{w}$ is the wave action defined by

$$
A_{w}=E_{\text {wave }} / \sigma
$$

where $E_{\text {wave }}$ is the wave energy described in equation 4.3 , and $\sigma$ is the intrinsic wave frequency from linear dispersion relation (Roelvink et al., 2007). The wave group velocity components for both the $\mathrm{x}$ - and $\mathrm{y}$ - direction in equation 4.1 are $\left(c_{g, x}, c_{g, y}\right)$ and the velocity in directional space component, $c_{\theta}$, accounts for bottom refraction and current refraction (Roelvink et al., 2007). D is the dissipation of the wave due to breaking and is solved as

$$
D_{\text {waves }}=2 \alpha f_{\text {rep }} E_{\text {wave }} Q_{b}
$$

which is based on the Roelvink (1993) equation. The variable $\alpha$ is on the order of 1 and $f_{\text {rep }}$ is a representative intrinsic frequency. The energy for the wave can be described as

$$
E_{\text {wave }}=\frac{1}{8} \rho g H_{r m s}^{2}
$$

where $\mathrm{H}_{\mathrm{rms}}$ is the root mean square wave height. The portion of wave breaking is described as

$$
Q_{b}=\min \left(1-e^{-\left(\frac{H_{r m s}}{\gamma h}\right)^{n}}, 1\right)
$$


and is used for the Roelvink wave breaking component (Roelvink et al., 2007). Baldock et al. (1998) also solves for the dissipation of wave energy and the percentage of wave breaking which can be described as

$$
\bar{D}=\frac{1}{4} \alpha Q_{b} \rho g f_{r e p}\left(H_{b}^{2}+H_{r m s}^{2}\right)
$$

and

$$
Q_{b}=\exp \left[-\left(\frac{H_{b}^{2}}{H_{r m s}^{2}}\right)\right]
$$

respectively. The breaking wave height can be described as

$$
H_{b}=\frac{0.88}{k} \tanh \left[\frac{\chi k h}{0.88}\right]
$$

where $\chi$ is a calibration parameter (Roelvink et al., 2007). The dissipation of the wave is distributed evenly over the wave directions (Roelvink et al., 2007). This is important for the model setup because one of the parameters is a wave breaking index. For this thesis, the wave breaking parameter is considered to be that of Baldock (1998) as described above.

After waves break, energy is redistributed and is included in XBeach as

$$
\frac{\partial E_{\text {roller }}}{\partial t}+\frac{\partial c_{x} E_{\text {roller }}}{\partial x}+\frac{\partial c_{y} E_{\text {roller }}}{\partial y}+\frac{\partial c_{\theta} E_{\text {roller }}}{\partial \theta}=-D_{\text {roller }}+D_{\text {waves }}
$$

where the waves and rollers are propagating in the same direction and the roller energy dissipation is as described by Deigaard (1993) and the shear stress caused by the roller is as described by Svendsen (1984). The roller energy is described as 


$$
E_{\text {roller }}=\frac{1}{2} \frac{\rho A_{R} c^{2}}{L_{R}}
$$

where the area and length of the roller are $A_{R}$ and $L_{R}$, respectively (Roelvink et al., 2007).

The XBeach model uses the following shallow water equations, which neglect Coriolis and horizontal diffusion terms as follows:

$$
\begin{gathered}
\frac{\partial u}{\partial t}+u \frac{\partial u}{\partial x}+v \frac{\partial u}{\partial y}=-\frac{\tau_{b x}}{\rho h}-g \frac{\partial \eta}{\partial x}+\frac{F_{x}}{\rho h} \\
\frac{\partial v}{\partial t}+u \frac{\partial v}{\partial x}+v \frac{\partial v}{\partial y}=-\frac{\tau_{b y}}{\rho h}-g \frac{\partial \eta}{\partial y}+\frac{F_{y}}{\rho h} \\
\frac{\partial \eta}{\partial t}+\frac{\partial h u}{\partial x}+\frac{\partial h v}{\partial y}=0
\end{gathered}
$$

which is the $h$ is the water depth, $u$ and $v$ are velocity in the $\mathrm{x}$ - and $\mathrm{y}$ - direction, respectively, $g$ is the acceleration due to gravity, $\tau_{b x}$ and $\tau_{b y}$ are the bed shear stresses, $\eta$ is the water level, and $F_{x}$ and $F_{y}$ are the wave-induced stresses (Roelvink et al., 2007). The water level gradients are found at the cell interfaces. Since this thesis does not consider any morphological changes, sediment transport and bottom updating can be ignored.

The boundary conditions within XBeach are such that at the offshore boundary waves and surges are generated. Wave forcing is only applied at the offshore boundary and allows for waves to be generated at an angle (Roelvink et al., 2007). Boundary conditions can be applied at all four corners including the bay side. For this thesis, the 
grids are created with an elevation that is sufficiently high to prevent water overtopping the dune line. As such, the bay side boundary conditions are not required. The lateral boundary conditions are Neumann boundary conditions and at the offshore the boundary conditions are only slightly reflective (Roelvink et al., 2007).

Offshore wave boundary conditions can be specified as stationary, periodically varying wave energy, first- or second- order longcrested irregular waves, JONSWAP, SWAN 2D, formatted spectrum, and there is an option to reuse the boundary conditions (Roelvink et al., 2007). The beginning and end of the boundary conditions is tapered to ensure that a smooth transition is obtained between boundary condition files (Roelvink et al., 2007). For the purposes of this thesis, the offshore wave boundary condition is generated by the JONSWAP (Joint North Sea Wave Project) spectrum (Hasselmann and Olbers, 1973). The significant wave height, spectral peakedness, main angle of wave, and directional spreading are fundamental parameters for the spectrum. Within XBeach, a time series of wave energy is created by assuming that the spectrum is comprised of individual wave components and together these wave components, such as specific frequency, phase, amplitude, and direction, form a times series of the sea state at the offshore boundary (Roelvink et al., 2007). The frequency of all the wave components are distributed around the spectral peak and the direction of the wave components are determined using a Cumulative Distribution Function (CDF). An example of the CDF for determining the direction of the wave components can be seen in Figure 18. The JONSWAP spectrum can be time-varying which would be more representative of wave conditions that result from a storm event. The duration of each wave condition must be 
included. However, for this thesis, the wave conditions will be constant for the duration of the XBeach run to ensure that the variability in runup can be quantified more readily by reducing the changing parameters.

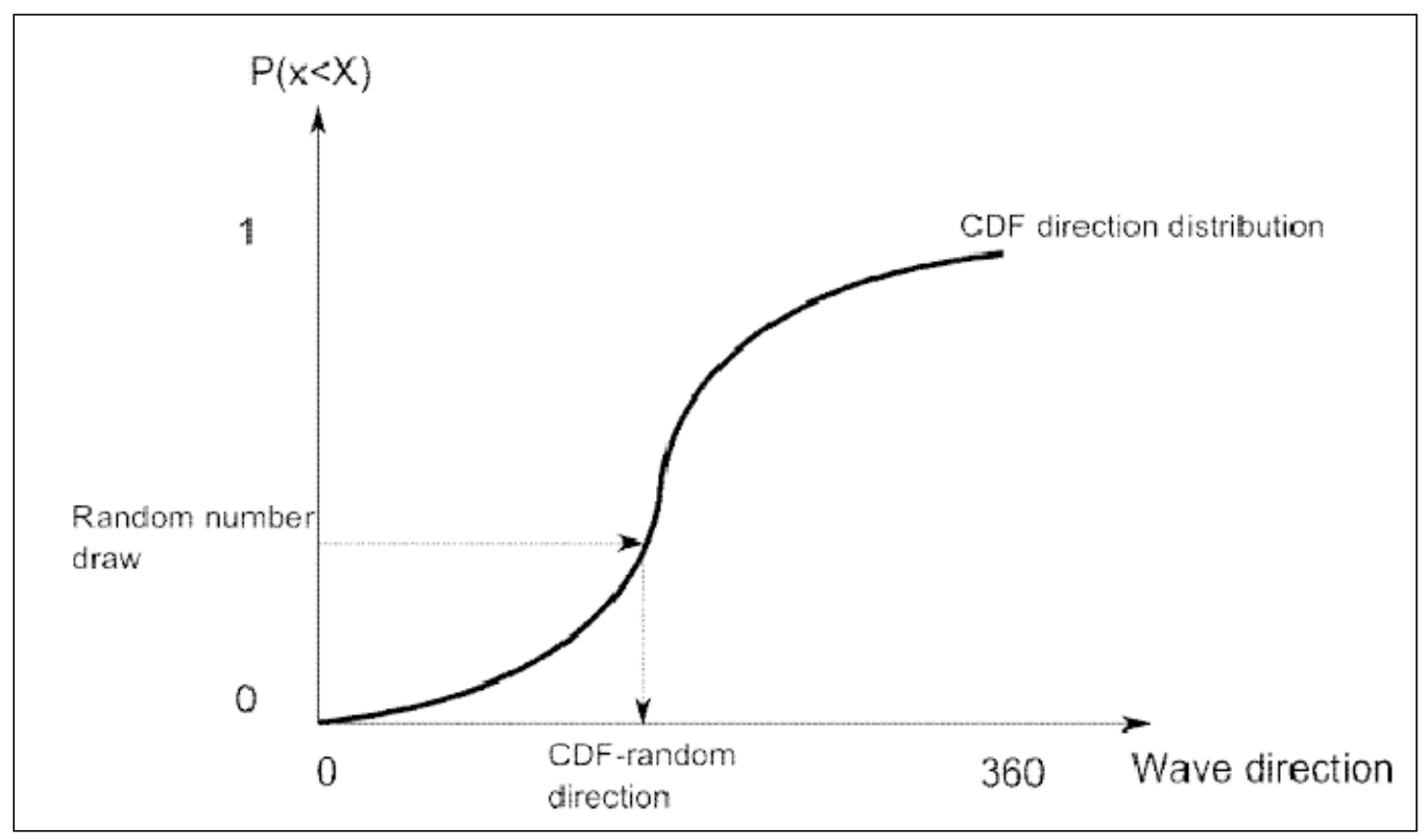

Figure 18. CDF for determining wave component direction for spectrum (From Roelvink et al., 2007)

XBeach also allows for the variation of tide and surge which is indicative of storm events, such as hurricanes. The tide can vary at the two offshore boundaries as well as the back bay boundaries (Roelvink et al., 2007). However, for this thesis, tidal influence is not considered because along the Florida panhandle the tidal range is very small. The addition of surge makes the simulation more in adherence with 
hydrodynamic conditions that would occur during a storm. Wind can be used to increase the surge affects, but for this thesis wind is not included in the XBeach simulations.

Another function within XBeach is the parameter to control the model time step. The time step allows for output to be procured for specified intervals (Roelvink et al., 2007). The XBeach simulation starts at time zero and the duration of the run is specified in seconds. The model time step can be specified as time-averaging, point, or global which provides output on the whole domain (Roelvink et al., 2007). For this thesis, data must be obtained to analyze the effects of long-wave runup due to bathymetric features. As such, acquiring data for the entire domain is advisable.

XBeach has parameters that limit unrealistic behavior especially in shallow water. The ratio between the root mean square wave height and water depth can be adjusted as well as the limit for flooding and drying (Roelvink et al., 2007). Adjusting these parameters will ensure that the results are more reasonable. At the shoreline, the hydrodynamic conditions that cause wetting and drying are the components that result in runup. Obtaining realistic values for the wet/dry area is fundamental to the research of this thesis.

$\mathrm{XBeach}$ is a robust numerical model that provides a means of analyzing morphological changes as a direct correlation to the hydrodynamic conditions that are used to force the model. XBeach accounts for erosion due to runup and overtopping of waves to causes breaches in the barrier island. Morphological changes to bathymetry and topography due to runup are beyond the immediate scope of the research; however, future research may include the effects of morphological change caused by runup. The 
research for this thesis focuses on runup at the shoreline and how bathymetric features influence the level of runup. XBeach assumes that coastal erosion at the land-sea interface is dominated by bound long-waves. As such, the long-wave runup will be analyzed at the land/sea interface. The long-waves are the mean motion. Short-waves are on top of the long-wave and cause an extra "push" of water at the shoreline. As such, the long-wave runup that is analyzed for this thesis is likely lower than would be experienced at an actual shoreline. Several hydrodynamic conditions with different wave and initial surge values will be used to force the model with the idealized grids which will be discussed in further detail in Section 4.3.

\subsection{Model Setup}

As mentioned previously, XBeach requires numerous inputs which are used to force the model. This section will address the input parameters that are fundamental to the acquired output that is used for the analysis. As the generation of the grid has already been discussed in detail in Section 3.3 only the key aspects will be mentioned henceforth. The input parameters will be addressed and justification for using the values will be discussed. The research for this thesis involves the three separate bathymetries and topographies generated from lidar data of Bay County, Florida and consists of no offshore bar, continuous offshore bar, and bar-rip. As required, the grids generated from the bathymetry and topography are rectangular. The grids are centered at $(0,0)$ world coordinates despite the fact that the orientation of the Florida location, which was used to create the grids, is not at $(0,0)$, making this assumption will not detract from the validity of the results. The grid is 750 meters in the y-direction (Figure 10) which is 
sufficiently wide to allow output to be obtained without the interference of boundary errors. This setup in the cross-shore direction will be important for the numerical model simulations by increasing efficiency by using fine resolution where data analysis will occur. The bathymetry in the longshore direction is spaced every 2 meters. The depth file, $x$-file, and $y$-file are used within XBeach to create the grid for the model simulation.

\subsection{Hydrodynamic Conditions}

XBeach requires boundary conditions for surge and wave conditions. The Florida panhandle is often razed with destruction from hurricanes due to waves and surge. Hurricane Ivan was the most intense storm to impact the Florida panhandle during the 2004 hurricane season. It was estimated that approximately $\$ 15.0$ billion in damages to private property and infrastructure was sustained (National Hurricane Center, 2008). As stated previously, coastal communities are heavily populated and infrastructure such as roads and bridges are vital to the economic prosperity and safety of the region. Therefore, understanding the dynamic environment and especially runup at the coast is very important, particularly after a storm event, such as Hurricane Ivan.

Hurricane Ivan made landfall on September 16 in Baldwin County, Alabama. Figure 19 shows the track of Hurricane Ivan along with the location of Panama City Beach, Florida which is located in Bay County where the profile for the grid generation was obtained. As such, surge and wave values were obtained from three buoys along the Florida panhandle. Tidal fluctuations were removed from the surge data by subtracting out the predicted tides for the duration of the hurricane. The surge and wave heights from the buoys were normalized to allow comparisons to be more easily observed (see 
Figures 20 and 21). The buoys for the surge data are located in Pensacola, FL, Dauphin Island, AL, and Panama City Beach, FL. At the Pensacola, FL buoy, the gauge failed during the hurricane, yet it appears that the gauge captured the peak surge. The buoys for the wave height data are located in Pensacola, FL, Panama City Beach, FL, and Tampa, FL. The wave height buoys are located offshore.

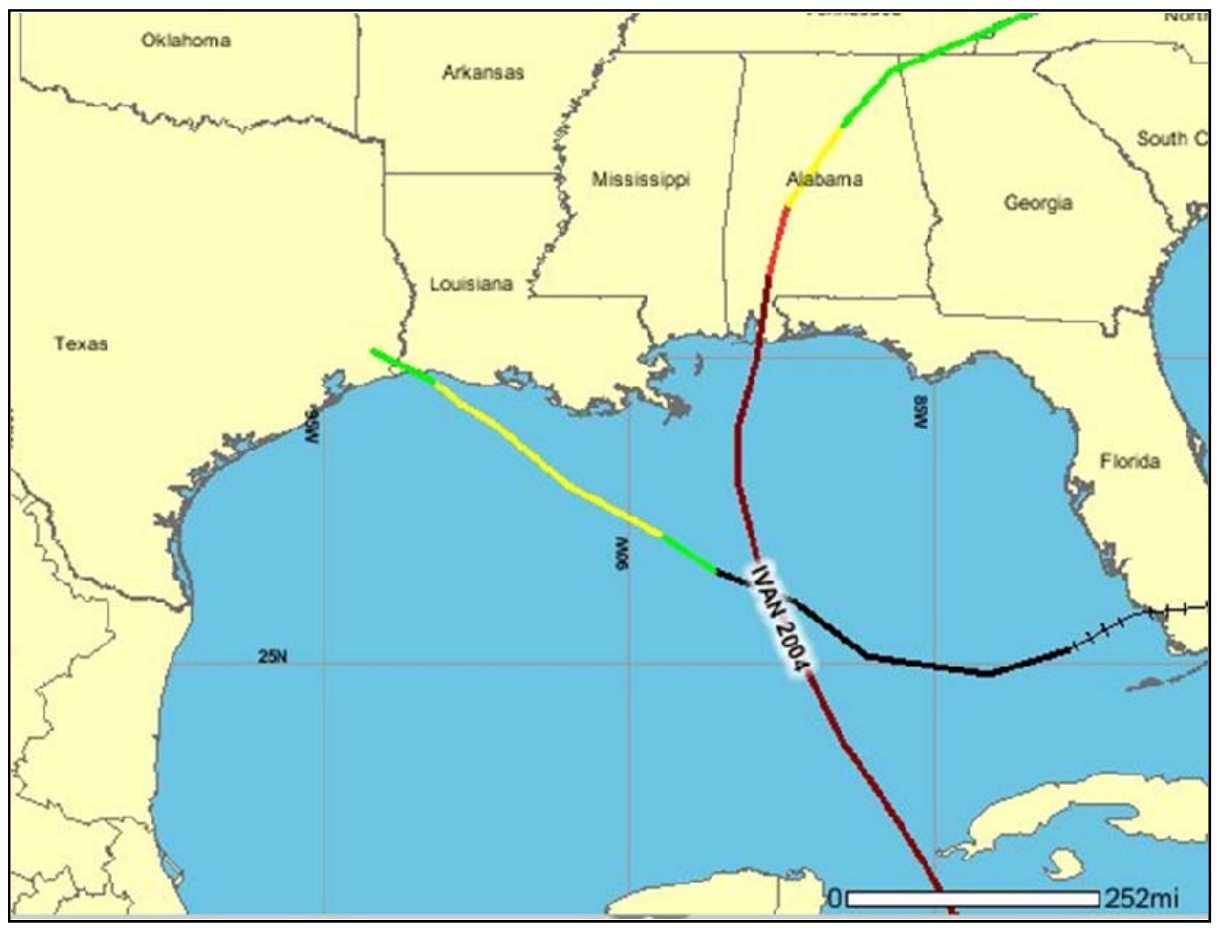

Figure 19. Hurricane Ivan (2004) track (From noaa.gov/hurricanes/viewer, 2010) 


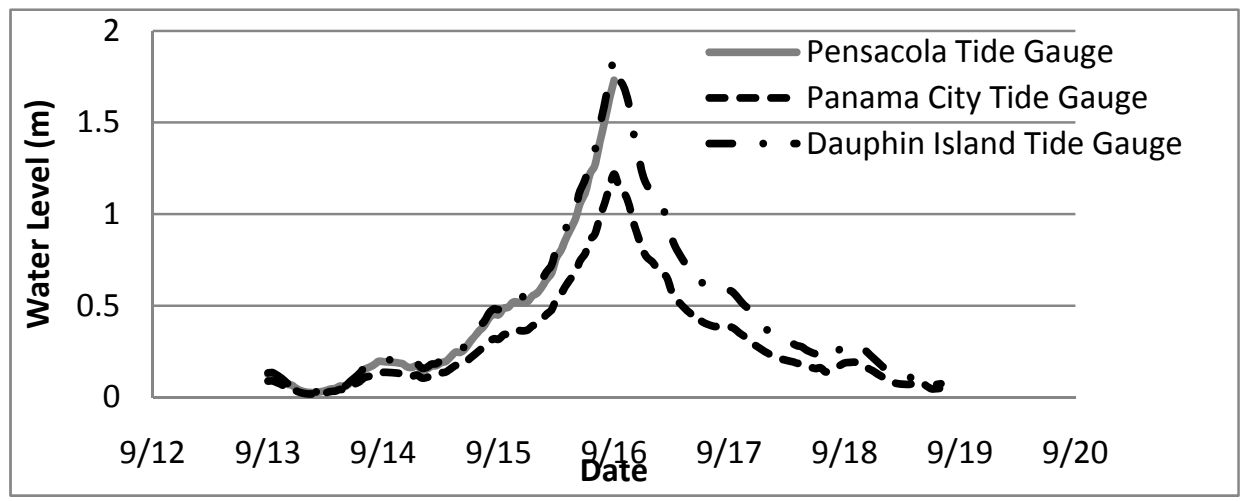

Figure 20. Surge data during Hurricane Ivan (2004) after tide removed

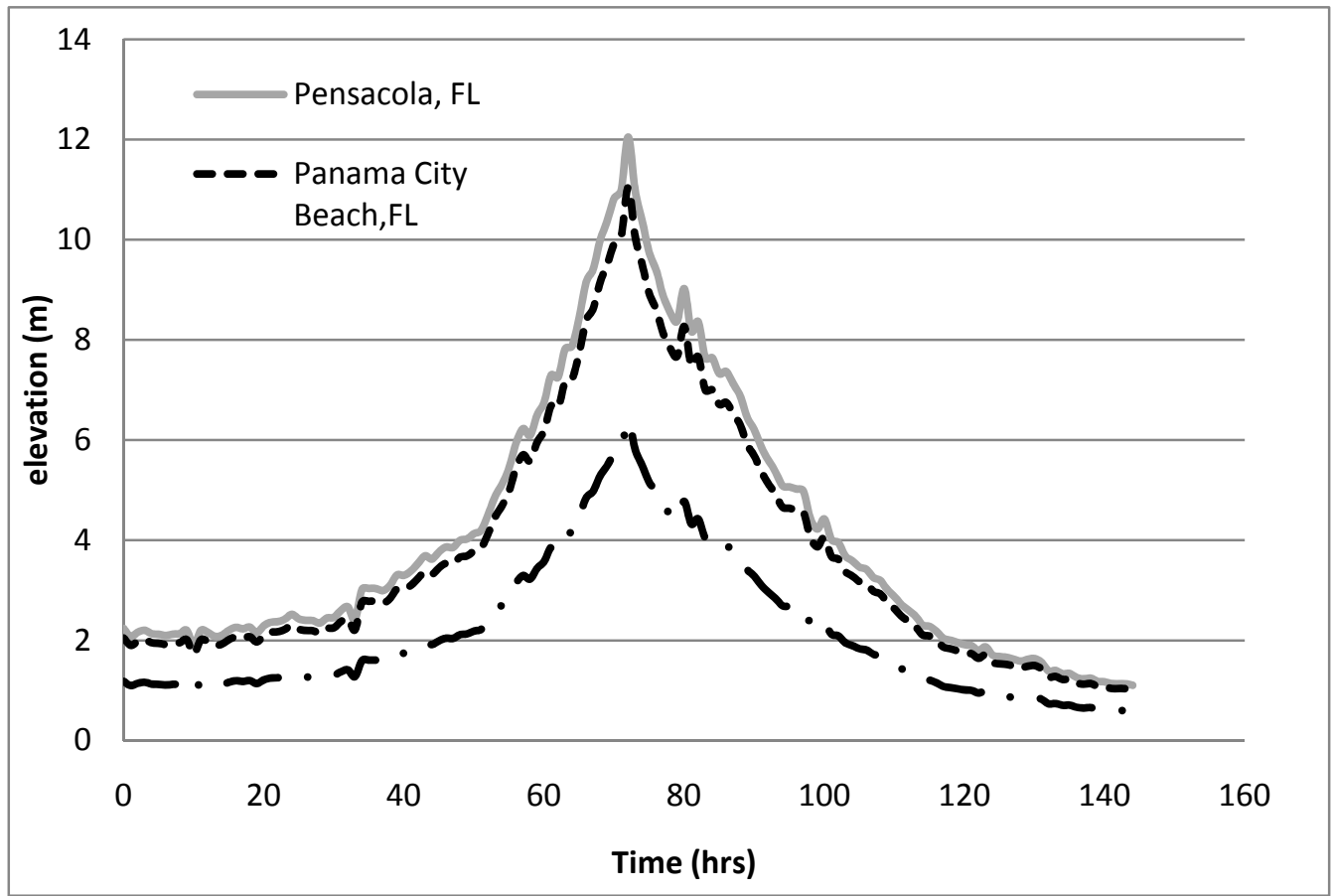

Figure 21. Wave height data during Hurricane Ivan (2004) 
Even though Hurricane Ivan made landfall well west of Panama City Beach, the area still experienced over 1 meter of surge. The surge values used to force the XBeach runs are indicative of the level of surge associated with Hurricane Ivan for Panama City Beach, Florida. For this thesis, the surge value used for the XBeach runs is $0.0 \mathrm{~m}$ in order to minimize the varying components of the simulation. Also, in order to more easily compare scenarios, the influence of surge was not considered. The wave values used to force the simulations varied from $3.0 \mathrm{~m}, 4.0 \mathrm{~m}, 5.0 \mathrm{~m}$, and $7.0 \mathrm{~m}$ (Table 1). These wave conditions can be observed as an extreme storm, such as a hurricane, comes ashore.

Table 1. Hydrodynamic conditions

\begin{tabular}{|c|c|c|c|}
\hline Waves (m) & \multicolumn{3}{|c|}{ Grids } \\
\cline { 1 - 1 } 3 & & & \\
\cline { 1 - 1 } 4 & \multirow{3}{*}{ No Bar } & Continuous Bar & Bar-Rip \\
\cline { 1 - 1 } 5 & & & \\
\hline
\end{tabular}

The surge and wave conditions do not vary during the XBeach simulation to ensure that the runup results are strictly correlated with the different bathymetric features. Based on prior investigations, waves propagating shore-normal generate the highest level of waves as the waves approach the shoreline. Since this thesis will be analyzing extreme runup, the most severe case is required, thus shore-normal waves were used. As mentioned previously, a JONSWAP spectrum is used to generate the 
wave conditions for the waves chosen. The main angle for the JONSWAP spectrum was specified as shore-normal; however, there is some degree of directionality. The peak wave period is 10 seconds.

The interval between time steps for the XBeach runs is every 1 second. The frequency of the output is important to the data analysis since runup is measured as waves interact with the land/sea interface. XBeach outputs the wave and water surface elevation data every 1 second for the duration of the simulation. Each hydrodynamic scenario is run for a total of 2 hours for each grid; however, data is only output for the last 1.5 hours. Allowing the XBeach run to "ramp up" for half an hour ensures that the data that is output is void of any inconsistencies due to the initiation of the waves and surge.

XBeach outputs include the bound long-wave and therefore interpreting runup at the last wet/dry location on the beach requires that the entire long-wave be captured. The long-wave period is typically on the order of 20 seconds. Acquiring output every 1 second ensures that the "crest" of the long wave is captured. For this thesis, output from the XBeach runs consists of the wave height and water surface elevation.

Newer versions of XBeach exist, but for the research conducted for this thesis, the slight modifications to some of the coding were not needed and XBeach version 12 had already been utilized for previous research (Frey, 2009). However, using XBeach version 12 required that the wetting of the beach due to the fluctuating water level must be resolved since the version 12 code keeps a thin film of water on the beach (approximately $1 \mathrm{~cm}$ ). Since runup analysis is to be conducted at the land/sea interface, 
it was important to remedy this part of the code. The issue of the remaining "film" of water on the beach was handled in the post processing for obtaining the runup which will be discussed in further detail in Section 4.5.

\subsection{Data Analysis}

The XBeach model was used to simulate the hydrodynamic conditions that are input onto the respective grids. The model is capable of outputting various data that can be used for analysis. For this thesis, the water level elevation, the wave height, and bed

elevation were required as output. The analysis of the XBeach output was accomplished using MATLAB for computational purposes, including statistical analyses to determine extreme long-wave runup. The process required to obtain the $2 \%$ runup is shown in the flow chart in Figure 22. The 2\% runup is the extreme runup that causes erosion of the beach and dune system (Stockdon et al, 2006). The first step in the process is to force XBeach with the hydrodynamic conditions where the model outputs the specified data. The water level elevation and bed level are used to get the long-wave runup values for the length of the grid in the longshore for the entire time set. Finally, the data is analyzed to determine the averages of the long-wave runup and then the statistical analysis of the data can be accomplished after the zero-up crossing analysis is utilized to determine wave characteristics, such as wave height, and period, for the free surface water level data. The wave heights are also analyzed to determine the energy dissipation relation after the waves have broken. 


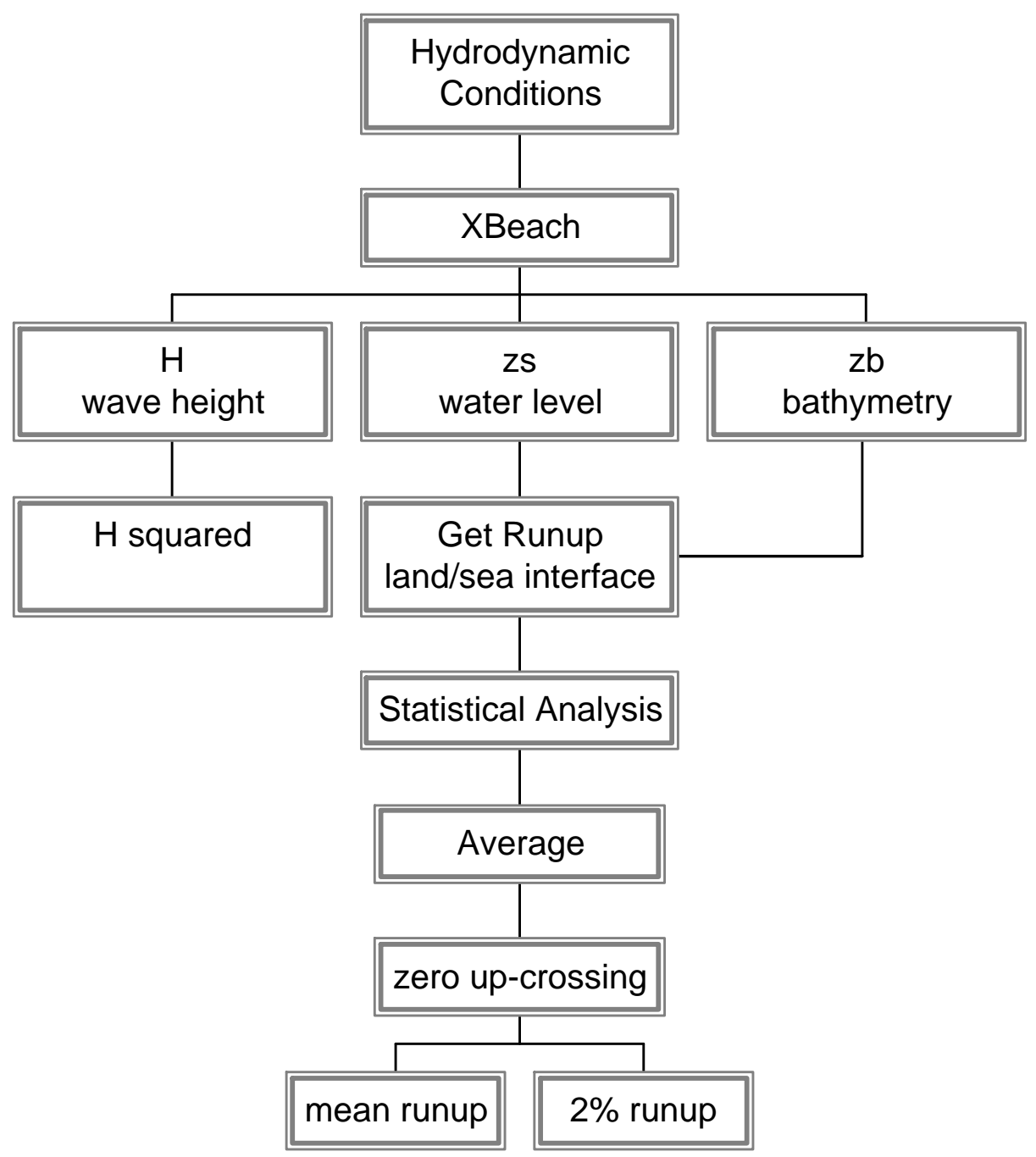

Figure 22. Flow chart for analysis 
The output files are rather large, approximately 4 gigabits for one output parameter. In order to organize the data, a MATLAB code was used to arrange the structure of the output parameters. This was necessary, since the time interval for output was set for every second over the entire grid. The MATLAB code read in the output files and arranged them into structures that could be used for the data analysis. The propagation of the waves is shore-normal with the grid setup in Cartesian coordinates. For each simulation, long-wave runup time series are developed by extracting the instantaneous land/sea interface profile-wise from the spatial XBeach water surface elevation output. As this thesis focuses on the analysis of runup, finding the long-wave runup values were of utmost importance. A MATLAB code was used to find the last wet/dry location on the grid. The location of the last wet/dry point can be seen in Figure 23 where a single cross-shore profile is shown for the continuous bar grid. As mentioned previously, XBeach version 12 has a film of water on the depth file that occurs when the water level fluctuates on the shoreline. This was resolved when the runup value was found. The film of water is approximately $1 \mathrm{~cm}$ and is on the entire topography of the depth file. The location of runup was found by subtracting the depth file with the water level file and adjusting the results to account for the small film of water. At the locations where the value was zero, the long-wave runup value was obtained. 


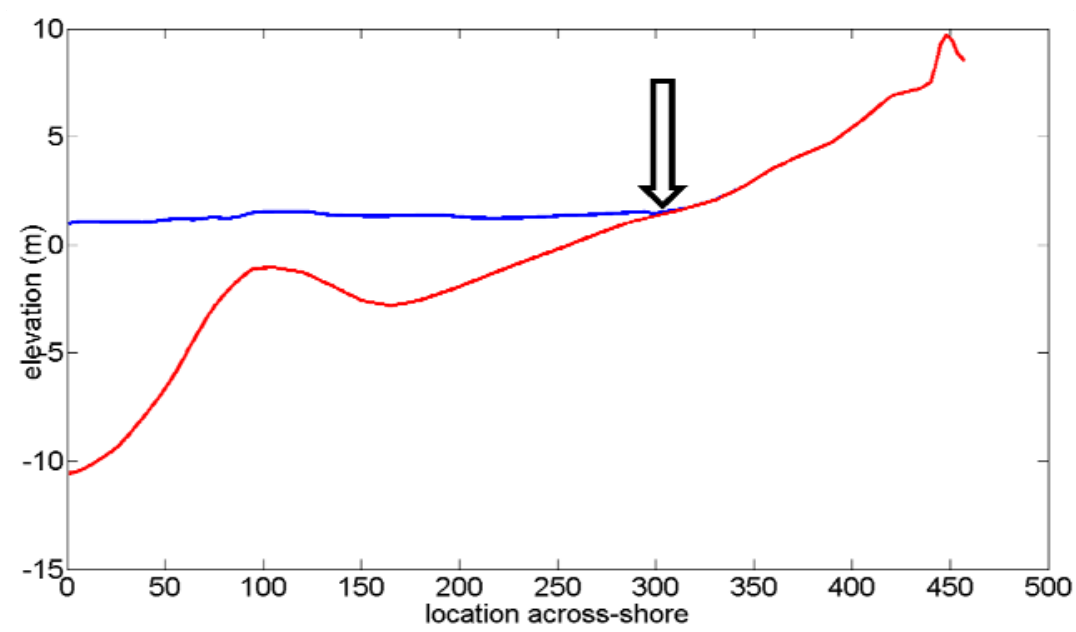

Figure 23. Location of last wet/dry point on the grid

After the long-wave runup values were obtained for the entire simulation along the grid, the average of the runup values were obtained. Figure 24 shows an example of long-wave runup time series. Figure 25 on page 62 shows an example of water level fluctuation along with the mean for one location on the grid.

The average of the long-wave runup for each location along the shore is important for computing the zero up-crossing analysis. Zero up-crossing analysis is used to determine long-wave characteristics for the free surface water level data. The extreme long-wave runup values were obtained for each location alongshore. The two percent runup (Stockdon et al., 2006) is determined by ranking the waves and obtaining the value for the $98^{\text {th }}$ percentile. The two percent runup is considered to be highly correlated with erosion (Stockdon et al., 2006). The mean long-wave runup is also obtained.

The wave heights for profiles alongshore were analyzed. The location of breaking was determined for each profile. The indication of energy dissipation of the broken wave heights was found through the surf zone. 


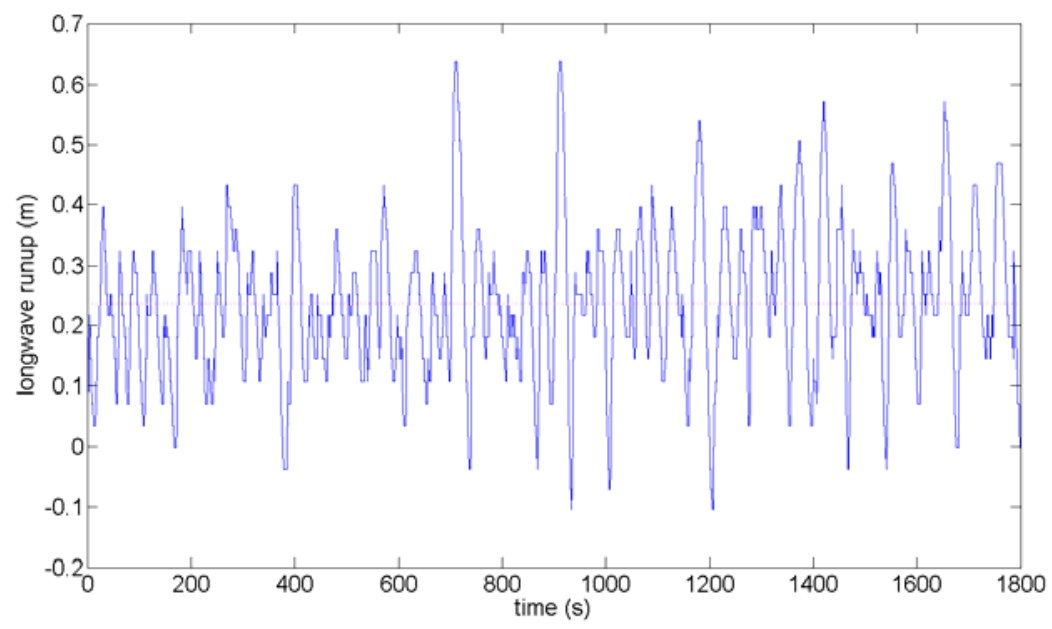

Figure 24. Long-wave runup time series

The wave heights for cross-shore profiles were determined to show the influence of offshore features on wave breaking. The wave heights for profiles alongshore were analyzed. The location of breaking was determined for each profile. The indication of energy dissipation of the broken wave heights was found through the surf zone. Also, the average of the wave heights for each cross-shore location were obtained to determine the influence of offshore features on wave height.

Runup and wave heights are analyzed to determine the effects of bathymetric features. The results from the analysis are discussed in Section 5. 


\section{RESULTS OF NUMERICAL EXPERIMENTS}

\subsection{Introduction}

This section includes the results from the XBeach simulations for the long-wave runup and wave height analysis in the surf zone for various hydrodynamic conditions. Section 5.2 will discuss the extreme long-wave runup (two-percent long-wave runup) results first for the same bathymetry with different wave conditions and then different bathymetries with the same wave conditions. Section 5.3 will discuss wave height analysis and the surfzone energy. This section will first compare the different wave conditions for the same bathymetry and then the bathymetries will be compared with the same wave conditions. Each of these sections will discuss the results from the XBeach simulations for the three bathymetric scenarios for the various hydrodynamic conditions.

\subsection{Extreme Long-wave Runup}

XBeach outputs the bound long-wave and therefore the long-wave runup was analyzed at the last wet/dry location on the beach for the three bathymetric grids (continuous bar, no bar, and bar-rip). For each simulation, long-wave runup time series were developed by extracting the instantaneous land-sea interface profile-wise from the spatial XBeach water surface elevation output. These time series were analyzed using zero up-crossing, and runup statistics were developed. The extreme long-wave runup (two-percent runup) values were determined since runup is considered to be highly correlated with erosion (Stockdon et al., 2006). The extreme long-wave runup for the same bathymetry, but with various wave conditions will first be discussed. Next, 
extreme long-wave runup will be discussed for different bathymetries with the same wave condition.

The no bar bathymetry is considered the "base" case, since the bathymetry is generated from the equilibrium beach profile concept (Dean, 1977). The extreme longwave runup in the longshore was found for each profile. Figure 25 shows the results for the 2 percent long-wave runup for the four different wave conditions. As can be seen, there is a slight undulating alongshore variation. This is likely due to the directionality imposed in the model when the JONSWAP spectrum is used. The extreme long-wave runup has a similar trend for the alongshore undulation for the $3.0 \mathrm{~m}, 4.0 \mathrm{~m}$, and $5.0 \mathrm{~m}$ wave conditions. However, the $7.0 \mathrm{~m}$ wave is more varied. The largest $\mathrm{H}_{\mathrm{mo}}$ recommended for use within XBeach is $5.0 \mathrm{~m}$. The non-uniform undulation for the $7.0 \mathrm{~m}$ extreme long-wave runup results may be due to model limitations.

The mean long-wave extreme runup is $13 \mathrm{~cm}$ larger for the $\mathrm{H}_{\mathrm{mo}}$ of $4 \mathrm{~m}$ compared to the $\mathrm{H}_{\mathrm{mo}}$ of $3 \mathrm{~m}$, which is a $10 \%$ increase. Table 2 provides results for the mean extreme long-wave runup for the no bar bathymetry for various wave conditions. As the wave increases to $5 \mathrm{~m}$ from $4 \mathrm{~m}$, the mean long-wave extreme runup increases by $26 \mathrm{~cm}$ for the no bar bathymetry, which is an $18 \%$ increase. The mean long-wave extreme runup is $2.53 \mathrm{~m}$ for the $\mathrm{H}_{\mathrm{mo}}$ of $7 \mathrm{~m}$, which is $51 \%$ larger than the mean long-wave extreme runup of the $\mathrm{H}_{\text {mo }}$ of $5 \mathrm{~m}$. This is expected since the wave height was increased by 2 meters. As the waves increase, the standard deviation is fairly consistent for the four wave conditions. The $7.0 \mathrm{~m}$ wave has the largest standard deviation which can be easily observed in Figure 25. 
Table 2. No Bar statistics for various waves

\begin{tabular}{|c|c|c|c|c|}
\hline \multirow{2}{*}{ Statistics } & \multicolumn{4}{|c|}{ Waves } \\
\cline { 2 - 5 } & $\mathrm{H}_{\mathrm{mo}} 3(\mathrm{~m})$ & $\mathrm{H}_{\mathrm{mo}} 4(\mathrm{~m})$ & $\mathrm{H}_{\mathrm{mo}} 5(\mathrm{~m})$ & $\mathrm{H}_{\mathrm{mo}} 7(\mathrm{~m})$ \\
\hline mean long-wave R2\% (m) & 1.28 & 1.41 & 1.67 & 2.53 \\
\hline standard deviation $(\mathrm{m})$ & 0.12 & 0.10 & 0.13 & 0.18 \\
\hline
\end{tabular}

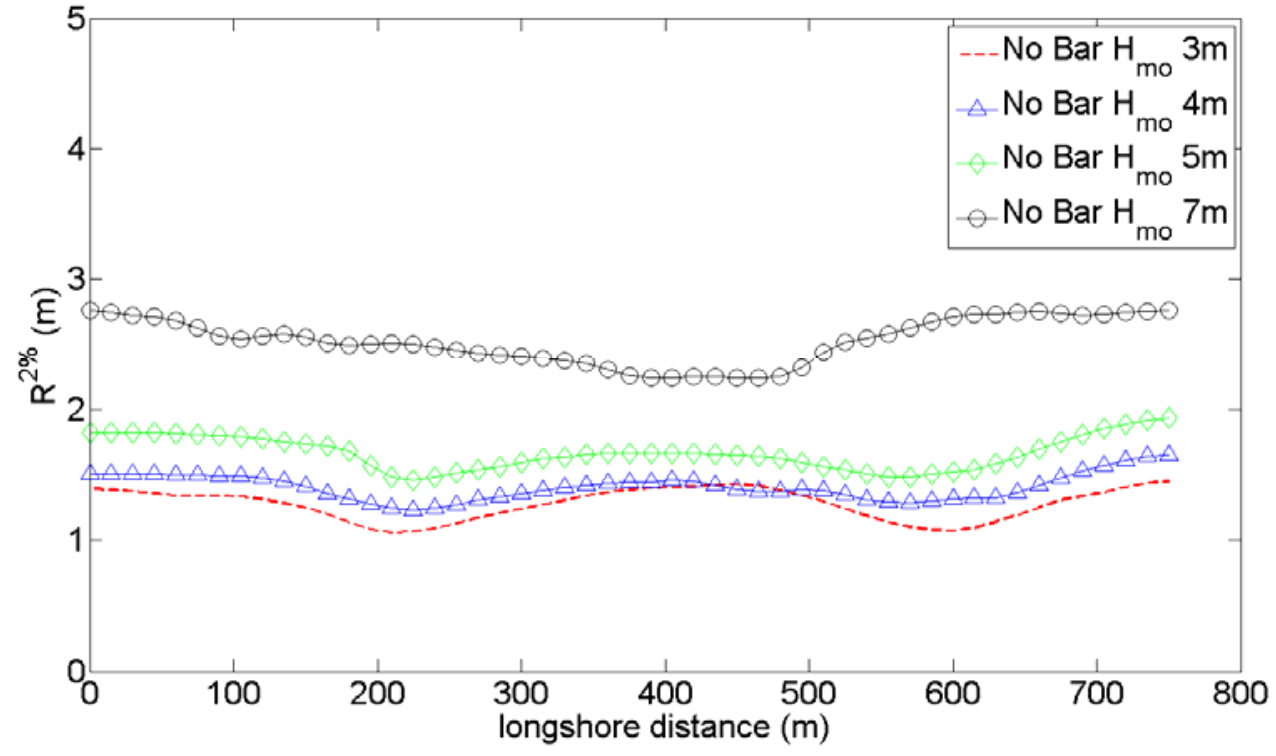

Figure 25. Extreme long-wave runup for no bar bathymetry

The bar bathymetry contains a uniform bar. The extreme long-wave runup in the longshore was found for each profile. The extreme long-wave runup is the two-percent long-wave runup value. Figure 26 shows the results for the extreme long-wave runup for the four different wave conditions. Table 3 includes results for the mean long-wave extreme runup for the continuous bar bathymetry. As was seen in the no bar bathymetry, there is a slight undulating alongshore variation which again is likely due to the 
directionality imposed in the model from using the JONSWAP spectrum. The extreme long-wave runup has a similar trend for the alongshore undulation for the $3.0 \mathrm{~m}, 4.0 \mathrm{~m}$, and $5.0 \mathrm{~m}$ wave conditions. However, the $7.0 \mathrm{~m}$ wave is more varied and the values for the center of the grid are lower than on the ends. This may be due to the model limit.

The mean long-wave extreme runup values were found for each wave condition for the continuous bar bathymetry. The effects due to the directionality of the waves are reduced by taking the mean long-wave extreme runup. The mean long-wave extreme runup is $24 \mathrm{~cm}$ larger for the $\mathrm{H}_{\mathrm{mo}}$ of $4.0 \mathrm{~m}$ compared to the $\mathrm{H}_{\mathrm{mo}}$ of $3.0 \mathrm{~m}$, which is a 23 $\%$ increase. As the wave increases from $4.0 \mathrm{~m} 5.0 \mathrm{~m}$, the mean long-wave extreme runup increases by $31 \mathrm{~cm}$, which is $24 \%$ increase. The mean long-wave extreme runup is $2.49 \mathrm{~m}$ for the $\mathrm{H}_{\mathrm{mo}}$ of $7.0 \mathrm{~m}$. As the waves increase in magnitude, the standard deviation is fairly consistent for the wave heights of $3.0 \mathrm{~m}, 4.0 \mathrm{~m}$, and $5.0 \mathrm{~m}$. The $7.0 \mathrm{~m}$ wave height causes considerable variability from the mean long-wave extreme runup. 


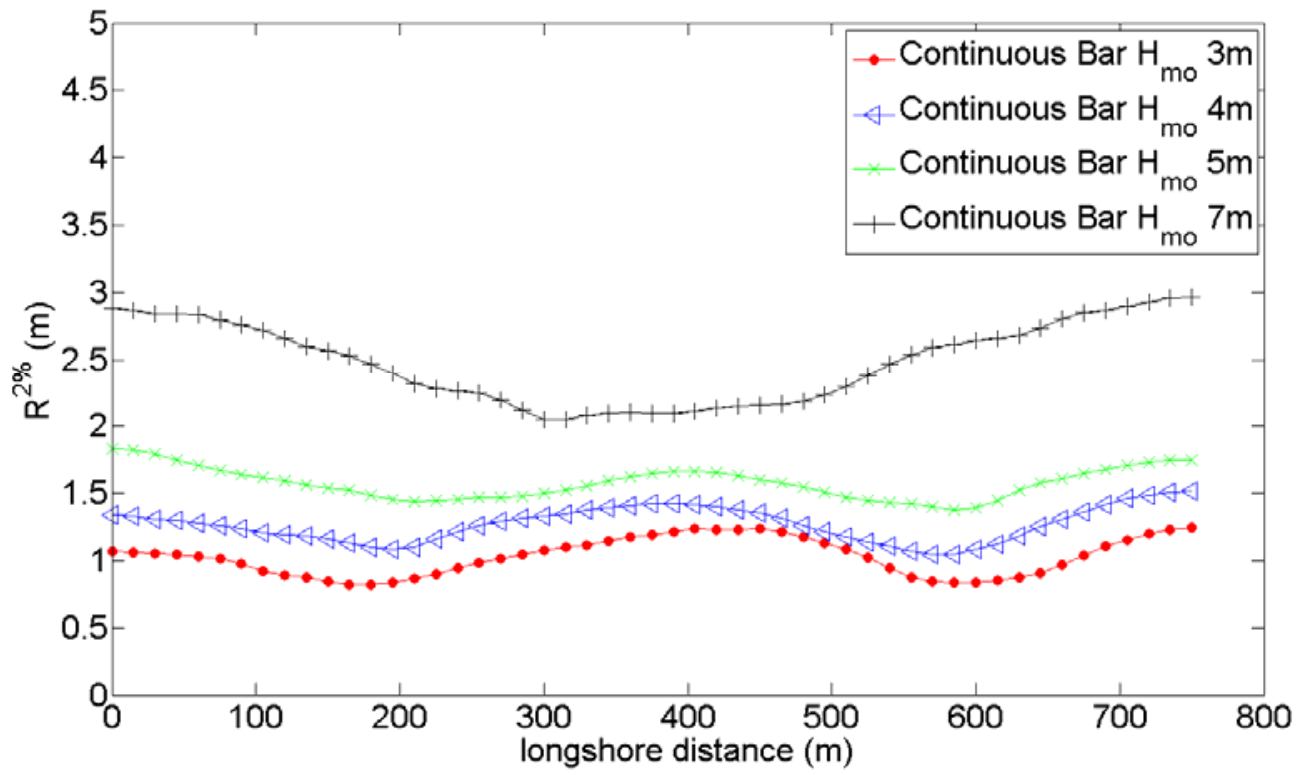

Figure 26. Extreme long-wave runup for continuous bar bathymetry

Table 3. Continuous Bar statistics for various waves

\begin{tabular}{|c|c|c|c|c|}
\hline \multirow{2}{*}{ Statistics } & \multicolumn{4}{|c|}{ Waves } \\
\cline { 2 - 5 } & $\mathrm{H}_{\mathrm{mo}} 3(\mathrm{~m})$ & $\mathrm{H}_{\mathrm{mo}} 4(\mathrm{~m})$ & $\mathrm{H}_{\mathrm{mo}} 5(\mathrm{~m})$ & $\mathrm{H}_{\mathrm{mo}} 7(\mathrm{~m})$ \\
\hline mean long-wave R2\% $(\mathrm{m})$ & 1.03 & 1.27 & 1.58 & 2.49 \\
\hline standard deviation $(\mathrm{m})$ & 0.14 & 0.13 & 0.12 & 0.31 \\
\hline
\end{tabular}

The bar-rip bathymetry is a combination of the continuous bar and the no bar bathymetries. The no bar bathymetry is located in the center and is bounded by the bar bathymetry. The rip occurs between 325 to 425 meters in the longshore. The extreme long-wave runup in the longshore was found for each profile. Figure 27 shows the results for the extreme long-wave runup for the four different wave conditions. There is considerable undulating alongshore variation for all of the wave conditions. The 
alongshore undulation is the least for the $\mathrm{H}_{\mathrm{mo}} 5.0 \mathrm{~m}$. Table 4 provides results for the mean long-wave extreme runup for the bar-rip bathymetry. The mean long-wave extreme runup is only $18 \mathrm{~cm}$ larger for the $\mathrm{H}_{\mathrm{mo}}$ of $4.0 \mathrm{~m}$ compared to the $\mathrm{H}_{\mathrm{mo}}$ of $3.0 \mathrm{~m}$, which is a $19 \%$ increase. As the wave increases to $5.0 \mathrm{~m}$ from $4.0 \mathrm{~m}$, the mean longwave extreme runup increases by $34 \mathrm{~cm}$, which is almost a $30 \%$ increase. The mean long-wave extreme runup is $2.60 \mathrm{~m}$ for the $\mathrm{H}_{\mathrm{mo}}$ of $7.0 \mathrm{~m}$, which is a $75 \%$ increase from the $\mathrm{H}_{\mathrm{mo}}$ of $5.0 \mathrm{~m}$. Comparing the $\mathrm{H}_{\mathrm{mo}}$ of $3.0 \mathrm{~m}$ and $\mathrm{H}_{\mathrm{mo}}$ of $5.0 \mathrm{~m}$, the percent increase is only $53 \%$. As the waves increase, the standard deviation is fairly consistent for the waves of $3.0 \mathrm{~m}$ and $4.0 \mathrm{~m}$. The $\mathrm{H}_{\mathrm{mo}}$ of $5.0 \mathrm{~m}$ has the least amount of variability and is almost two times less than for $\mathrm{H}_{\mathrm{mo}}$ of $4.0 \mathrm{~m}$.

Table 4. Bar-rip statistics for various waves

\begin{tabular}{|c|r|r|r|r|}
\hline \multirow{2}{*}{ Statistics } & \multicolumn{4}{|c|}{ Waves } \\
\cline { 2 - 5 } & $\mathrm{H}_{\mathrm{mo}} 3(\mathrm{~m})$ & $\mathrm{H}_{\mathrm{mo}} 4(\mathrm{~m})$ & $\mathrm{H}_{\mathrm{mo}} 5(\mathrm{~m})$ & $\mathrm{H}_{\mathrm{mo}} 7(\mathrm{~m})$ \\
\hline mean long-wave R2\% (m) & 0.96 & 1.14 & 1.48 & 2.60 \\
\hline standard deviation $(\mathrm{m})$ & 0.17 & 0.20 & 0.12 & 0.31 \\
\hline
\end{tabular}




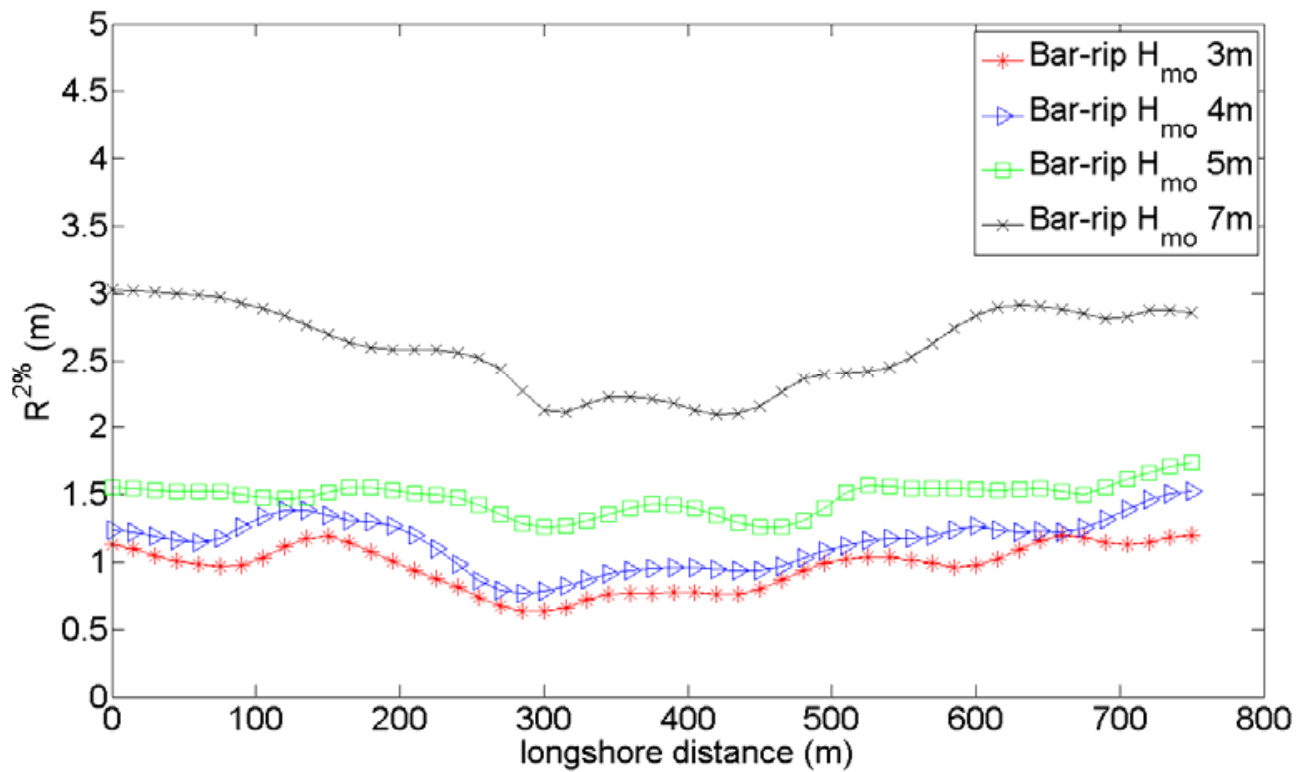

Figure 27. Extreme long-wave runup for bar-rip bathymetry

The bathymetries with different wave conditions had similar trends for the extreme long-wave runup (two-percent long-wave runup). For all cases, there was an undulating alongshore variability. However, for the largest wave condition $\left(\mathrm{H}_{\mathrm{mo}}\right.$ of 7.0 $\mathrm{m})$, the variability is more pronounced. The main wave angle is shore-normal, but there is a degree of directionality associated with using the JONSWAP spectrum. The directionality is likely the cause of the alongshore undulation of the extreme long-wave runup. 
The mean of the extreme long-wave runup alongshore removes the directionality component and thus the results can be more easily understood. As expected, the increase in waves caused the mean extreme long-wave runup to increase. Increasing the wave height by 2.0 meters $(3.0 \mathrm{~m}$ to $5.0 \mathrm{~m}$ and $5.0 \mathrm{~m}$ to $7.0 \mathrm{~m})$ had more of an effect on the mean extreme long-wave runup for the $\mathrm{H}_{\mathrm{mo}}$ of $5.0 \mathrm{~m}$ to $\mathrm{H}_{\mathrm{mo}}$ of $7.0 \mathrm{~m}$ for all bathymetries where the increase was almost 1 meter as compared to 0.5 meters for the $\mathrm{H}_{\mathrm{mo}}$ of $3.0 \mathrm{~m}$ to $\mathrm{H}_{\mathrm{mo}}$ of $5.0 \mathrm{~m}$ increase.

Different bathymetric scenarios (no bar, continuous bar, bar-rip) are compared for the same wave conditions. The extreme long-wave runup, mean of the extreme long-wave runup, and cumulative distributions are compared for different bathymetries. Long-wave runup data was ranked and plotted to determine the distribution. At all longshore locations, long-wave runup appears to follow a normal distribution as can be seen in Figure 28. Cumulative distributions for the long-wave runup were obtained for profiles from three different locations along the shore. The profiles chosen are located at distance 200, 400, and 600 which are to the left, center, and right of the rip in the bar-rip bathymetry. 


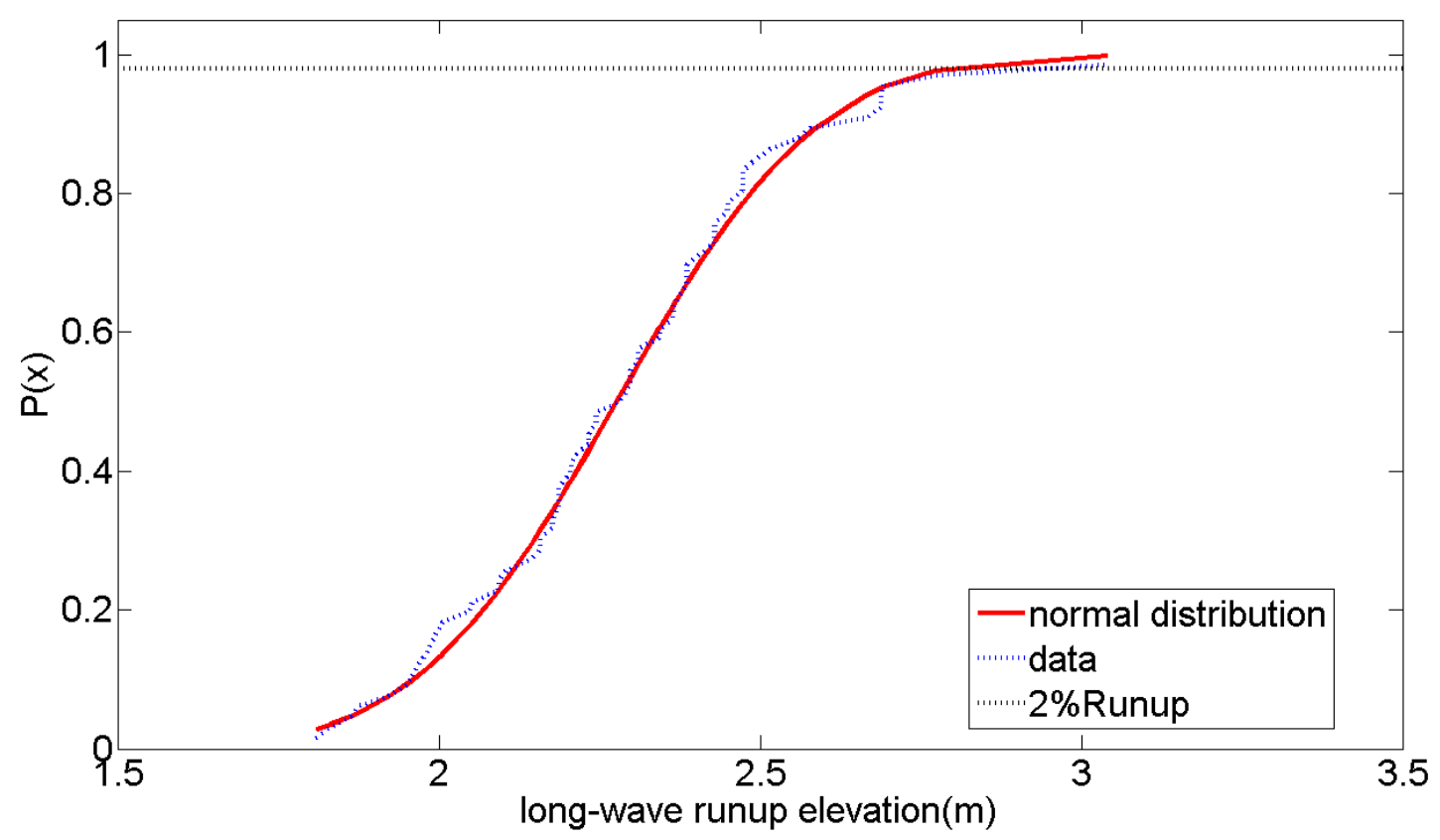

Figure 28. CDF of long-wave runup

$\underline{\operatorname{Hmo} 3.0 \mathrm{~m}}$

The $\mathrm{H}_{\mathrm{mo}}$ of $3.0 \mathrm{~m}$ is the smallest wave simulated with XBeach for this thesis. Figure 29 shows the results for the extreme long-wave runup for the three different bathymetries. There is considerable undulating alongshore variation for all of the bathymetries. However, the no bar and continuous bar bathymetry have a similar shape to the undulation. The bar-rip bathymetry has highly variable extreme long-wave runup alongshore. Table 5 provides the values for the mean extreme long-wave runup and the standard deviation. The no bar bathymetry has a mean extreme long-wave runup value that is about $24 \%$ and $33 \%$ larger than the continuous bar and bar-rip bathymetries, 
respectively. For this wave condition, it appears that bathymetry does affect the extreme long-wave runup. The no bar bathymetry has the least variability of the mean extreme long-wave runup. Not having a nearshore feature, increased the mean extreme longwave runup for the $\mathrm{H}_{\mathrm{mo}}$ of $3.0 \mathrm{~m}$ and reduced the variability alongshore. The cumulative distribution of the long-wave runup was obtained for three profiles. Figure 30 shows the three profile distributions. The long-wave runup is normally distributed for all three profiles for the three separate bathymetries. The distribution of the no bar bathymetry and continuous bar bathymetry are uniform, but the bar-rip bathymetry fluctuates for the three profiles.

Table 5. Extreme long-wave runup statistics for $\mathrm{H}_{\mathrm{mo}} 3 \mathrm{~m}$

\begin{tabular}{|c|r|r|r|}
\hline \multirow{2}{*}{ Statistics } & \multicolumn{3}{|c|}{ Bathymetry } \\
\cline { 2 - 4 } & No Bar & Continuous Bar & Bar-Rip \\
\hline mean long-wave R2\% & 1.28 & 1.03 & 0.96 \\
\hline standard deviation & 0.12 & 0.14 & 0.17 \\
\hline
\end{tabular}




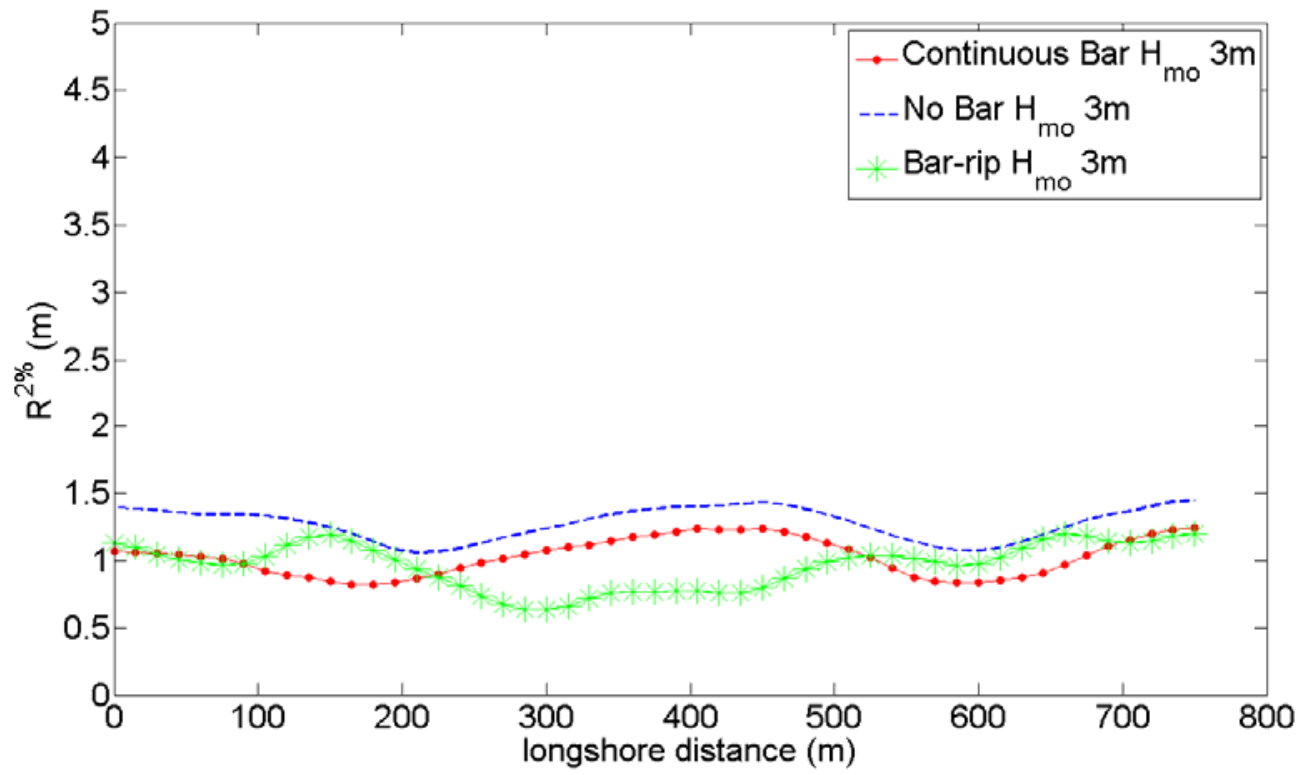

Figure 29. Extreme long-wave runup for $\mathrm{H}_{\mathrm{mo}} 3.0 \mathrm{~m}$
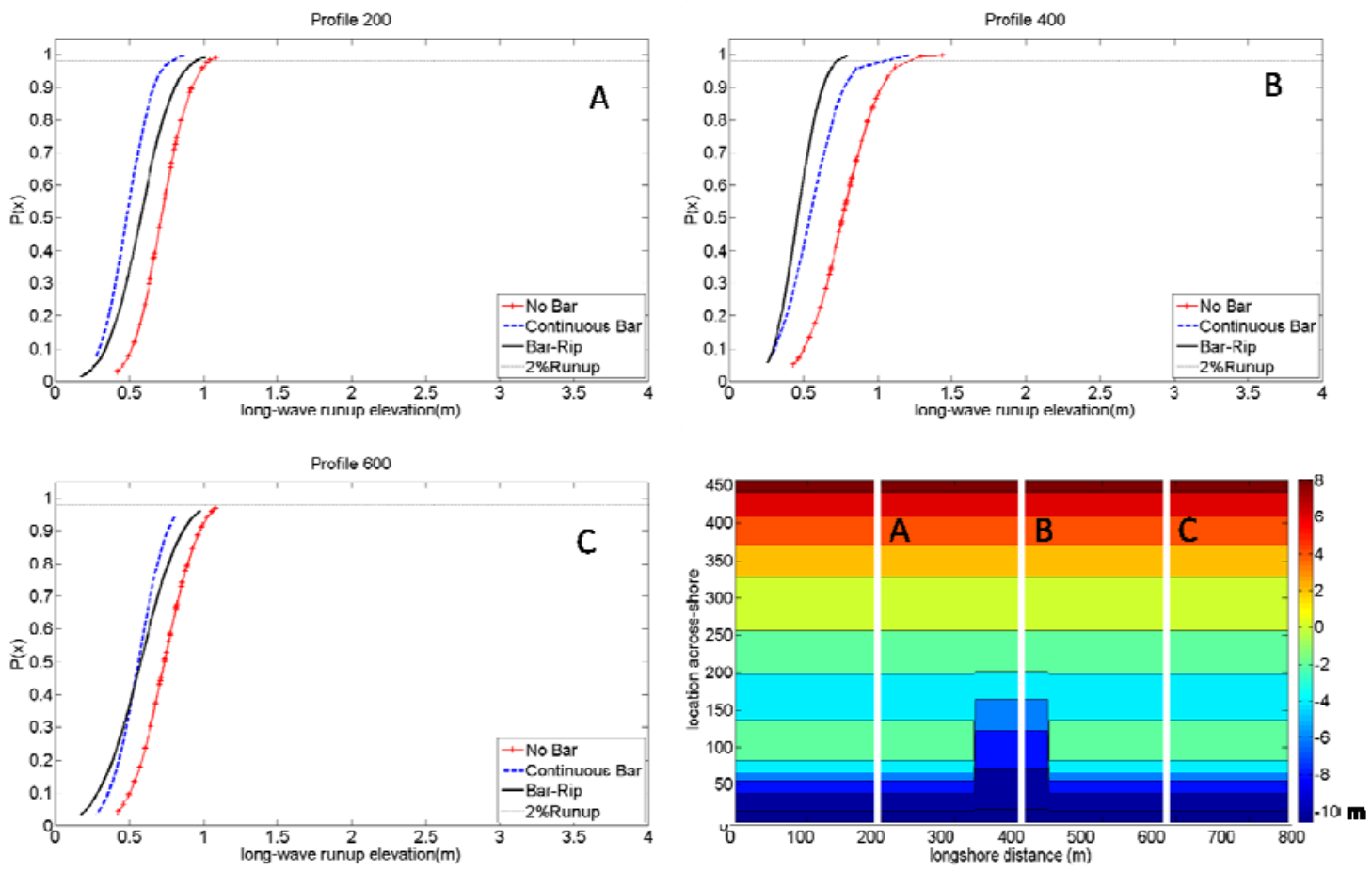

Figure 30. CDF long-wave runup $\mathrm{H}_{\mathrm{mo}} 3.0 \mathrm{~m}$ 
$\underline{\mathrm{H}}_{\mathrm{mo}} \underline{4.0 \mathrm{~m}}$

Figure 31 shows the results for the extreme long-wave runup for the three different bathymetries for the $4.0 \mathrm{~m}$ wave height. There is considerable undulating alongshore variation for all of the bathymetries. However, the no bar and continuous bar bathymetry have a similar shape to the undulation and at this wave height the no bar and continuous bar extreme long-wave runup values are almost the same, especially at the center. The bar-rip bathymetry has highly variable extreme long-wave runup alongshore. Table 6 provides the values for the mean long-wave extreme runup and the standard deviation. The no bar bathymetry has a mean extreme long-wave runup value that is only $14 \mathrm{~cm}$ larger than that of the continuous bar bathymetry. As can be seen, the variability of the no bar and continuous bar bathymetries are small and the bar-rip bathymetry is highly variable alongshore. There is only a $10 \%$ difference between the mean long-wave extreme runup for the no bar bathymetry and continuous bar bathymetry. There is a $23 \%$ difference between the no bar bathymetry and the bar-rip bathymetry for the mean long-wave extreme runup For this wave condition, it appears that bathymetry has less of an effect on the long-wave extreme runup than was experienced for the $3.0 \mathrm{~m}$ wave. The presence of the continuous bar only reduces the mean long-wave extreme runup by $10 \%$. The cumulative distribution of the long-wave runup was obtained for three profiles. Figure 32 shows the three profile distributions. The long-wave runup is normally distributed for all three profiles for the three separate bathymetries. The distribution at profile 200 and 600 are very similar, but the 
distribution at profile 400 for the bar-rip bathymetry varies from the other profile distributions.

Table 6. Extreme long-wave runup statistics for $\mathrm{H}_{\mathrm{mo}} 4.0 \mathrm{~m}$

\begin{tabular}{|c|r|r|r|}
\hline \multirow{2}{*}{ Statistics } & \multicolumn{3}{|c|}{ Bathymetry } \\
\cline { 2 - 4 } & No Bar & Continuous Bar & Bar-Rip \\
\hline mean long-wave R2\% (m) & 1.41 & 1.27 & 1.14 \\
\hline standard deviation (m) & 0.10 & 0.13 & 0.20 \\
\hline
\end{tabular}

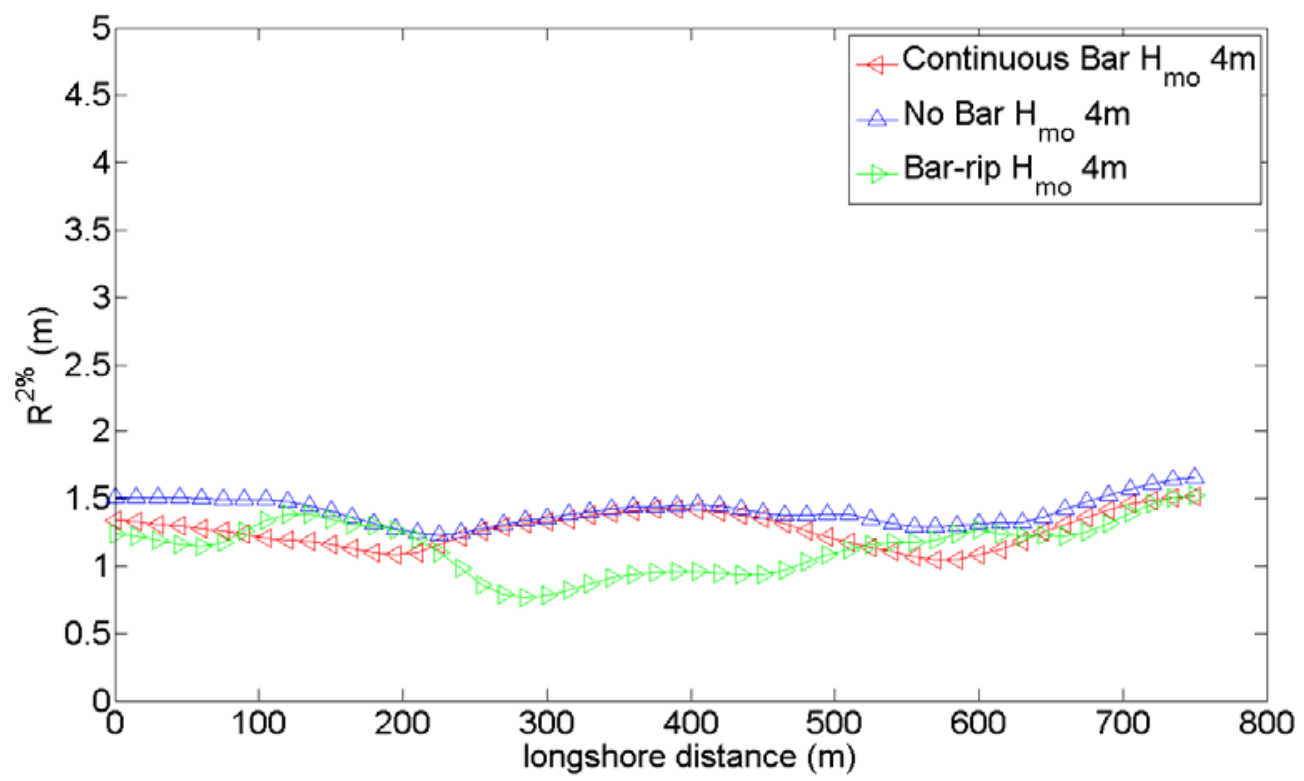

Figure 31. Extreme long-wave runup for $\mathrm{H}_{\mathrm{mo}} 4.0 \mathrm{~m}$ 

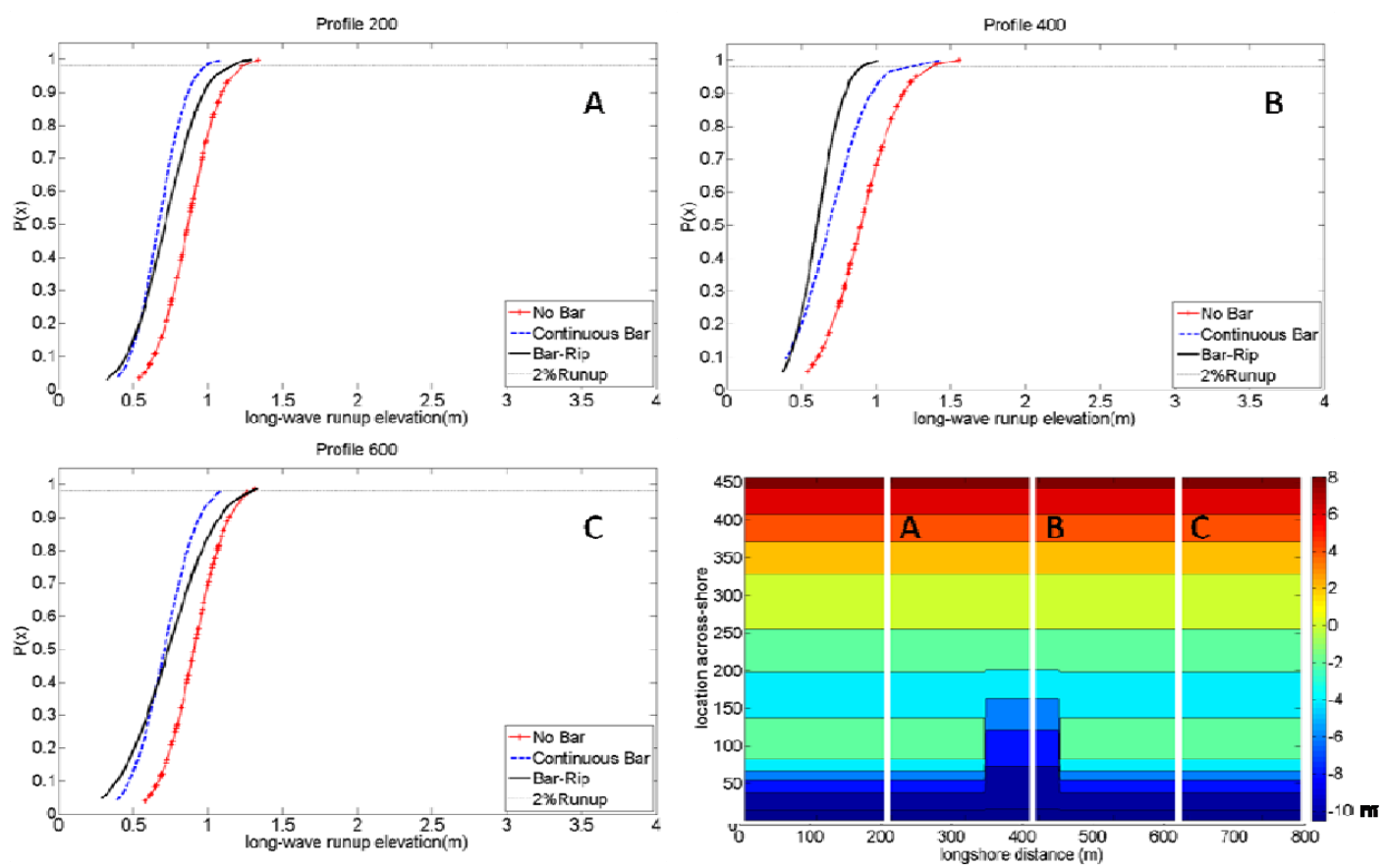

Figure 32. CDF long-wave runup $\mathrm{H}_{\mathrm{mo}} 4.0 \mathrm{~m}$

\section{$\underline{\text { Hmo } 5.0 \mathrm{~m}}$}

Figure 33 shows the results for the 2 percent long-wave runup for the three different bathymetries for the $5.0 \mathrm{~m}$ wave height. There is undulating alongshore variation for all of the bathymetries. However, the no bar and continuous bar bathymetry have a similar shape to the undulation and at this wave height the no bar and continuous bar extreme long-wave runup values are almost the same, especially at the center. At this wave condition, the water level is at an elevation where there is very little influence from the nearshore bathymetries. The bar-rip bathymetry has more variability in the extreme long-wave runup alongshore, but the variability is less than for the $4.0 \mathrm{~m}$ 
wave height condition. Table 7 provides the values for the mean long-wave extreme runup and the standard deviation. The no bar bathymetry has a mean extreme long-wave runup value that is only $9 \mathrm{~cm}$ larger than that of the continuous bar bathymetry. As can be seen, the variability of the no bar and continuous bar bathymetries are small. There is only a $6 \%$ difference between the mean long-wave extreme runup for the no bar bathymetry and continuous bar bathymetry. There is a $13 \%$ difference between the no bar bathymetry and the bar-rip bathymetry for the mean long-wave extreme runup For this wave condition, it appears that bathymetry has less of an effect on the long-wave extreme runup than was experienced for the $4.0 \mathrm{~m}$ wave. The presence of the continuous bar only reduces the mean long-wave extreme runup by $6 \%$. Also, the standard deviation for all three bathymetries is approximately equal to $0.12 \mathrm{~m}$. The cumulative distribution of the long-wave runup was obtained for three profiles. Figure 34 shows the three profile distributions. The long-wave runup is normally distributed for all three profiles for the three separate bathymetries. As has been observed for the previous wave conditions, the distribution for the no bar and continuous bar bathymetry have a constant distribution for all three profile, where as the bar-rip bathymetry has a highly varying distribution between the profiles.

Table 7. Extreme long-wave runup statistics for Hmo 5.0m

\begin{tabular}{|c|r|r|r|}
\hline \multirow{2}{*}{ Statistics } & \multicolumn{3}{|c|}{ Bathymetry } \\
\cline { 2 - 4 } & No Bar & Continuous Bar & Bar-Rip \\
\hline mean long-wave R2\% (m) & 1.67 & 1.58 & 1.48 \\
\hline standard deviation $(\mathrm{m})$ & 0.13 & 0.12 & 0.12 \\
\hline
\end{tabular}




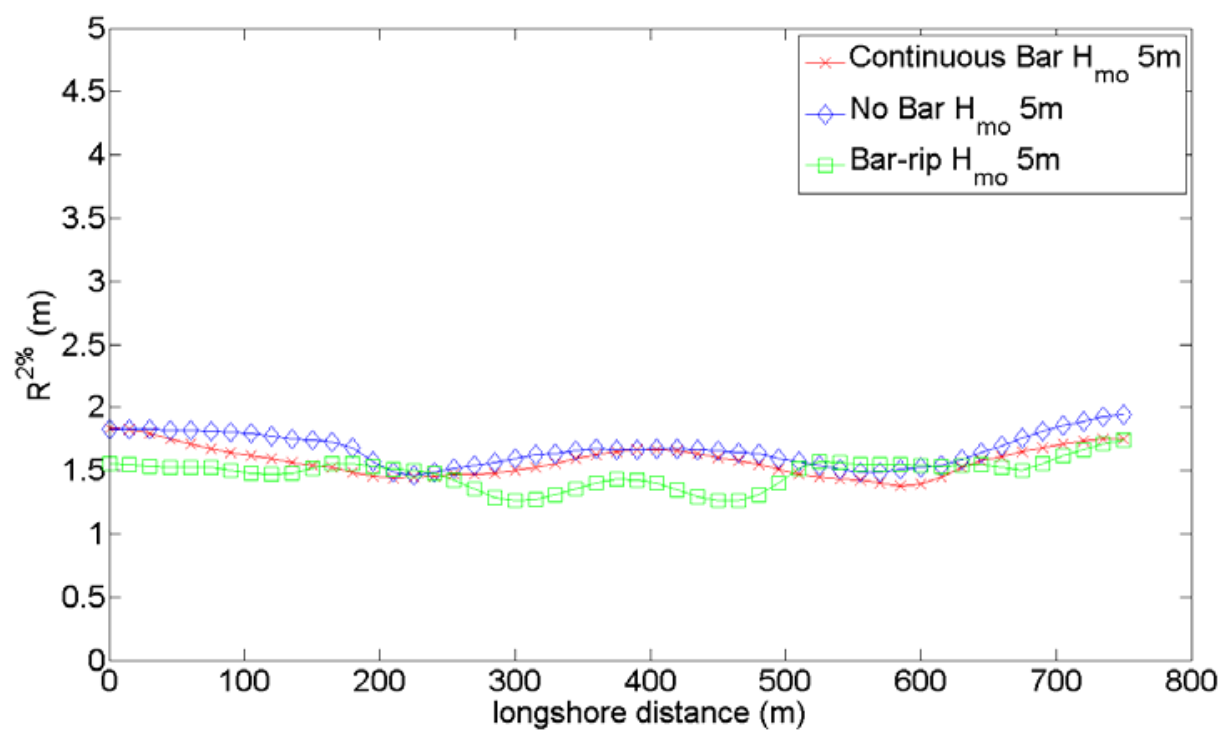

Figure 33. Extreme long-wave runup for $\mathrm{H}_{\mathrm{mo}} 5.0 \mathrm{~m}$
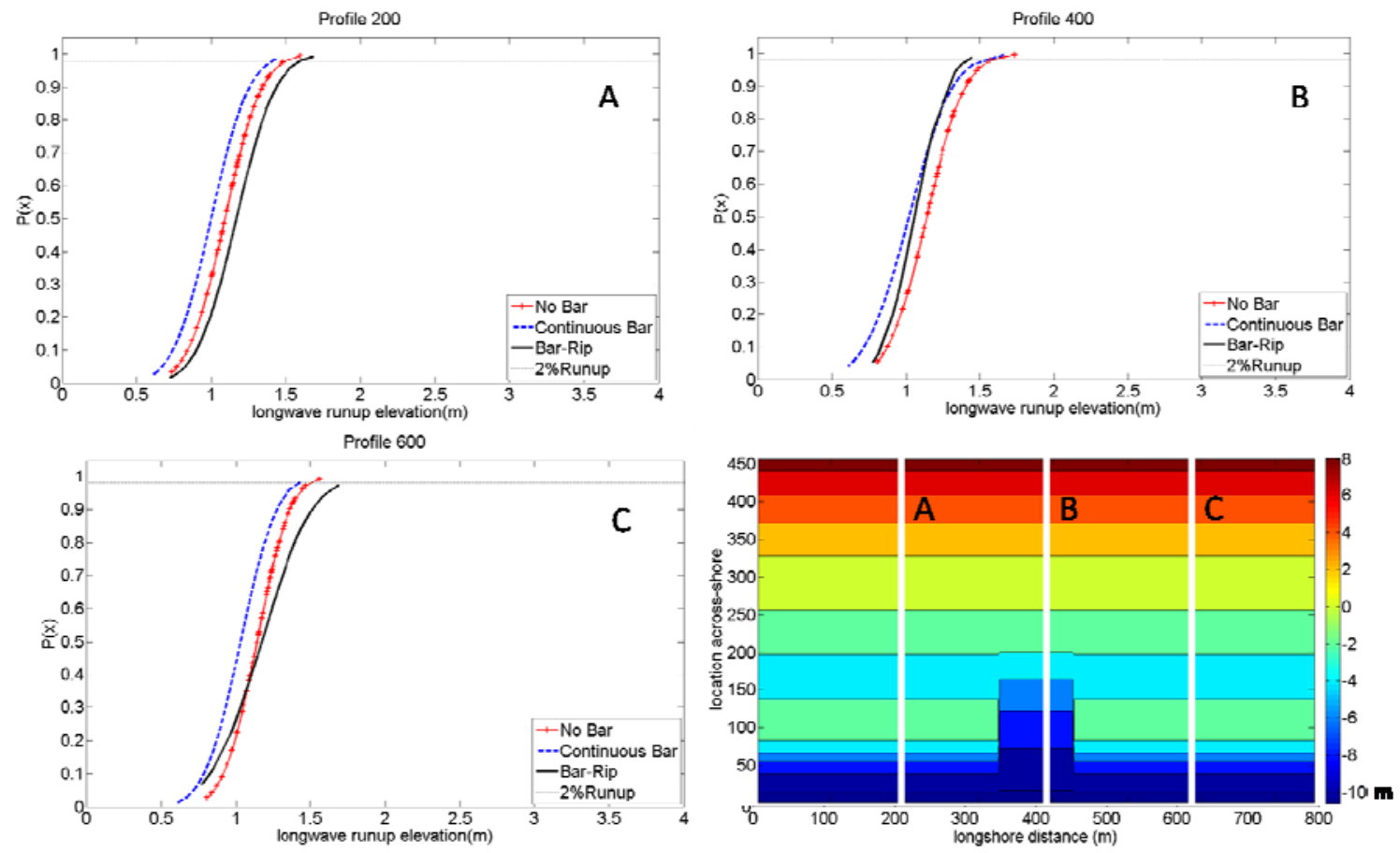

Figure 34. CDF long-wave runup for $\mathrm{H}_{\mathrm{mo}} 5.0 \mathrm{~m}$ 
$\underline{\operatorname{Hmo}} 7.0 \mathrm{~m}$

Figure 35 shows the results for the extreme long-wave runup for the three different bathymetries for the $7.0 \mathrm{~m}$ wave height. The $7.0 \mathrm{~m}$ wave is larger than the highest recommended wave height of the model $(5.0 \mathrm{~m})$, which may result in some nonuniform undulation. There is some undulating alongshore variation for all of the bathymetries. For this wave condition, there is not a definite undulating shape of the long-wave extreme runup that was present for the previous wave conditions. The extreme long-wave runup appears to be much more variable for all of the bathymetries. Table 8 provides the values for the mean long-wave extreme runup and the standard deviation. The no bar bathymetry has a mean extreme long-wave runup value that is only $4 \mathrm{~cm}$ larger than that of the continuous bar bathymetry. As can be seen, the variability of the continuous bar and bar-rip bathymetries are quite large, $(0.31 \mathrm{~m})$. There is only a $2 \%$ difference between the mean long-wave extreme runup for the no bar bathymetry and continuous bar bathymetry as well as for the no bar and bar-rip bathymetries. For this wave condition, it appears that bathymetry has very little affect on the extreme long-wave runup. The presence of the continuous bar only reduces the mean long-wave extreme runup by $2 \%$. The cumulative distribution of the long-wave runup was obtained for three profiles. Figure 36 shows the three profile distributions. The long-wave runup is normally distributed for all three profiles for the three separate bathymetries. The distribution of the no bar bathymetry and continuous bar bathymetry are uniform, but the bar-rip bathymetry fluctuates for the three profiles. 
Table 8. Extreme long-wave runup statistics for $\mathrm{H}_{\mathrm{mo}} 7.0 \mathrm{~m}$

\begin{tabular}{|c|r|r|r|}
\hline \multirow{2}{*}{ Statistics } & \multicolumn{3}{|c|}{ Bathymetry } \\
\cline { 2 - 4 } & No Bar & Continuous Bar & Bar-Rip \\
\hline mean long-wave R2\% (m) & 2.53 & 2.49 & 2.60 \\
\hline standard deviation $(\mathrm{m})$ & 0.18 & 0.31 & 0.31 \\
\hline
\end{tabular}

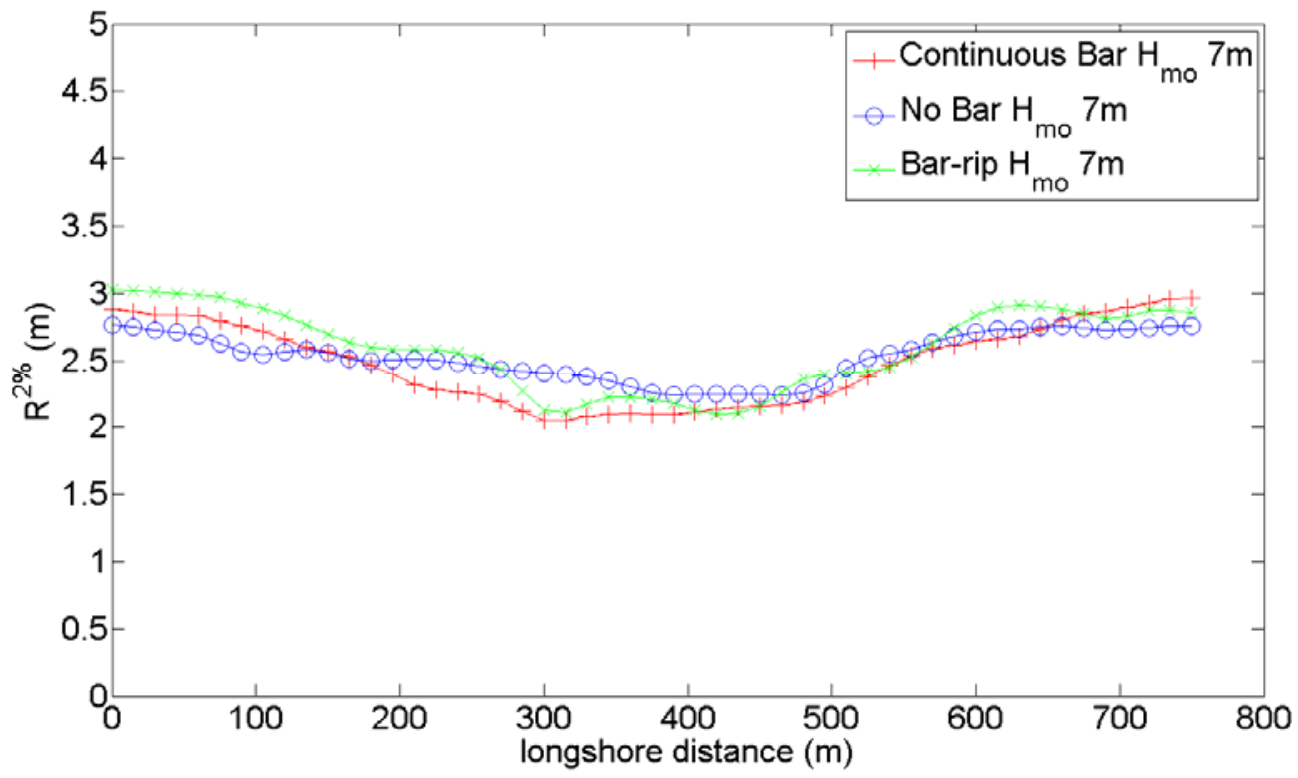

Figure 35. Extreme long-wave runup for $\mathrm{H}_{\mathrm{mo}} 7.0 \mathrm{~m}$ 

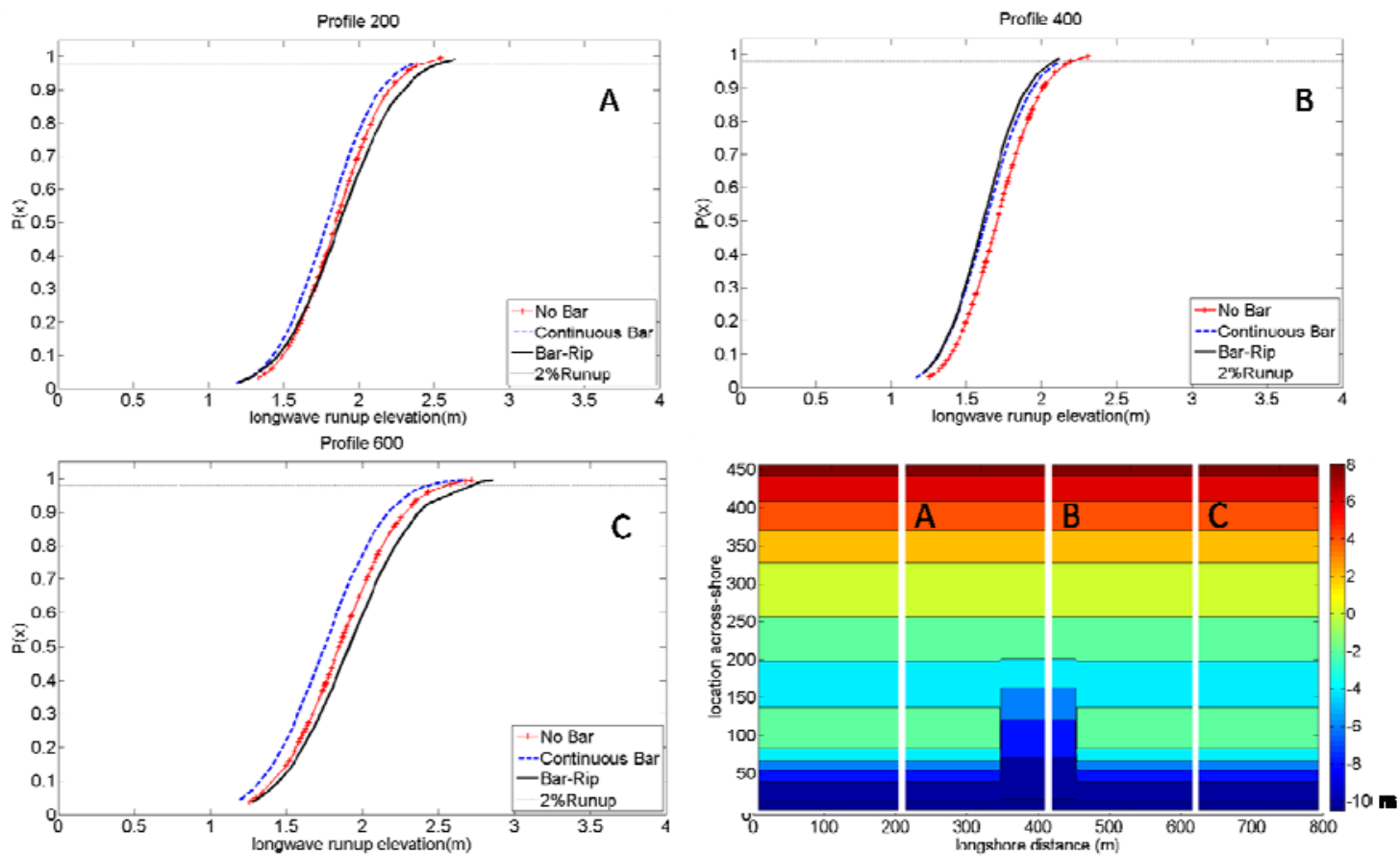

Figure 36. CDF long-wave runup $\mathrm{H}_{\mathrm{mo}} 7.0 \mathrm{~m}$

The bathymetries with the same wave conditions had similar trends for the extreme long-wave runup. For all cases, there was an undulating alongshore variability. As expected, the increase in wave heights caused the mean extreme long-wave runup to increase. Comparing the no bar bathymetry to the continuous bar and bar-rip bathymetries provides some insight into the influence of nearshore features on longwave runup. As the wave heights increased, the percent change in the values decreased. Table 9 gives results for the comparison of no bar bathymetry with the continuous bar and bar-rip bathymetry. Figure 37 shows the mean extreme long-wave runup for the four different wave conditions. The lowest wave height results in the largest difference between mean long-wave extreme runup. As expected, this indicates that the influence of the nearshore features is highly correlated with the wave condition. Figure 38 shows 
the standard deviation for the longshore mean long-wave extreme runup. For all bathymetries, the standard deviation for the $\mathrm{H}_{\mathrm{mo}} 3.0 \mathrm{~m}, \mathrm{H}_{\mathrm{mo}} 4.0 \mathrm{~m}$, and $\mathrm{H}_{\mathrm{mo}} 5.0 \mathrm{~m}$ is between 10 and $20 \mathrm{~cm}$. However, the standard deviation shows that the longshore mean long-wave extreme runup is highly variable for the $\mathrm{H}_{\mathrm{mo}} 7.0 \mathrm{~m}$ for the continuous bar and bar-rip bathymetries. The variability for this largest wave height may be due to model limitations. The extreme long-wave runup is caused by the largest waves in the spectrum. The larger waves cause an increase in water level resulting in bathymetric influence decreasing. The bar-rip bathymetry has considerable current interaction as waves are "forced" through the rip, which may be an indication of the significant variability of the extreme long-wave runup. 


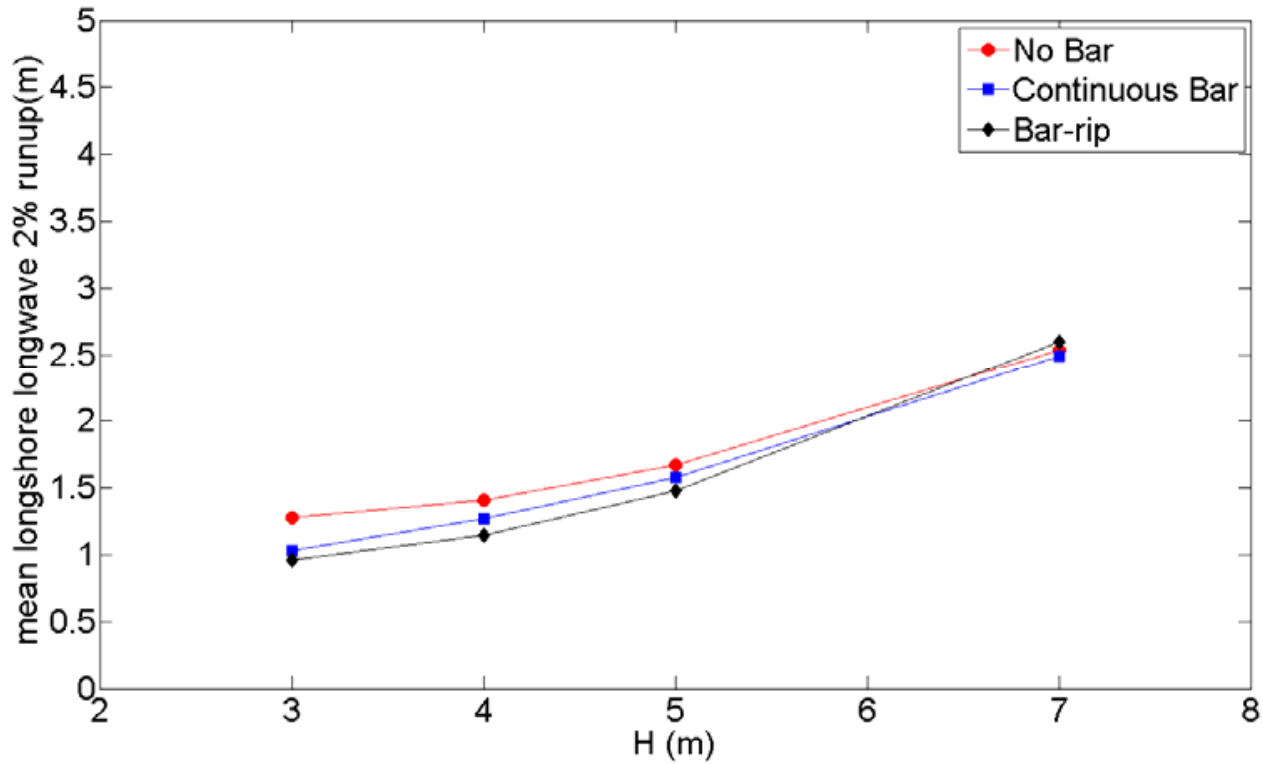

Figure 37. Mean extreme long-wave runup for various wave conditions

Table 9. Mean extreme long-wave runup comparison of no bar bathymetry with other bathymetries

\begin{tabular}{|l|r|r|r|r|}
\hline \multirow{2}{*}{$\begin{array}{c}\text { Mean long-wave R2\% } \\
\text { percent change Compared } \\
\text { to No Bar Bathymetry }\end{array}$} & $\mathrm{H}_{\mathrm{mo}} 3(\mathrm{~m})$ & $\mathrm{H}_{\mathrm{mo}} 4(\mathrm{~m})$ & $\mathrm{H}_{\mathrm{mo}} 5(\mathrm{~m})$ & $\mathrm{H}_{\mathrm{mo}} 7(\mathrm{~m})$ \\
\cline { 2 - 6 } Continuous Bar (\%) & 23.96 & 10.87 & 5.74 & 1.85 \\
\hline Bar-Rip (\%) & 32.60 & 23.35 & 12.89 & 2.44 \\
\hline
\end{tabular}




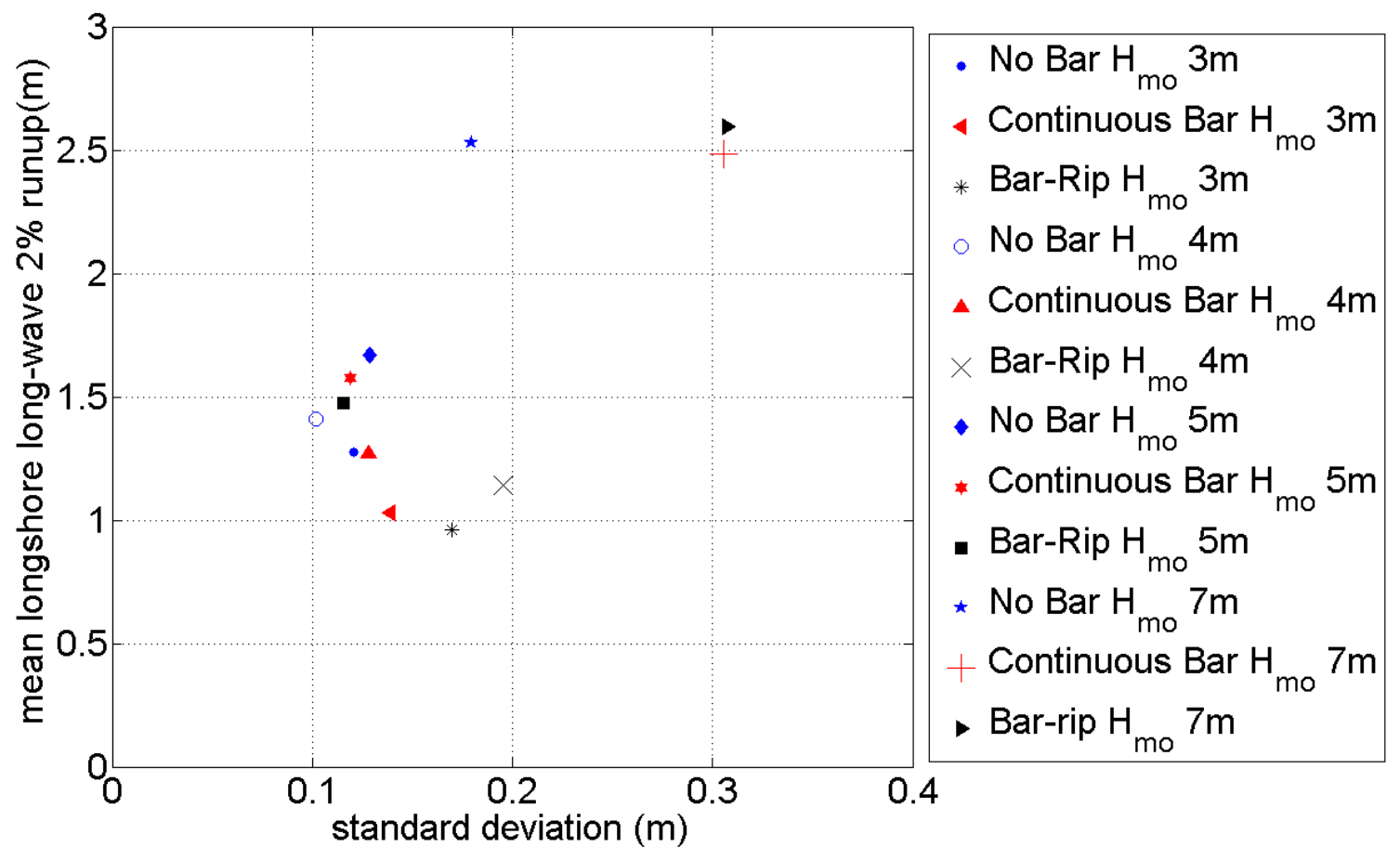

Figure 38. Mean extreme long-wave runup standard deviation for various wave conditions 


\subsection{Wave Height}

This section discusses the results for wave height analysis and the surfzone energy. The different wave conditions for the same bathymetry will be compared first and then the bathymetries will be compared with the same wave conditions. The wave heights for profiles alongshore were analyzed. The location of breaking was determined for each profile. The integral of the squared wave height for broken waves was found through the surfzone. The $\int H^{2} d x$ can be considered as an indication of energy through the surfzone as a mechanism for energy dissipation (Equation 2.11) and as a measure of radiation stress which is described as

$$
S_{x x}=\frac{1}{16} \rho g H^{2}\left[\left(1+\frac{2 k h}{\sinh 2 k h}\right) \cos ^{2} \alpha_{w}+\frac{2 k h}{\sinh 2 k h}\right]
$$

for the x component (Svendsen, 2006). Energy dissipation can be an indication of erosion due to sediment transport. Radiation stress decreases as wave energy dissipates through the surfzone (Svendsen, 2006). The decreasing radiation stress causes a setup of the mean water level. Radiation stress drives nearshore circulation and thus is an indication of sediment transport and erosion potential. The location of wave breaking was determined for profiles alongshore. The $\int H^{2} d x$ was found through the surfzone for broken waves. Figure 39 shows the indication of energy through the surfzone for the no bar bathymetry. As seen, the $\int H^{2} d x$ is consistent alongshore for the various wave conditions for the no bar bathymetry. Increasing the wave height causes energy through the surfzone to increase since the waves are breaking farther offshore. 
Similarly, the bar bathymetry has uniform $\int H^{2} d x$ alongshore for the various wave conditions (Figure 40). The energy through the surfzone is much lower for the continuous bar bathymetry. The $\mathrm{H}_{\mathrm{mo}}$ of $3.0 \mathrm{~m}, 4.0 \mathrm{~m}$, and $5.0 \mathrm{~m}$ have almost the same values for the energy dissipation correlation. The wave heights are lower due to the continuous bar feature.

The bar-rip bathymetry has highly irregular energy through the surfzone alongshore for the various wave conditions (Figure 41). The shape is similar for the various wave conditions. The increase in the energy through the surfzone occurs in the center of the bar-rip bathymetry which is the location of the rip. The rip in the bar-rip bathymetry begins at distance $325 \mathrm{~m}$ and continues to distance $425 \mathrm{~m}$. The rip in the bar-rip bathymetry causes the energy through the surfzone to be much larger than at the locations where the bar feature is present. Where the rip in the bar-rip bathymetry occurs, the waves are breaking offshore, reforming, and then breaking again. Larger waves result in a wider and more energetic surfzone and thus erosion potential increases due to the presence of these larger forces.

The presence of the rip in the bar-rip bathymetry greatly increases the energy through the surfzone. The indication of energy through the surfzone for the no bar bathymetry is greater for all wave conditions than the energy through the surfzone for the continuous bar bathymetry. The presence of the nearshore feature, either the continuous bar or the bar-rip, influences the energy through the surfzone. 


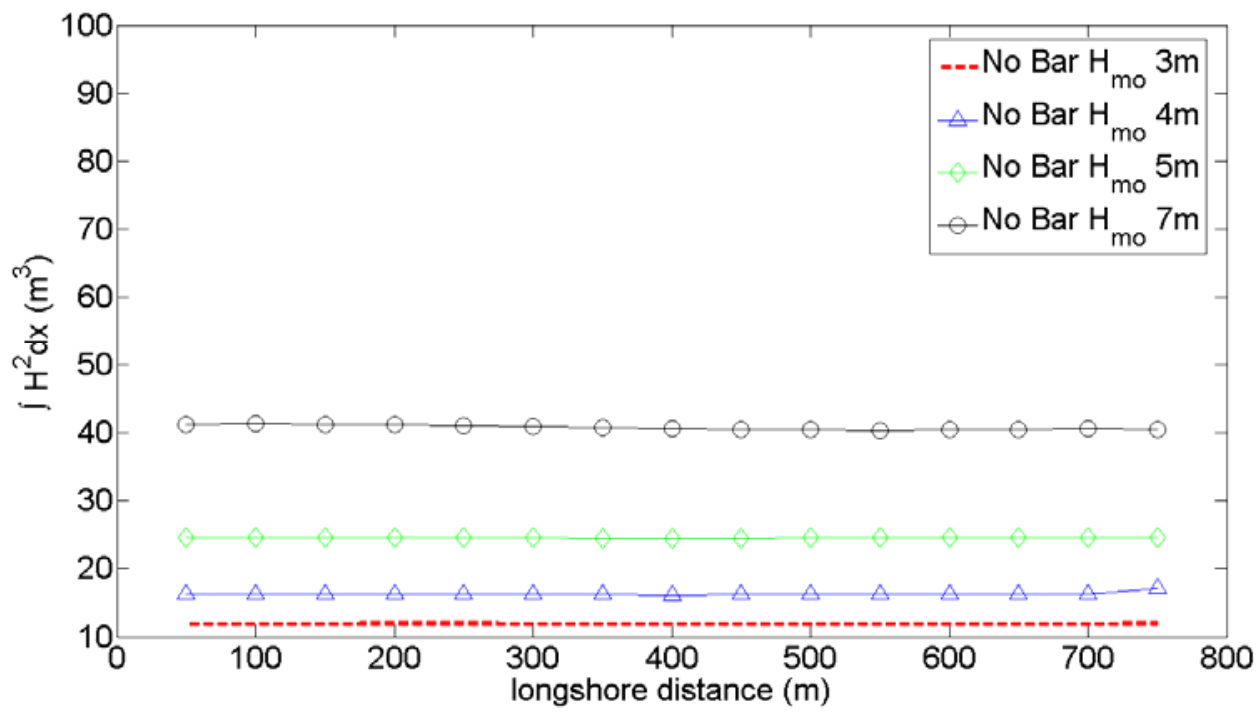

Figure 39. Energy through the surfzone for no bar bathymetry

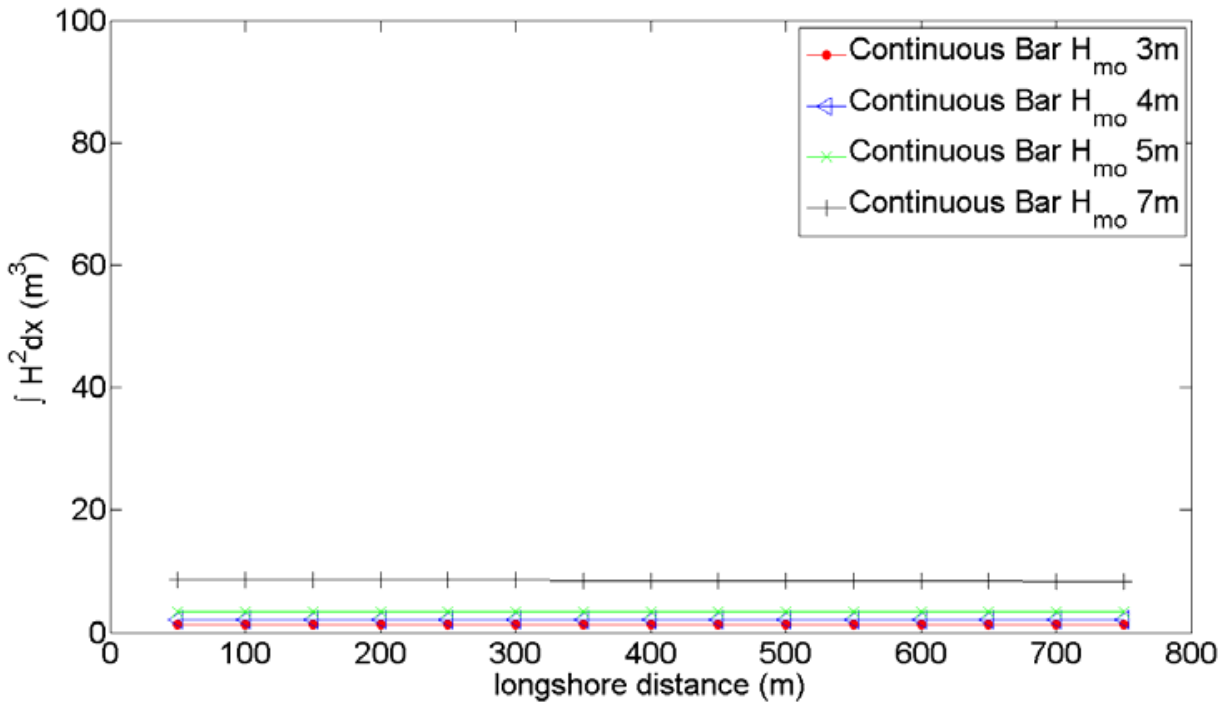

Figure 40. Energy through the surfzone for continuous bar bathymetry 


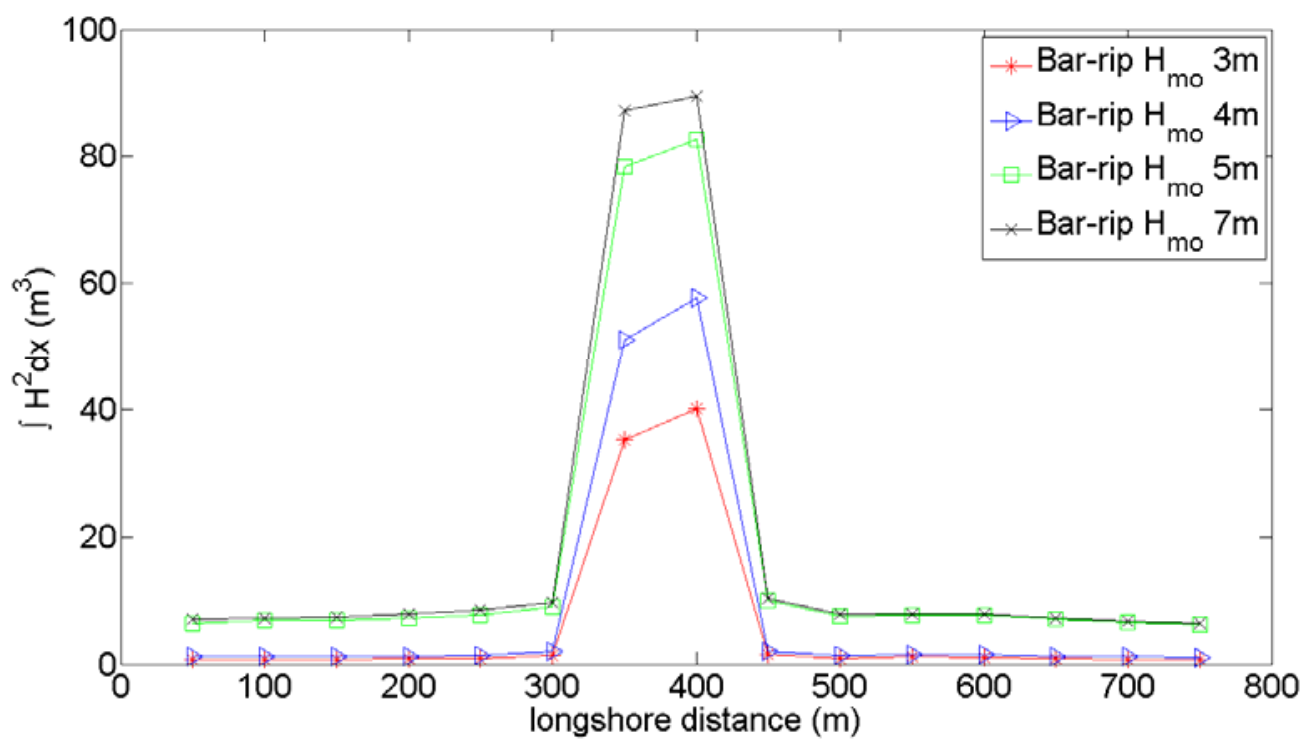

Figure 41. Energy through the surfzone for bar-rip bathymetry

Figure 42 shows the wave heights and velocities for $\mathrm{H}_{\text {mo }} 3.0 \mathrm{~m}$. As can be seen, the wave heights are uniform for the no bar and continuous bar bathymetry; however, for the bar-rip bathymetry the flow through the rip is considerably higher than at the locations where the bar is present. After the flow moves through the rip, there is considerable spreading and lowering at the coast, which is likely the cause of the variability of the extreme long-wave runup seen in Figure 27. Also, the wave heights through the rip are larger than is seen where the bar is present. The increased wave height results in larger energy through the surfzone. 

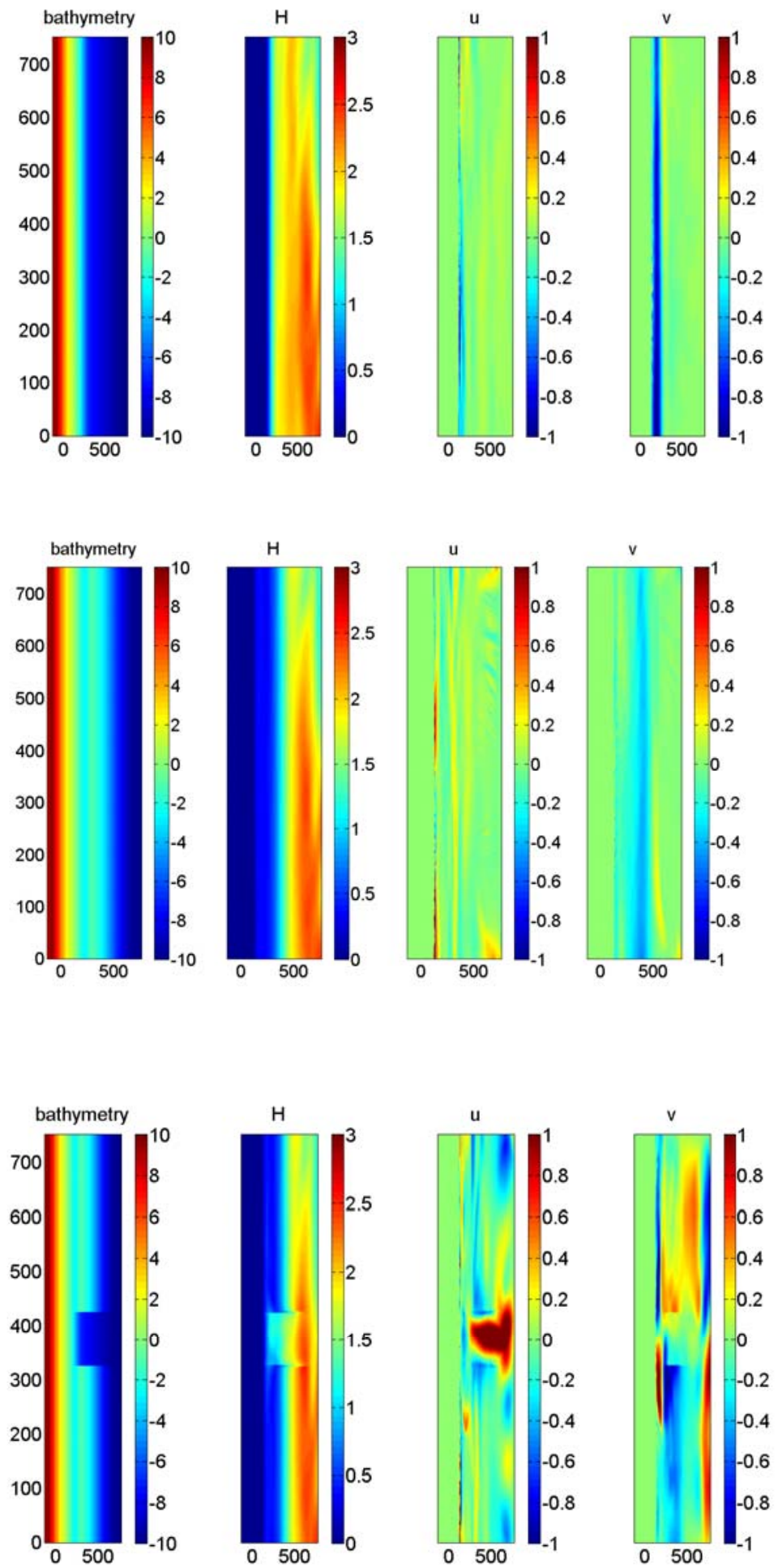

Figure 42. Wave height and velocities for $\mathrm{H}_{\mathrm{mo}} 3.0 \mathrm{~m}$ for no bar bathymetry (top), continuous bar bathymetry (middle), and bar-rip bathymetry (bottom) 
$\underline{\mathrm{H}}_{\mathrm{mo}} 3.0 \mathrm{~m}$

The wave condition increases the magnitude of the energy through the surfzone. Figure 43 shows the energy through the surfzone for the wave height of $3.0 \mathrm{~m}$. The energy through the surfzone for the no bar bathymetry is greater than for the continuous bar and the ends of the bar-rip bathymetries. The energy through the surfzone for the bar-rip bathymetry is similar to that of the continuous bar where the bar is present. However, in the center of the bar-rip bathymetry (distance $325 \mathrm{~m}$ to $425 \mathrm{~m}$ ), where the rip occurs, the energy through the surfzone is larger. The energy through the surfzone varies from about $1 \mathrm{~m}^{3}$ to $40 \mathrm{~m}^{3}$ due to the nearshore bar-rip bathymetry. Erosion is likely to be more accelerated for the no bar bathymetry and the center of the bar-rip bathymetry. Figure 44 shows the wave heights and water levels for the three bathymetries. The wave heights are larger for the no bar bathymetry than for the continuous bar bathymetry. Also, the bar-rip bathymetry has larger waves for the profile in the center where the rip occurs.

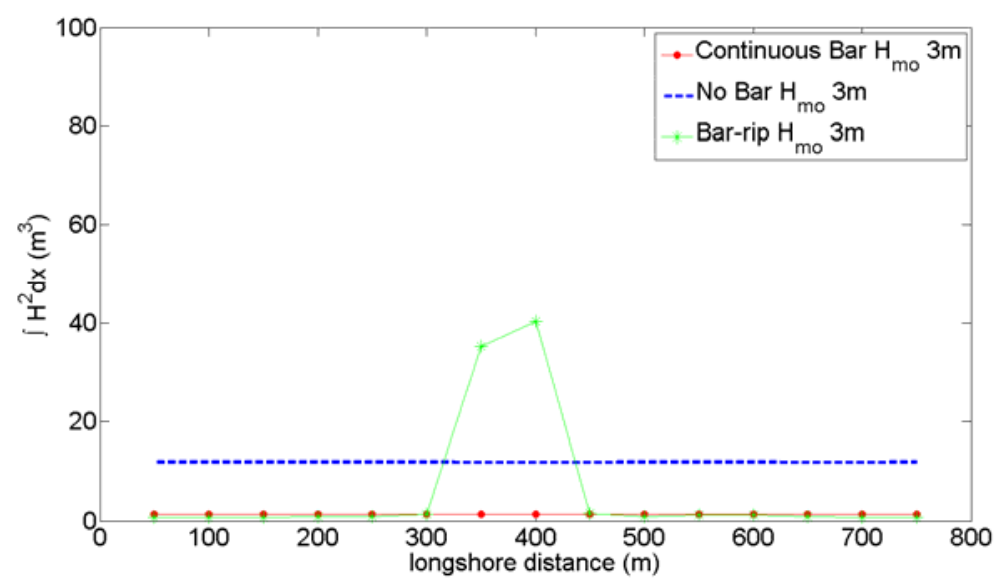

Figure 43. Energy indicator through the surfzone for $\mathrm{H}_{\mathrm{mo}} 3.0 \mathrm{~m}$ 

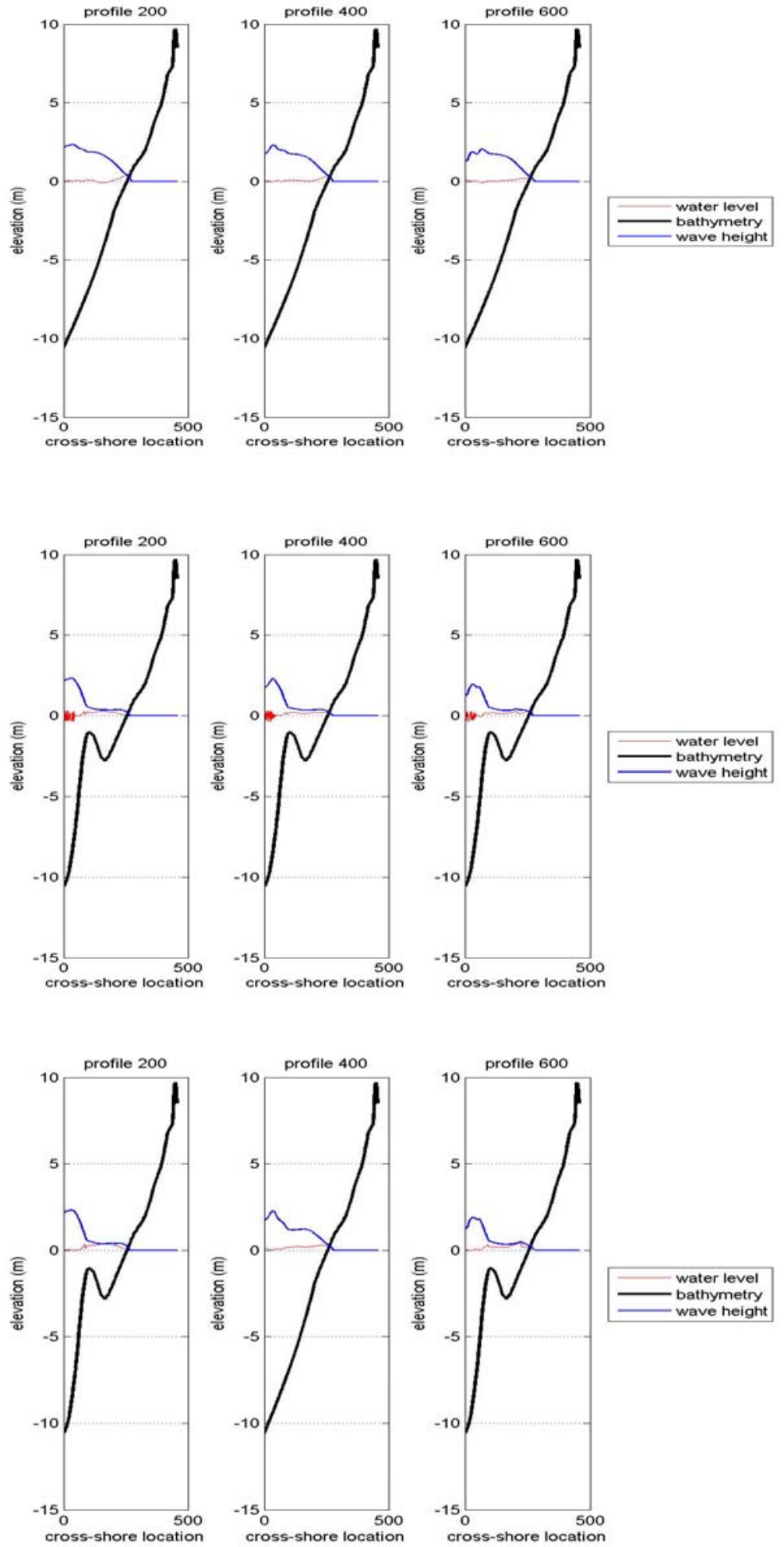

Figure 44. Wave height and water level for $\mathrm{H}_{\mathrm{mo}} 3.0 \mathrm{~m}$ for no bar bathymetry (top), continuous bar bathymetry (middle), and bar-rip bathymetry (bottom) 
$\underline{\mathrm{H}_{\mathrm{mo}}} \underline{4.0 \mathrm{~m}}$

The wave condition increases the magnitude of the energy indicator through the surfzone. Figure 45 shows the energy through the surfzone for the wave height of $4.0 \mathrm{~m}$. The indicator of energy through the surfzone for the no bar bathymetry is greater than for the continuous bar and the ends of the bar-rip bathymetries. The energy through the surfzone for the bar-rip bathymetry is similar to that of the continuous bar where the bar feature is present. However, in the center of the bar-rip bathymetry (distance $325 \mathrm{~m}$ to $425 \mathrm{~m}$ ), where the rip occurs, the indicator of energy through the surfzone is larger. The energy through the surfzone varies from about $1.5 \mathrm{~m}^{3}$ to $55 \mathrm{~m}^{3}$ due to the nearshore bathymetry. Erosion is likely to be more accelerated for the no bar bathymetry and the center of the bar-rip bathymetry. The nearshore feature has a significant influence on the energy through the surfzone. Figure 46 shows the wave heights and water levels for the three bathymetries. The wave heights are larger for the no bar and in the center of the bar-rip bathymetry.

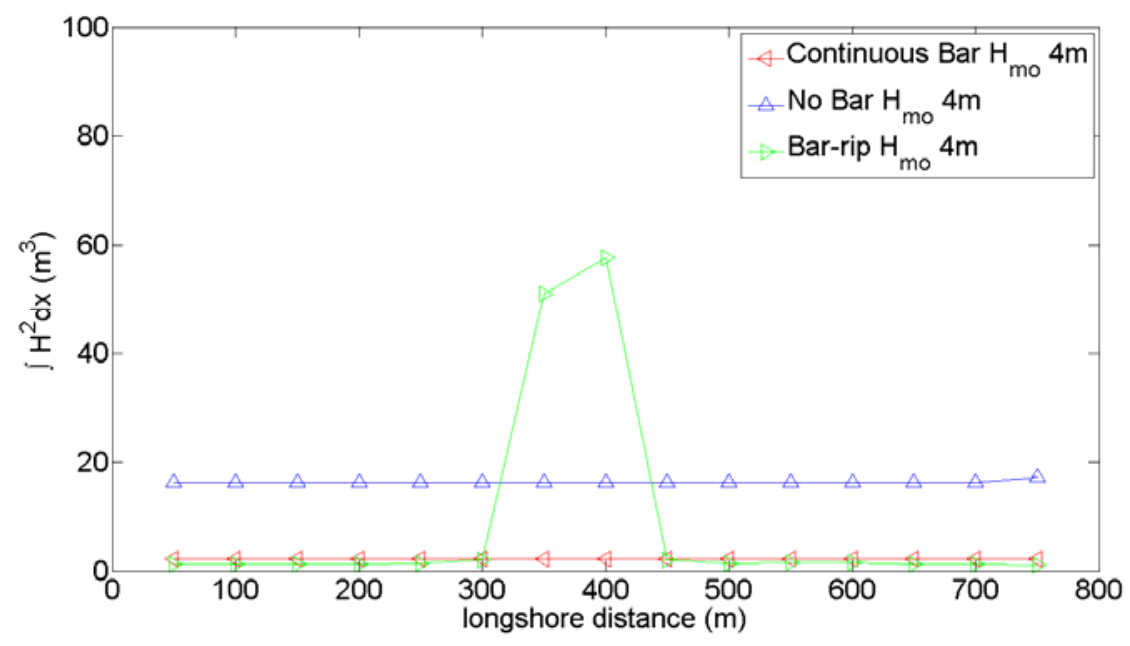

Figure 45. Energy indicator through the surfzone for $\mathrm{H}_{\mathrm{mo}} 4.0 \mathrm{~m}$ 

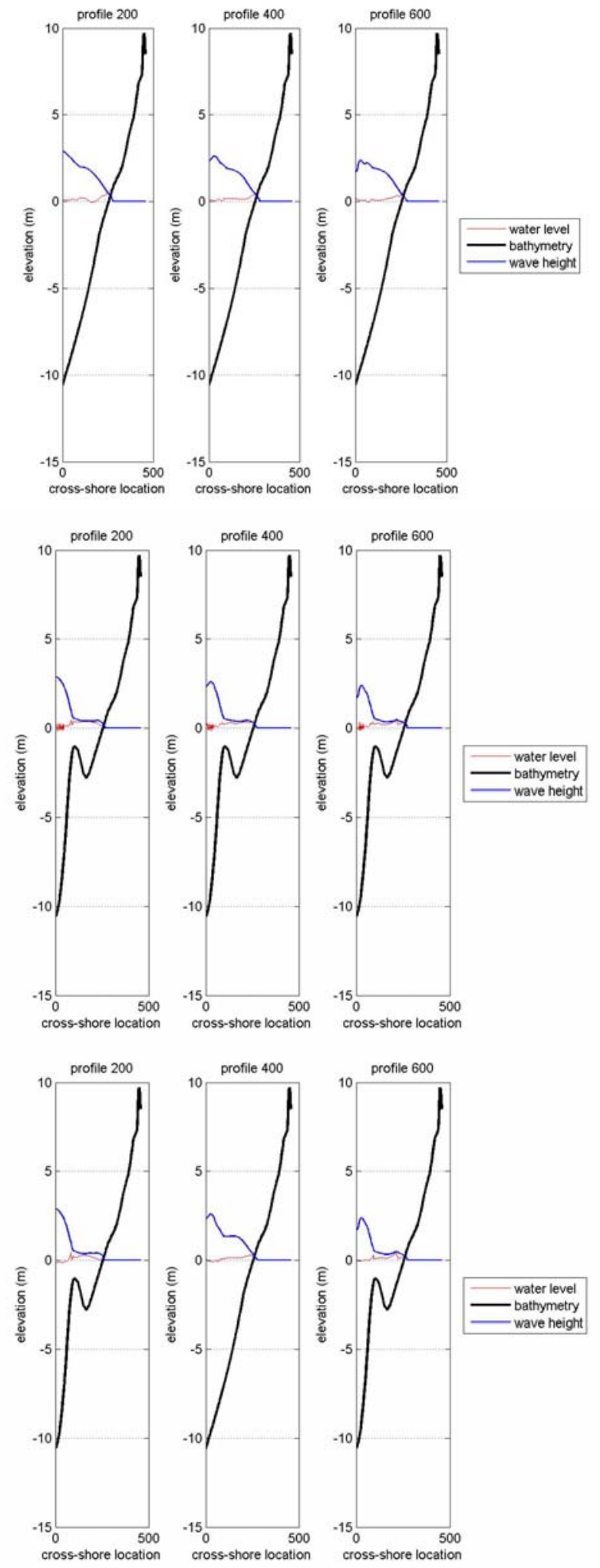

Figure 46. Wave height and water level for $\mathrm{H}_{\mathrm{mo}} 4.0 \mathrm{~m}$ for no bar bathymetry (top), continuous bar bathymetry (middle), and bar-rip bathymetry (bottom) 
$\underline{\mathrm{H}}_{\mathrm{mo}} \underline{5.0 \mathrm{~m}}$

The wave condition increases the magnitude of the energy through the surfzone. Figure 47 shows the energy through the surfzone for the wave height of $5.0 \mathrm{~m}$. The energy through the surfzone for the no bar bathymetry is greater than for the continuous bar and the ends of the bar-rip bathymetries. The energy through the surfzone for the bar-rip bathymetry is similar to that of the continuous bar where the bar feature is present. However, in the center of the bar-rip bathymetry (distance $325 \mathrm{~m}$ to $425 \mathrm{~m}$ ), where the rip occurs, the energy through the surfzone is larger. The energy through the surfzone varies from about $7.0 \mathrm{~m}^{3}$ to $80 \mathrm{~m}^{3}$ due to the nearshore bathymetry. The nearshore feature has a significant influence on the energy through the surfzone. The wave heights are much larger for the no bar and center of the bar-rip bathymetry than for the continuous bar bathymetry (Figure 48).

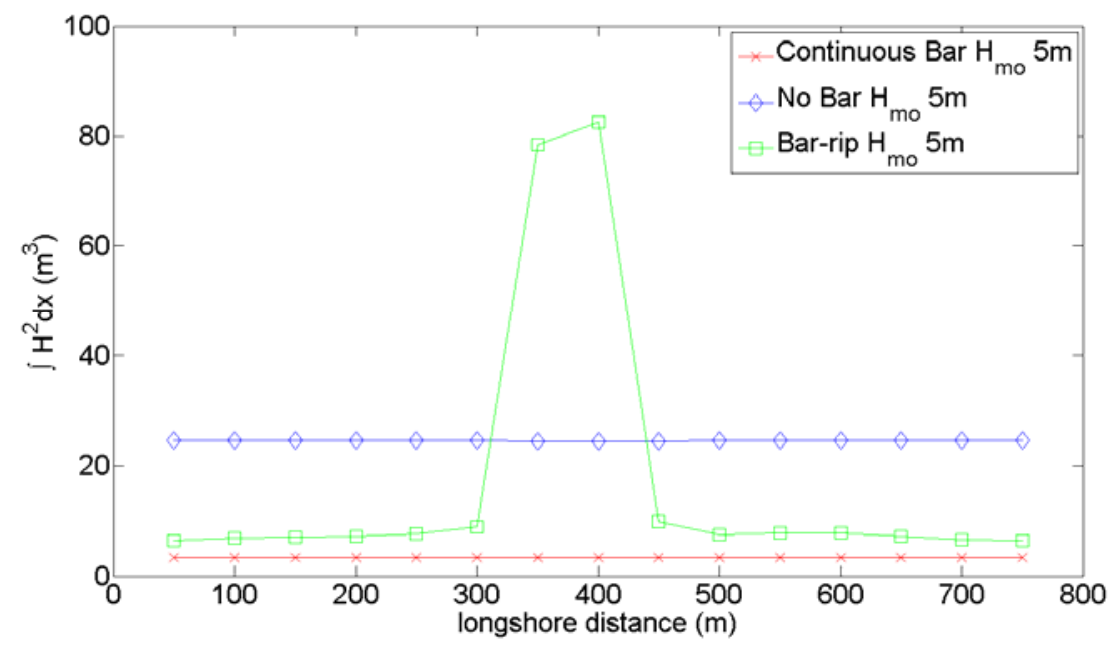

Figure 47. Energy indicator through the surfzone for $\mathrm{H}_{\mathrm{mo}} 5.0 \mathrm{~m}$ 

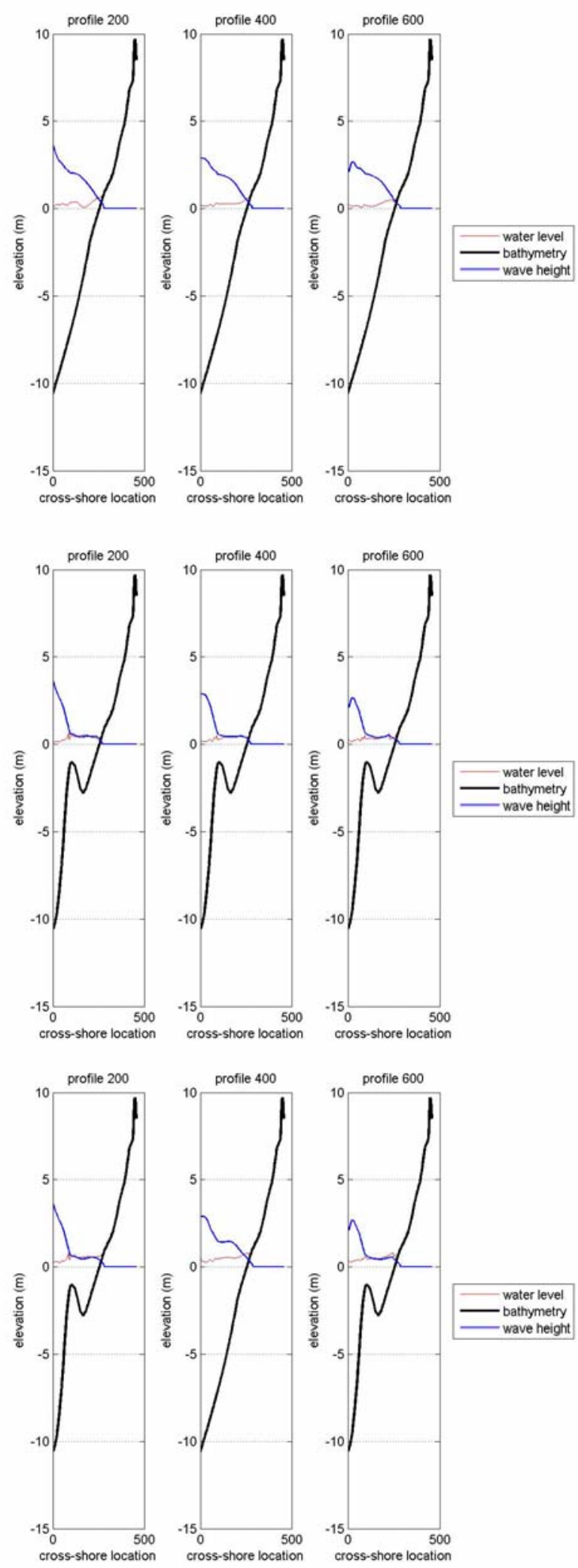

Figure 48. Wave height and water level for $\mathrm{H}_{\mathrm{mo}} 5.0 \mathrm{~m}$ for no bar bathymetry (top), continuous bar bathymetry (middle), and bar-rip bathymetry (bottom) 
$\underline{\mathrm{H}}_{\mathrm{mo}} \underline{7.0 \mathrm{~m}}$

The wave condition increases the magnitude of the energy through the surfzone. Figure 49 shows the energy through the surfzone for the wave height of $7.0 \mathrm{~m}$. As has been seen for the previous wave conditions, the indicator of energy through the surfzone for the no bar bathymetry is greater than for the continuous bar and the ends of the barrip bathymetries. The energy through the surfzone for the ends of the bar-rip bathymetry is similar to that of the continuous bar. However, where the rip occurs in the bar-rip bathymetry (distance $325 \mathrm{~m}$ to $425 \mathrm{~m}$ ), the energy through the surfzone is much larger. The energy through the surfzone varies from about $9.0 \mathrm{~m}^{3}$ to $90 \mathrm{~m}^{3}$ due to the nearshore bathymetry. The larger waves of the no bar bathymetry and center of the bar-rip bathymetry greatly increase the energy through the surfzone (Figure 50).

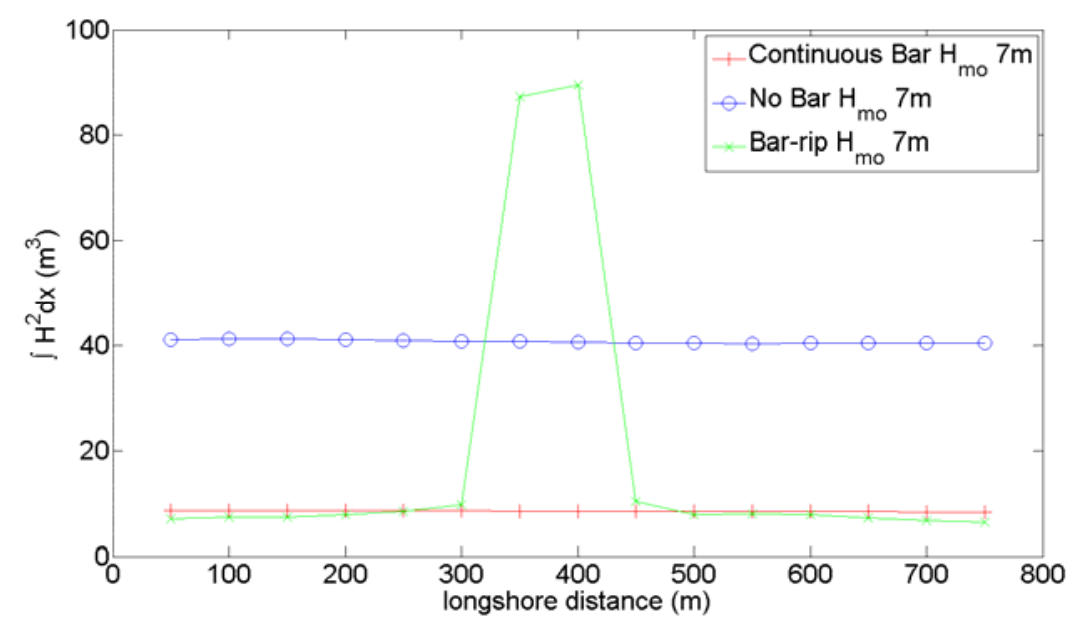

Figure 49. Energy indicator through the surfzone for $\mathrm{H}_{\mathrm{mo}} 7.0 \mathrm{~m}$ 

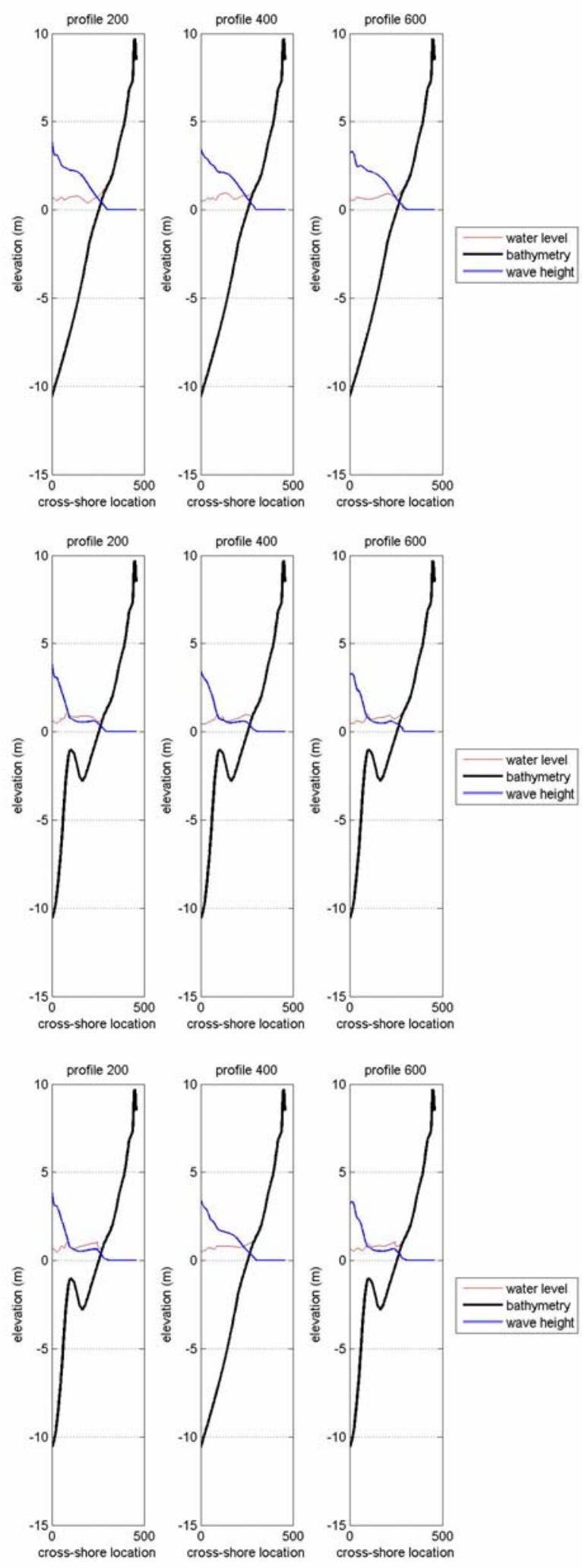

Figure 50. Wave height and water level for $\mathrm{H}_{\mathrm{mo}} 7.0 \mathrm{~m}$ for no bar bathymetry (top), continuous bar bathymetry (middle), and bar-rip bathymetry (bottom) 
The presence of nearshore features has a significant influence on the energy through the surfzone. As the waves increase, the location of wave breaking changes. The continuous bar bathymetry consistently had the lowest energy through the surfzone for all wave conditions. The no bar bathymetry had uniform energy through the surfzone that varied according to the wave condition. The bar-rip bathymetry had similar energy through the surfzone on the ends where the bathymetry is similar to that of the continuous bar bathymetry. However, in the center of the bar-rip bathymetry, where the rip occurs, the energy through the surfzone is much larger. In the center of the bar-rip bathymetry, waves break farther offshore and then break again in the surfzone. The energy through the surfzone can be considered to be an indication of erosion potential since the radiation stress drives nearshore circulation (Equation 5.1). Erosion is likely to be more accelerated for the no bar bathymetry and the center of the bar-rip bathymetry than for the continuous bar bathymetry.

The mean longshore energy through the surfzone was determined for the various wave conditions for the three bathymetries (Figure 51). As expected, increasing the wave heights increases the energy through the surfzone. However, the critical wave height appears to be $5.0 \mathrm{~m}$ for the bar-rip bathymetry because after the $5.0 \mathrm{~m}$ wave height, the mean energy through the surfzone does not increase. This was also seen in Figure 41 where the difference between the energy through the surfzone for the $5.0 \mathrm{~m}$ and $7.0 \mathrm{~m}$ waves was not as significant as was seen for the $3.0 \mathrm{~m}$ and $4.0 \mathrm{~m}$ waves. 


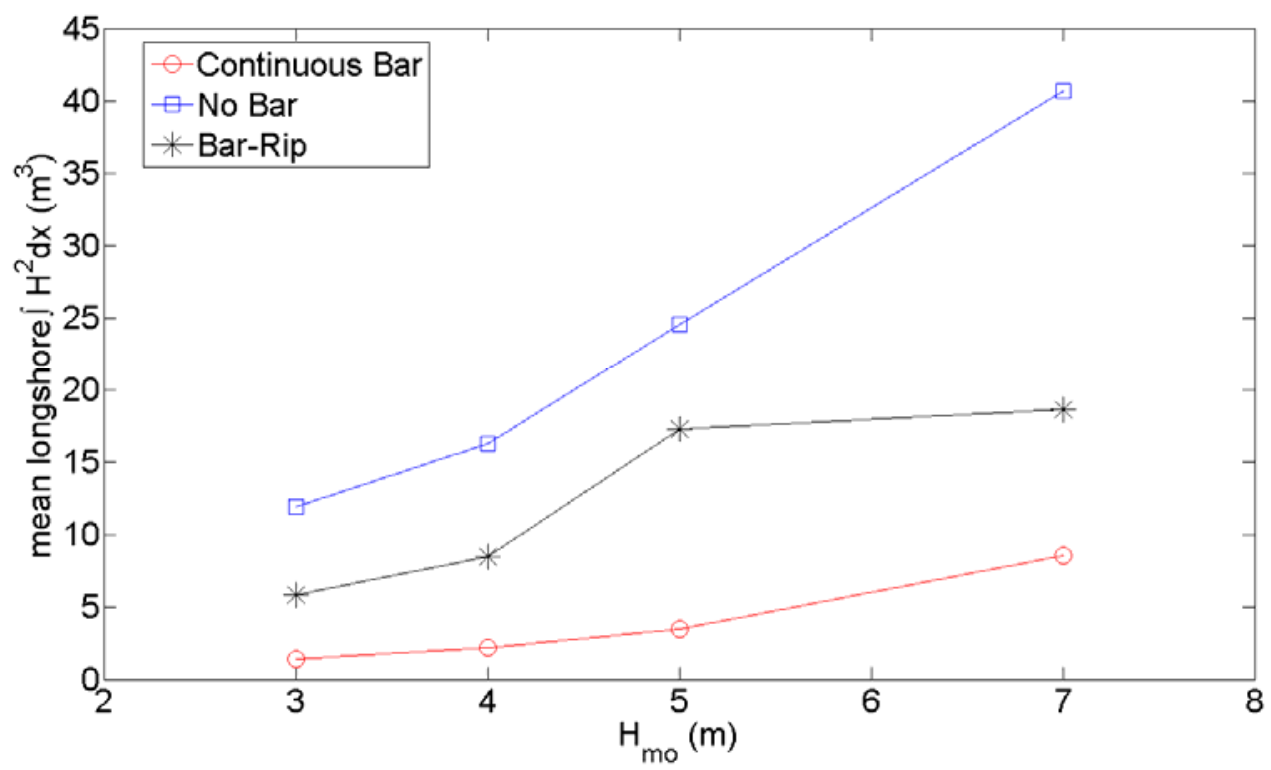

Figure 51. Mean longshore energy through the surfzone

The results from the analysis suggest that the extreme long-wave runup and energy through the surfzone are influenced by nearshore bathymetry, especially for the smaller waves. The smaller waves associated with an approaching storm are likely to be more influenced by bathymetry. As the storm progresses, the waves will reach an elevation where the water level is raised to a point where the bathymetry has little influence.

The velocities and wave heights through the center of the bar-rip bathymetry experienced a significant increase than at the locations where the bar was present. Also, on the shoreward side of the rip, the flow through the center dispersed along the coast (Figure 42). This reduction in velocities on the shoreward side of the rip may be the cause for the lower extreme long-wave runup in the center of the bar-rip bathymetry 
(Figures 30, 31, 33, and 35).

The presence of the bar for both the bar bathymetry and on the ends of the bar-rip bathymetry appeared to reduce the energy through the surfzone, which can be considered as an indication of potential erosion. Having a bar reduces the extreme long-wave runup as well as the energy through the surfzone. The amount of erosion protection that results from the bar is more significant for the lower wave conditions. As stated previously, the waves will reach an elevation where the water level is raised to a point where the bathymetry has little influence. However, for the lower wave conditions, the nearshore bar was shown to reduce the extreme long-wave runup and the energy through the surfzone. 


\section{SUMMARY AND CONCLUSIONS}

Beaches and barrier islands are vulnerable to extreme storm events, such as hurricanes, that can cause severe erosion and overwash to the system. The spatial variation in nearshore features, such as sandbars, can alter nearshore hydrodynamics, including wave setup and runup. The influence of bathymetric features on long-wave runup can be used for evaluating the vulnerability of coastal regions to erosion and dune overtopping (Stockdon et al. 2006), evaluating the changing morphology, and implementing plans to protect infrastructure.

The numerical model, XBeach, was used to force several wave conditions for three bathymetries. The bathymetries consisted of an equilibrium beach profile concept (no bar), continuous offshore bar (continuous bar), and a continuous offshore bar with a rip in the center (bar-rip). The bathymetries used for the model simulation are idealized from lidar data from Bay County, Florida. The objective of this research is to determine the influence of nearshore features on long-wave runup at the land/sea interface and quantify energy dissipation relation within the surf zone as an indication of erosion potential. Understanding the influence of extreme long-wave runup and energy through the surfzone due to nearshore features will provide insight on protecting existing coastal infrastructure and for improving planning of future coastal development projects.

The wave condition was significant in the amount of influence that the nearshore feature has on extreme long-wave runup and energy dissipation relation. The lowest wave condition, $\mathrm{H}_{\mathrm{mo}} 3.0 \mathrm{~m}$, resulted in the most influence of the nearshore features on extreme long-wave runup. For this wave condition, having a continuous bar reduced the 
mean extreme long-wave runup by $23 \%$, as compared to the no bar bathymetry. As the waves increased in size, the level of influence of the nearshore features decreased, where at the highest wave condition, $\mathrm{H}_{\mathrm{mo}} 7.0 \mathrm{~m}$, the nearshore feature had very little impact on reducing the mean long-wave extreme runup.

The presence of nearshore features has a significant influence on the energy through the surfzone. As the waves increase, the location of wave breaking changes. In the center of the bar-rip bathymetry, waves break farther offshore and then break again in the surfzone. Radiation stress drives nearshore circulation and thus can be an indication of the erosion potential. Erosion is likely to be more accelerated for the no bar bathymetry and the center of the bar-rip bathymetry than for the continuous bar bathymetry.

One conclusion from this research is that long-wave runup variability was greatest for the smaller wave conditions. As the waves increased, the influence that nearshore features have on reducing the extreme long-wave runup decreases. Also, the energy through the surfzone was highly influenced by the nearshore features. The barrip bathymetry experienced significant increase in the wave heights in the center of the bar-rip, which also increased the energy through the surfzone and suggests that erosion would be more accelerated.

The smaller waves associated with an approaching storm are likely to be more influenced by bathymetry. As the storm progresses, the waves will reach an elevation where the water level is raised to a point where the bathymetry has little influence. 
Knowing the influence that complex bathymetric features have on instantaneous water levels at the coast is essential for predicting the vulnerability of a coastal region to erosion during extreme storm events. A few topics for future research include:

- Consider a greater range of wave conditions

- Consider different bathymetries

- Remove the directionality component implementation of JONSWAP spectrum in XBeach

- Consider morphological changes

- Expand the study to other locations along the Gulf Coast. 


\section{REFERENCES}

Battjes, J.A. (1974), Surf Similarity, Proceedings of the $14^{\text {th }}$ Conference of Coastal Engineering, ASCE, 466-480.

Battjes, J.A. and J.P.F.M. Janssen (1978), Energy loss and set-up due to breaking in random waves, Proc. $16^{\text {th }}$ Coastal Engineering Conference, Hamburg, Part 1, pp. 569587.

Bowen, A.J., Inman, D.L., and V.P. Simmons (1968), Wave 'set-down' and 'set-up', Journal of Geophysical Research, 73 (8), 2569-2577.

Brock, J.C., Wright, C.W., Sallenger, A.H., Krabill, W.B. and R.N. Swift, ( 2002), Basis and methods of NASA airborne topographic mapped lidar surveys for coastal studies, Journal of Coastal Research, 18(1), 1-13.

Dean, R.G. (1991), Equilibrium beach profiles: characteristics and applications, Journal of Coastal Research, 7, 53-84.

Dean, R.G., (1977), Equilibrium beach profiles: U.S. Atlantic and Gulf coasts. Dept. of Civil Engineering and College of Marine Studies, University of Delaware, Newark.

Dean, R.G. and R.A. Dalrymple (2002), Coastal Processes with Engineering Applications, Cambridge University

Deigaard, R. (1993), A note on the three-dimensional shear stress distribution in a surf zone, Coastal Engineering, 20, 157-171.

Douglass, S.L., Chen, Q., Olsen, J.M., Edge, B.L., and D. Brown (2006), Wave forces on bridge decks, U.S. Department of Transportation, Federal Highway Administration, Washington, D.C., <southalabama.edu/usacterec/waveforces.pdf>, 1-82.

ESRI (Environmental Systems Research Institute) (2009), Geographic Information Systems (GIS), www.esri.com.

Frey, A.E. (2009), The impact of climate change on hurricane flooding inundation, property damages, and population affected, Master Thesis, Texas A\&M University Zachry Department of Civil Engineering.

Google Imagery/Maps (2010), Bay County, FL, maps.google.com.

Guenther, G.C., LaRocque, P.E., and W.J. Lillycrop, (1994), Multiple surface channels in SHOALS airborne lidar, SPIE, 2258, 422-430. 
Hasselmann, K. and D. Olbers (1973), Measurements of wind-wave growth and swell decay during the Joint North Sea Wave Project (JONSWAP), Deutsche Hydrographische Zeitschrift, Hamburg, Reihe A, (8) 12, 1- 95.

Holman, R.A. (1986), Extreme value statistics for wave run-up on a natural beach, Coastal Engineering, (9) 527-544.

Hunt, I.A. (1959), Design of seawalls and breakwaters, Journal of Waterways and Harbors Division, ASCE, 85, 123-152.

Kennedy, A.B., Chen, Q., Kirby, J.T., and Dalrymple R.A. (2000), Boussinesq modeling of wave transformation, breaking, and runup. I: 1D, Journal of Waterway, Port, Coastal, and Ocean Engineering, 126 (1), 39-47.

Kobayashi, N., Tega, Y. and M.W. Hancock (1996), Wave reflection and overwash of Dunes, Journal of Waterway, Port, Coastal and Ocean Engineering, 122(3), 150-153.

Longuet-Higgins, M.S. and R.W. Stewart (1964), Radiation stresses in water waves; a physical discussion, with applications, Deep-Sea Research, 11, 529-562.

McCall, R.T., Van Thiel de Vries, J.S.M., Plant, N.G., Van Dongeren, A.R., Roelvink, J.A., Thompson, D.M. and A.J.H.M. Reniers (2010), Two-Dimensional time dependent hurricane overwash and erosion modeling at Santa Rosa Island, Coastal Engineering, 116

McCowan, J. (1894), On the highest wave of permanent type, Phil. Mag., 38, 351-357.

Morton, R.A. and A.H. Sallenger (2003), Morphological impacts of extreme storms on sandy beaches and barriers, Journal of Coastal Research, 19(3), 560-573.

National Hurricane Center (2008), Tropical Cyclone Report, Hurricane Ivan in: S.R., Stewart, www.nhc.noaa.gov.

National Oceanic and Atmospheric Administration (NOAA) (1998), Population Distribution, density and growth, NOAA's state of the coast report, Silver Spring, MD. 24 January 2010.

$<$ http://oceanservice.noaa.gov/programs/mb/supp_cstl_population.html>

Plant, N.G., and R. Holman (1997), Strange kinematics of Sandbars, Coastal Dynamics, 355-365.

Reniers, A.J.H.M., (1999), Longshore current dynamics, Delft University of Technology, Delft. 
Roelvink, J.A., (1993), Dissipation in random wave groups incident on a beach, Coastal Engineering, 19, 127-150.

Roelvink, J.A. and Stive, M.J.F., (1989), Bar-generating cross-shore flow mechanisms on a beach, Journal of Geophysical Research, 94(C4), 4785-4800.

Roelvink, D., Reniers, A., vanDongeren, A., Van Thiel de Vries, J.S.M., Lescinski, J., and D-J. Walstra (2007), XBeach annual report and model description, UNESCO-IHE Institute for Water Education, WL $\mid$ Delft Hydraulics, and Delft University of Technology.

Ruggiero, P., Holman, R.A., and R.A. Beach (2004), Wave run-up on a high-energy dissipative beach, Journal of Geophysical Research, 109, C06025.

U.S. Census Bureau (2009), Coastal Area Populations and Densities, December 2009, $<$ http://www.census.gov.htm>.

Sallenger, A.H. (2000), Storm impact scale for barrier islands, Journal of Coastal Research, 16 (3), 890-895.

Schaffer, H.A., Madsen, P.A. and Deigaard R. (1993), A Boussinsesq model for waves breaking in shallow water, Coastal Engineering, 20, 185-202.

State of Florida (2010), Tourism, <stateofflorida.com>.

Srinivas, R. and Dean, R.G., 1996. Cross-shore hydrodynamics and profile response modeling. Coastal Engineering, 27: 195-221.

Stockdon, H.F., Holman, R.A., Howd, P.A., and Sallenger, Jr., A.H., (2006), Empirical parameterization of setup, swash, and runup, Coastal Engineering, 53, 573-588.

Svendsen, I.A., Madsen, P.A. and J.B. Hansen (1978), Wave characteristics in the surfzone, Proceedings of the $16^{\text {th }}$ Coastal Engineering Conference, Hamburg, 1(Chap. 29), 520-539.

Svendsen, I.A. (2006), Introduction to nearshore hydrodynamics, Advanced series on ocean engineering, 24, World Scientific, River Edge, N.J.

Svendsen, I.A. (1984), Wave heights and set-up in a surf zone, Coastal Engineering, 8, 303-329.

van Dongeren, A.R. and Svendsen, I.A., (1997), Absorbing-generating boundary condition for shallow water models, Journal of Waterway, Port, Coastal and Ocean Engineering, 123(6): 303-313. 
Van Gent, M.R.A. and C. C. Giarrusso (2005), Influence of foreshore mobility on wave boundary conditions, Proceedings of International Conference on Ocean, Offshore, and Arctic Engineering

Wang, P. and A. Davis, Jr. (1998), A beach profile model for a barred coast: case study from Sand Key, West-Central Florida, Journal of Coastal Research, 14(3), 981-991. 
VITA

Name:

Lauren McNeill Dunkin

Email Address: $\quad$ lpmeneill@gmail.com

Education: $\quad$ B.S., Civil Engineering, University of South Alabama, 2007

M.S., Civil Engineering, Texas A\&M University, 2010

Mailing Address: $\quad 3136$ TAMU

College Station, TX 77843-3136 